\title{
LETTER
}

Immunotherapy

\section{CD133-directed CAR T-cells for MLL leukemia: on-target, off-tumor myeloablative toxicity}

\author{
Clara Bueno ${ }^{1}$ - Talia Velasco-Hernandez ${ }^{1}$ Francisco Gutiérrez-Agüera ${ }^{1}$ Samanta Romina Zanetti ${ }^{1}$. \\ Matteo L. Baroni ${ }^{1}$ - Diego Sánchez-Martínez ${ }^{1}$ - Oscar Molina ${ }^{1} \cdot$ Adria Closa ${ }^{2}$ - Antonio Agraz-Doblás ${ }^{1,3}$. \\ Pedro Marín ${ }^{4} \cdot$ Eduardo Eyras ${ }^{2,5} \cdot{\text { Ignacio Varela } \mathbb{I}^{3} \cdot \text { Pablo Menéndez }}^{1,5,6}$
}

Received: 16 October 2018 / Revised: 28 November 2018 / Accepted: 12 December 2018 / Published online: 18 February 2019

(c) The Author(s) 2019. This article is published with open access

\section{To the Editor:}

Chimeric antigen receptors (CARs) have undoubtedly revolutionized immunotherapy, especially in the B-cell acute lymphoblastic leukemia (ALL) arena where over $80 \%$ of complete remissions are observed in refractory/relapsed (R/R) B-cell ALL patients treated with CD19-directed CAR T-cells (CARTs) [1]. However, despite holding an unprecedented promise, several issues still have to be resolved before CARTs can be expanded to novel targets and/or malignancies or even provided as first-line treatment in Bcell ALL [2]. For instance, toxicities such as cytokine release syndrome and immune escape mechanisms including loss of the antigen under CART-mediated pressure remain major concerns, urging further research on the mechanisms underlying CARTs cytotoxicity.

In this sense, loss of CD19 antigen is frequently observed after CD19-directed CARTs therapy in B-cell ALL [3, 4], but is particularly common in MLL-rearranged (MLLr) B-

Clara Bueno

cbueno@carrerasresearch.org

$\triangle$ Pablo Menéndez

pmenendez@carrerasresearch.org

1 Josep Carreras Leukemia Research Institute and Department of Biomedicine, School of Medicine, University of Barcelona, Barcelona, Spain

2 Pompeu Fabra University, Barcelona, Spain

3 Instituto de Biomedicina y Biotecnología de Cantabria (CSIC-UCSodercan), Departamento de Biología Molecular, Universidad de Cantabria, Santander, Spain

4 Hematology Department, Hospital Clínico de Barcelona, Barcelona, Spain

5 Instituciò Catalana de Recerca i Estudis Avançats (ICREA), Barcelona, Spain

6 Centro de Investigación Biomédica en Red de Cáncer (CIBERONC), ISCIII, Barcelona, Spain cell ALL, an aggressive subtype of B-cell ALL (dismal in MLL-AF4+ infants) associated with lymphoid-to-myeloid lineage switch $[3,5,6]$. We read with interest the work recently published in Leukemia by $\mathrm{Li}$ et al. reporting a novel CAR targeting both CD19 and CD133 [7]. This study proposes to use a bi-specific CAR targeting both CD19 and CD133 antigens in a Boolean OR-gate approach for MLLr B-cell ALL as a strategy to avoid and treat CD19- relapses. The authors reasoned that CD133, encoded by PROM1 gene, is a specific marker for MLLr leukemia because PROM1 is an MLL target, especially in MLL-AF4 B-cell ALL [8-10]. They went on and performed in vitro assays showing than CD19/CD133 bi-specific CAR triggers robust cytotoxicity against CD19 + CD133 + and CD19-CD133+ B-cell lines [7], thus suggesting it may help in reducing subsequent lineage switch in MLLr B-cell ALL.

A major drawback for CD133 as target in immunotherapy is its expression in hematopoietic stem and progenitor cells (HSPCs), which would likely exert "ontarget off-tumor" myeloablative, life-threatening toxicity $[11,12]$. Because B-cell ALL is molecularly heterogeneous and can be diagnosed during infancy, childhood and adulthood, we have characterized PROM1/CD133 expression in a large cohort of cytogenetically distinct Bcell ALL subgroups ( $n=212$ patients) as well as in different subpopulations of normal CD34+ HSPCs obtained across hematopoietic ontogeny from 22-weeks old human fetal liver (FL, prenatal), cord blood (CB, perinatal), and adult G-CSF-mobilized peripheral blood/bone marrow (PB/BM, postnatal). An initial analysis of publicly available RNA-seq data [13] from 170 diagnostic B-cell ALL patients confirmed that PROMI is overexpressed in patients with MLLr B-cell ALL, although its expression is not significantly higher than in other cytogenetic subgroups (Fig. 1a). We then analyzed PROM1 during HSPC development and observed that PROM1 is highly expressed in early normal hematopoietic stem cells (HSC) 
A

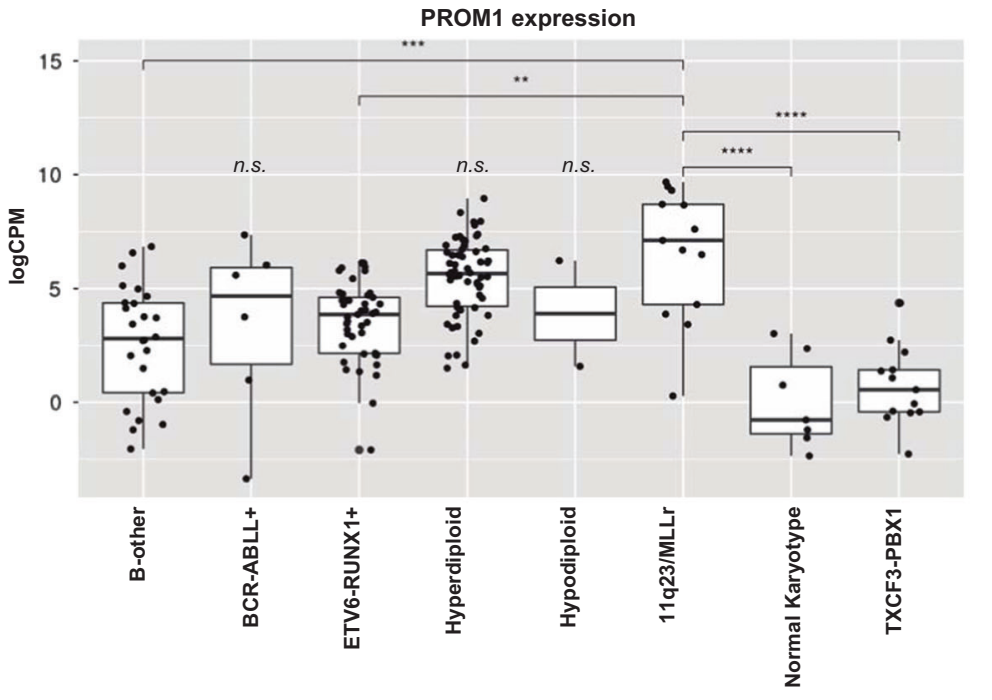

B

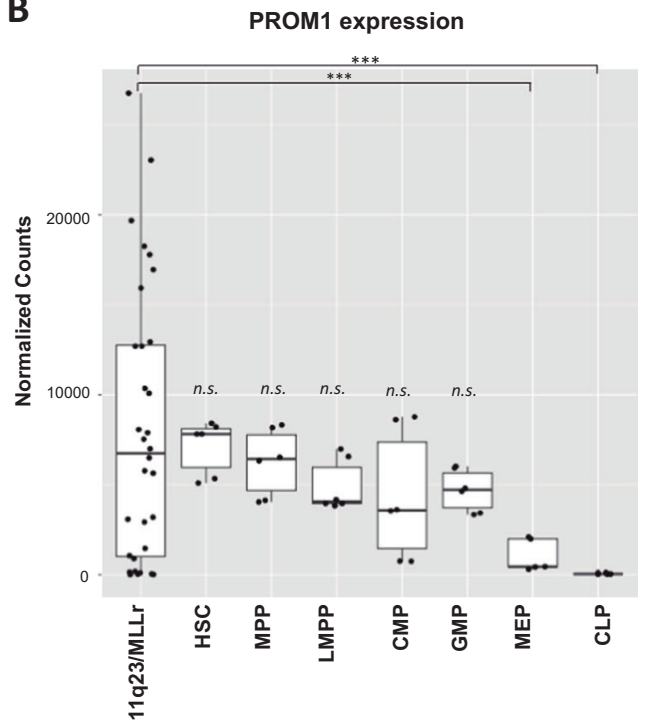

C

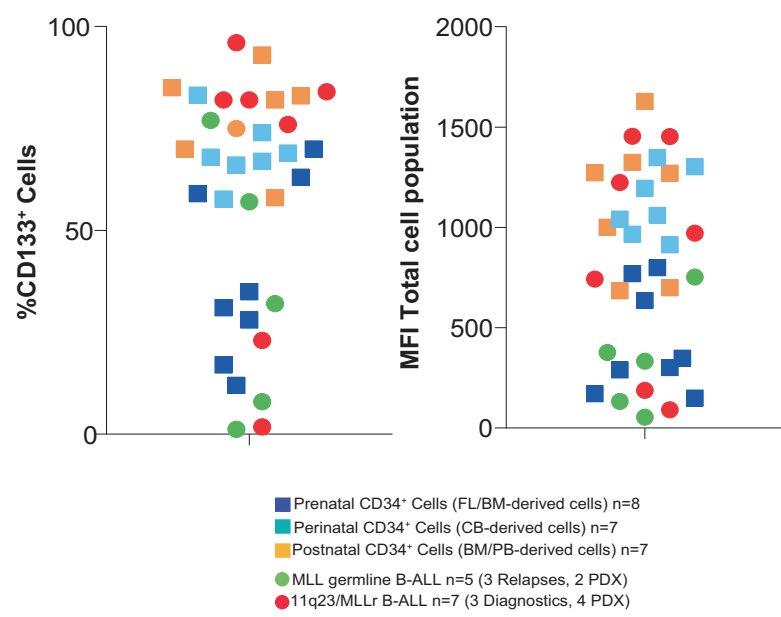

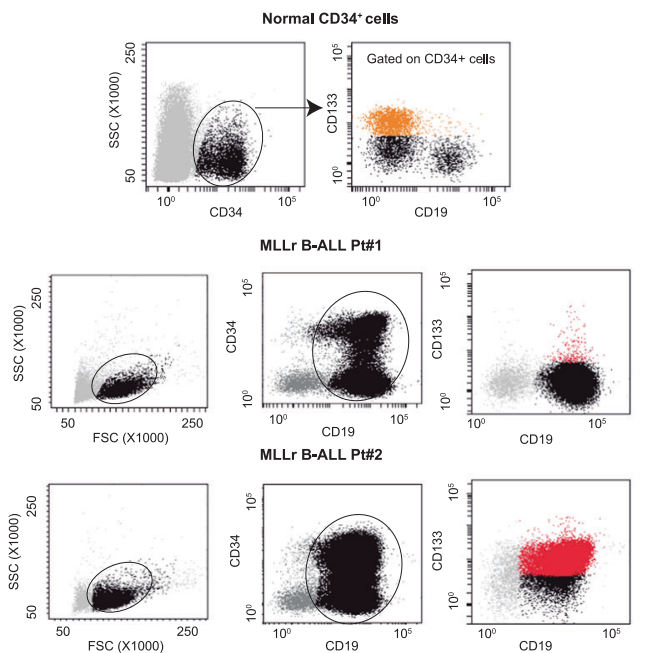

common lymphoid progenitors (CLP) [14]. Data shown as normalized counts. The boxes define the first and third quartiles. The horizontal line within the box represents the median. c Frequency (left) and mean fluorescence intensity (MFI, middle) of CD133+ BM blasts/cells in $\operatorname{MLLr}(n=7)$ and non-MLL B-cell ALLs $(n=5)$ primary diagnostic/ relapse samples or primografts (PDXs), and normal CD34+ HSPCs derived from FL $(n=8), \mathrm{CB}(n=7)$ and adult $\mathrm{PB} / \mathrm{BM}(n=7)$. Representative FACS dot plots for CD133 in normal CD34+ HSPCs (upper right) and BM samples from two independent MLLr B-cell ALL patients (bottom right)

(13/32) PROM1 levels that HSCs and MPPs, which raises doubts about the suitability of PROM1 as a target for Bcell ALL immunotherapy [15].

FACS clinical immunophenotyping provides a priori a more rapid and feasible clinically relevant diagnostic information than RNA-seq during the decision-making process. Thus, we next FACS-analyzed the expression of CD133 (PROM1 gene product) in the cell surface of BMMLL-AF4 and MLL-AF9) express equal (9/32) or lower 
derived primary blasts and primografts (PDXs) obtained from 11q23/MLLr $(n=7)$ and non-MLL $(n=5)$ B-cell ALL patients, and in comparison with healthy prenatal (22 weeks old FL), perinatal (CB) and adult (PB/BM) CD34 + HSPCs (Fig. 1c). Consistent with the RNA-seq data, the expression of CD133 in 11q23/MLLr blasts is intermingled with that observed in CD34+ HSPCs across hematopoietic ontogeny (Fig. 1c).

Our data demonstrates that $P R O M 1 / \mathrm{CD} 133$ is similarly expressed between MLLr B-cell ALL primary blasts and normal non-lymphoid HSPCs across ontogeny, thus indicating that "on-target, off-tumor" toxic/myeloablative effects are likely to occur if used in a bi-specific CAR approach where CD133 antigen will be constantly targeted regardless of the co-expression of CD19 in the same cell. Our data therefore raises concerns about using CD133 as a target for MLLr B-cell ALL immunotherapy. An alternative to circumvent HSPC toxicity would be to engineer dual CAR T-cells with one CAR engaging an antigen (i.e., CD19) mediating T-cell activation and another CAR engaging a second antigen (i.e., CD133) mediating T-cell co-stimulation [16]. Unfortunately, although such a CD19/ CD133 dual CAR might be likely safe due to its cytotoxicity being restrained only to cells co-expressing CD19 and CD133, its specific cytotoxic performance will be poor since not the entire MLLr B-cell ALL blast population is CD19 + CD133+ (Fig. 1c). Another alternative approach to prevent HSPC toxicity would be to have in place a potent molecular switch (i.e., iCas9) to eliminate CAR133expressing T-cells as necessary [17]. Further long-term in vivo studies using both primary B-cell ALL cells and normal HSCPs remain to be conducted to elucidate the efficacy versus the myeloablative toxicity of a CAR CD133 $[18,19]$.

\section{Data availability}

All genomic data is already publicly available. A full data availability will be provided.

Acknowledgements We thank the Interfant treatment protocol and local physicians for contributing patient samples: Dr. Ronald W Stam (Princess Maxima Centre, Utrech), Dr. Mireia Camos and Dr. Jose Luis Fuster (Spanish Society of Pediatric Hematoncology), Dr. Paola Ballerini (A. Trousseau Hospital, Paris). We also thank Prof. Paresh Vyas (Oxford Univeristy, UK) and Prof. Kajsa Paulsson (Lund University, Sweden) for facilitating access to their RNA-seq database. This work has been supported by the European Research Council (CoG-2014-646903, PoC-2018-811220) to PM, the Spanish Ministry of Economy and Competitiveness (MINECO, SAF-SAF2016-80481$\mathrm{R}, \mathrm{BIO} 2017-85364-\mathrm{R})$ to PM and EE, the Generalitat de Catalunya (SGR330, SGR102 and PERIS) to PM and EE, the Spanish Association against cancer (AECC-CI-2015) to CB, and the Health Institute Carlos III (ISCIII/FEDER, PI14-01191) to CB. PM also acknowledges financial support from the Obra Social La Caixa-Fundaciò Josep Carreras. SRZ and TV are supported by a Marie Curie fellowships. $\mathrm{OM}$ is supported by the Catalan Government through a Beatriu de Pinos fellowship. MB is supported by MINECO through a $\mathrm{PhD}$ scholarship. PM is an investigator of the Spanish Cell Therapy cooperative network (TERCEL).

\section{Compliance with ethical standards}

Conflict of interest The authors declare that they have no conflict of interest.

Publisher's note: Springer Nature remains neutral with regard to jurisdictional claims in published maps and institutional affiliations.

Open Access This article is licensed under a Creative Commons Attribution 4.0 International License, which permits use, sharing, adaptation, distribution and reproduction in any medium or format, as long as you give appropriate credit to the original author(s) and the source, provide a link to the Creative Commons license, and indicate if changes were made. The images or other third party material in this article are included in the article's Creative Commons license, unless indicated otherwise in a credit line to the material. If material is not included in the article's Creative Commons license and your intended use is not permitted by statutory regulation or exceeds the permitted use, you will need to obtain permission directly from the copyright holder. To view a copy of this license, visit http://creativecommons. org/licenses/by/4.0/.

\section{References}

1. Maude, SL, Laetsch TW, Buechner J, Rives S, Boyer M, Bittencourt $\mathrm{H}$, et al. Tisagenlecleucel in Children and Young Adults with B-Cell Lymphoblastic Leukemia. N Engl J Med. 2018;378:439-48.

2. Ghorashian S, Amrolia P, Veys P. Open access? Widening access to chimeric antigen receptor (CAR) therapy for ALL. Exp Hematol. 2018;66:5-16.

3. Gardner R, Wu D, Cherian S, Fang M, Hanafi LA, Finney O, et al. Acquisition of a CD19-negative myeloid phenotype allows immune escape of MLL-rearranged B-ALL from CD19 CAR-Tcell therapy. Blood. 2016;127:2406-10.

4. Sotillo E, Barrett DM, Black KL, Bagashev A, Oldridge D, Wu G, et al. Convergence of acquired mutations and alternative splicing of CD19 enables resistance to CART-19 immunotherapy. Cancer Discov. 2015;5:1282-95.

5. Sanjuan-Pla A, Bueno C, Prieto C, Acha P, Stam RW, Marschalek R, et al. Revisiting the biology of infant t(4;11)/MLLAF4 + B-cell acute lymphoblastic leukemia. Blood. 2015; 126:2676-85.

6. Weiland J, Pal D, Case M, Irving J, Ponthan F, Koschmieder S, et al. BCP-ALL blasts are not dependent on CD19 expression for leukaemic maintenance. Leukemia. 2016;30:1920-3.

7. Li D, Hu Y, Jin Z, Zhai Y, Tan Y, Sun Y, et al. TanCAR T cells targeting CD19 and CD133 efficiently eliminate MLL leukemic cells. Leukemia. 2018;32:2012-6.

8. Guenther MG, Lawton LN, Rozovskaia T, Frampton GM, Levine SS, Volkert TL, et al. Aberrant chromatin at genes encoding stem cell regulators in human mixed-lineage leukemia. Genes Dev. 2008;22:3403-8. 
9. Mak AB, Nixon AM, Moffat J. The mixed lineage leukemia (MLL) fusion-associated gene AF4 promotes CD133 transcription. Cancer Res. 2012;72:1929-34.

10. Wuchter C, Ratei R, Spahn G, Schoch C, Harbott J, Schnittger $\mathrm{S}$, et al. Impact of CD133 (AC133) and CD90 expression analysis for acute leukemia immunophenotyping. Haematologica. 2001;86:154-61.

11. Menendez P, Caballero MD, Prosper F, Del Canizo MC, PerezSimon JA, Mateos MV, et al. The composition of leukapheresis products impacts on the hematopoietic recovery after autologous transplantation independently of the mobilization regimen. Transfusion. 2002;42:1159-72.

12. Yin AH, Miraglia S, Zanjani ED, Almeida-Porada G, Ogawa M, Leary AG, et al. AC133, a novel marker for human hematopoietic stem and progenitor cells. Blood. 1997;90:5002-12.

13. Paulsson K, Lilljebjorn H, Biloglav A, Olsson L, Rissler M, Castor A, et al. The genomic landscape of high hyperdiploid childhood acute lymphoblastic leukemia. Nat Genet. 2015;47:672-6.

14. Quek L, Otto GW, Garnett C, Lhermitte L, Karamitros D, Stoilova $\mathrm{B}$, et al. Genetically distinct leukemic stem cells in human CD34- acute myeloid leukemia are arrested at a hemopoietic precursor-like stage. J Exp Med. 2016;213:1513-35.
15. Agraz-Doblas A, Bueno C, Bashford-Rogers R, Anindita R, Schneider P, Bardini M, et al. Unravelling the cellular origin and clinical prognosis markers of infant B-cell acute lymphoblastic leukemia using genome-wide analysis. Haematologica. 2018; in press.

16. Aldoss I, Bargou RC, Nagorsen D, Friberg GR, Baeuerle PA, Forman SJ. Redirecting $\mathrm{T}$ cells to eradicate B-cell acute lymphoblastic leukemia: bispecific T-cell engagers and chimeric antigen receptors. Leukemia. 2017;31:777-87.

17. Diaconu I, Ballard B, Zhang M, Chen Y, West J, Dotti G, et al. Inducible Caspase-9 selectively modulates the toxicities of CD19Specific chimeric antigen receptor-modified $\mathrm{T}$ cells. Mol Ther. 2017;25:580-92.

18. Pizzitola I, Anjos-Afonso F, Rouault-Pierre K, Lassailly F, Tettamanti S, Spinelli $\mathrm{O}$, et al. Chimeric antigen recptors against CD33/CD123 antigens efficiently target primary acute myeloid cells in vivo. Leukemia. 2014;28:1596-605.

19. Kenderian SS, Ruella M, Shestova O, Klichincky M, Aikawa V, Morrissette JJD, et al. CD33-directed chimeric antigen receptor $\mathrm{T}$ cells exhibit potent preclinical activity against human acute myeloid leukemia. Leukemia. 2015;29:1637-47.

Leukemia (2019) 33:2093-2097

https://doi.org/10.1038/s41375-019-0423-y

Chronic lymphocytic leukemia

\title{
Telomere fusions associate with coding sequence and copy number alterations in CLL
}

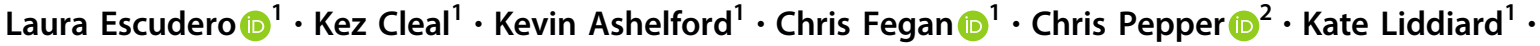 \\ Duncan M. Baird (iD ${ }^{1}$
}

Received: 6 September 2018 / Revised: 19 October 2018 / Accepted: 11 February 2019 / Published online: 22 February 2019

(c) The Author(s) 2019. This article is published with open access

\section{To the Editor:}

Short-dysfunctional telomeres are detected prior to clinical progression in chronic lymphocytic leukaemia (CLL) and result in chromosomal fusions that propagate genome

These authors contributed equally: Kate Liddiard, Duncan M. Baird.

Supplementary information The online version of this article (https:// doi.org/10.1038/s41375-019-0423-y) contains supplementary material, which is available to authorized users.

Duncan M. Baird

bairddm@cf.ac.uk

1 Division of Cancer and Genetics, School of Medicine, Cardiff University, Cardiff, UK

2 Brighton and Sussex Medical School, Sussex University, Brighton, UK instability, driving disease progression. To investigate the impact of telomere dysfunction on the CLL genome, we performed a large-scale molecular characterisation of telomere fusion events in CLL B-cells. A cohort of 276 CLL patient samples was selected for analysis based on short telomere length (TL) profiles, with the majority $(97 \%, n=$ 269) having mean TL within the previously-defined fusogenic range in CLL [1]. Patient samples were screened for the presence of telomere fusions using a single-molecule telomere fusion assay [2] modified to include the 5p telomere (Supplementary Figure 1). Telomere fusions were detected in $72 \%(198 / 276)$ of the samples, which were subsequently arbitrarily stratified by fusion frequency (Supplementary Table 1). Fusions were detected for all telomeres assayed, including the $5 \mathrm{p}$ telomere, for which fusions were present in $23 \%$ (40/177) of patient samples (Supplementary Figure 2, Supplementary Table 2).

High-resolution characterisation of single-molecule amplified telomere fusions from nine CLL patients with 

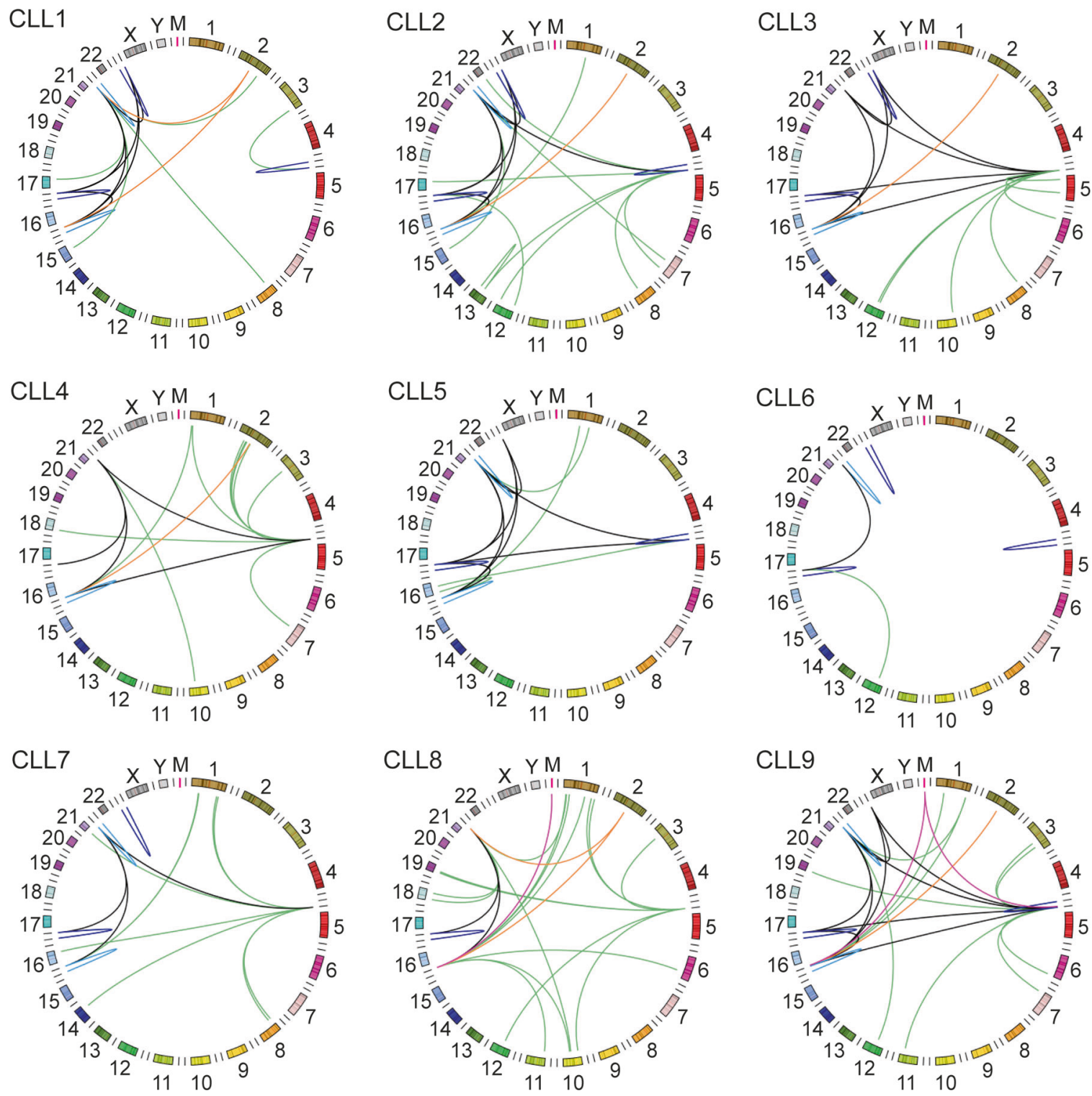

Fig. 1 Signature of telomere fusions for 9 CLL patient samples. Circos plots showing the validated results obtained from the interchromosomal and intra-chromosomal telomere fusion analysis from nine CLL patient samples. Circos plot with each chromosome and its telomeres (1p telomere, Chr1, 1q telomere) around the circle orientated clockwise. Additional notches indicate linkages specifically aligning with subtelomeric sequence references derived from
Stong et al. [12]. Colour code: telomere-telomere inter-chromosomal (black), telomere-telomere intra-chromosomal for 5p, 17p and XpYp (blue), inter-chromosomal or intra-chromosomal for $16 \mathrm{p}$ and $21 \mathrm{q}$ families (light blue), and inter-chromosomal telomere-genomic (green), telomere-2q13 (orange) and telomere-ChrM (pink). Telomere fusion events with unknown sub-telomeric sequence were not included the highest fusion frequency was performed by Illumina HiSeq4000 paired-end sequencing. Following a customised bioinformatics analysis pipeline [3] and manual curation (Supplementary Figure 3), 914 unique telomere fusions were resolved (Supplementary Figure 4), of which 19\% (172/914) involved the $5 p$ telomere (Supplementary Figure 5). Intra(sister-chromatid) or inter-chromosomal telomere fusion events were identified, as well as recombinations involving non-telomeric loci incorporated into telomere fusions (Fig. 1; Supplementary Figure 4, Supplementary Table 3).
These captured loci included; the ancestral telomere at Chr2q13-14 $(n=11)$, mitochondrial DNA $(n=4)$ and other non-telomeric genomic loci $(n=78)$. Complex interchromosomal events involving multiple disparate loci were also detected ( $n=7$ ) (Supplementary Figures 5-9).

Distinct signatures of telomere fusions across the genome could be described for each CLL patient sample (Fig. 1). Two patients (CLL3 and CLL6) displayed simple signatures, defined by the presence solely of intrachromosomal and/or inter-chromosomal telomere-telomere 
fusions. In contrast, the CLL8 sample telomere fusion profile revealed abundant genomic linkages, including with the ancestral telomere at $2 \mathrm{q} 13$ and mitochondrial DNA. Samples CLL1, CLL2, CLL4, CLL5, CLL7 and CLL9 were characterised by complex signatures with a combination of most or all categories of telomere fusion events identified in this study (Fig. 1; Supplementary Table 4).

Telomere dysfunction is associated with increased genomic instability and disease progression in CLL [1, 4], therefore a comprehensive analysis of all patient-derived telomere fusions with non-telomeric genomic loci was undertaken. Locations and junction sequences pertaining to all 93 (10\% total fusions) identified inter-chromosomal fusions were investigated to determine commonality of global or local sequence context as well as providing evidence for the engagement of specific DNA repair processes. These inter-chromosomal genomic fusions were less abundant than pure telomeric inter-chromosomal fusions that represented $38 \%$ of all fusions characterised.

Inter-chromosomal fusions with non-telomeric genomic loci were identified in all nine CLL patient samples. Individual events were validated by manual sequence analysis, revealing 68\% (63/93) had fusion junctions covered by junction-spanning sequence read pairs $(\mathrm{mFJ})$ and $32 \%$ (30/93) had unmapped junctions (uFJ). Each fusion junction location was depicted on the ideogram in Fig. 2a. Notably, the loci disrupted by telomere fusions (summarised in Supplementary Table 5) were not randomly distributed throughout the genome since there was no simple correlation with chromosome length $\left(r^{2}=0.44\right)$ or coding gene density of the respective chromosomes $\left(r^{2}=0.32\right)$ (Fig. $2 b$, Supplementary Figure 10). However, loci with previouslyreported copy number aberrations in CLL [5] were found to be incorporated into telomere fusions, including $2 \mathrm{p} 15$, 2p11.2 (2 events), 2q13 (11 events), 6q22.31, 11q22.2 and 18q21.32 (single events). In addition, a complex telomere fusion was detected involving four distinct loci including 13q14.2 that is frequently deleted in CLL (Supplementary Figure 4B).

Inter-chromosomal telomere fusions occurred within coding DNA more frequently than expected by chance. Over half $(57 \%)$ of $\mathrm{mFJ}$ were within introns and exons of proteincoding genes (Supplementary Table 5), significantly higher (Chi-squared analysis $p=0.0024$ ) than the average $42 \%$ gene content of the human genome (based on the hg19 RefGene). We also observed $15 \%$ and $9 \% \mathrm{mFJ}$ fused with Common Fragile Sites (CFSs) and Alu elements, respectively; however, these were similar to the proportion of CFSs (15\%) and Alu sequences (11\%) identified across the human genome [6].

All 31 protein-coding genes disrupted by telomere fusions with $\mathrm{mFJ}$ were further investigated for potential association with CLL pathogenesis (Supplementary Table 6). An enrichment in genes overexpressed in $\mathrm{CD} 38^{+}$patient
CLL B-cells was revealed using GSEA Gene Set Enrichment Analysis (GSEA, v5.2) Molecular Signatures Database (MSigDB) [7]. This gene set included HTR7, KIF26B and LPHN1 ( $p$-value $1.5 \mathrm{e}^{-6}$; FDR $q$-value $2.7 \mathrm{e}^{-2}$ ) -genes previously found to be upregulated in $\mathrm{CD}^{+} / \mathrm{CD} 19^{+} / \mathrm{CD} 38^{+}$ CLL cells associated with worse patient prognosis, compared with patient-matched $\mathrm{CD}^{-} / \mathrm{CD} 19^{-} / \mathrm{CD} 38^{-}$CLL cells in a panel of six patient samples [8]. Strikingly, 36\% (11/31) of all genes disrupted by a telomere fusion event for which the junction could be validated were classified as expressed or associated with B lymphocytes or CLL B-cells. These genes included CD8A, RORA, TESPA1, DMD, NOX5, NTF3, EVI5 and FTO (Supplementary Table 7) with documented pathological relevance. A significant enrichment in genes possessing binding motifs matching the B-cell-expressed homeobox transcription factor, HNF1 $\alpha$ (TCF1) [9], within their promoters was also identified (DMD, RORA, NTF3 and HTR7; $p$-value $2.51 \mathrm{e}^{-5}$; FDR $q$-value $1.31 \mathrm{e}^{-2}$; Supplementary Table 8). Furthermore, a noteworthy association of fusiondisrupted genes with gene sets over-expressed in other types of cancer including breast and liver was also revealed by these analyses.

We have previously shown that intra-chromosomal telomere fusion is accompanied by extensive resection that results in asymmetric deletion of the participating sister-chromatids [3]. To assess whether this was true for CLL B-cells, the extent of DNA end-processing at each sister-chromatid was examined for intra-chromosomal fusions with $\mathrm{mFJ}$. The distance from the start of the telomere repeat sequences to the fusion junction for each of the chromatids involved in the fusion event was determined and the difference calculated to obtain a measure of asymmetry (Fig. 2c, d; Supplementary Tables 910). The uneven distribution of fusion junctions across the $5 p$ sub-telomere $(n=14)$ is consistent with the location of a $\mathrm{CpG}$ island and suggests that the GC-rich sequence may hamper the detection of $5 p$ fusion events (Supplementary Figure 11). Thus, $5 p$ telomere fusions may be under-represented in the data and may have an even greater impact on CLL disease than presently recognised. In contrast, telomere fusion junctions were effectively captured across the $17 \mathrm{p}(n=30)$ and XpYp $(n=20)$ telomeres (Fig. 2c). Asymmetry of sisterchromatids was observed for $5 \mathrm{p}, 17 \mathrm{p}$ and XpYp with a mean of $1408 \mathrm{bp}, 1240 \mathrm{bp}$ and $695 \mathrm{bp}$, respectively (Fig. 2d). The degree of asymmetry was significantly greater than the theoretical value 0 (one sample $t$-test, $p<0.001$ ). This indicates that fusion occurs between sister-chromatids of different lengths in CLL B-cells, consistent with our observations in other models $[2,3,10]$. No significant differences were found in the extent of asymmetry between the 5p, 17p and XpYp chromosome ends (Kruskal-Wallis, $p=0.1661$ ).

High-resolution analysis of each CLL mFJ was performed to investigate candidate DNA repair mechanisms that may underlie distinct types of telomere fusion events. 

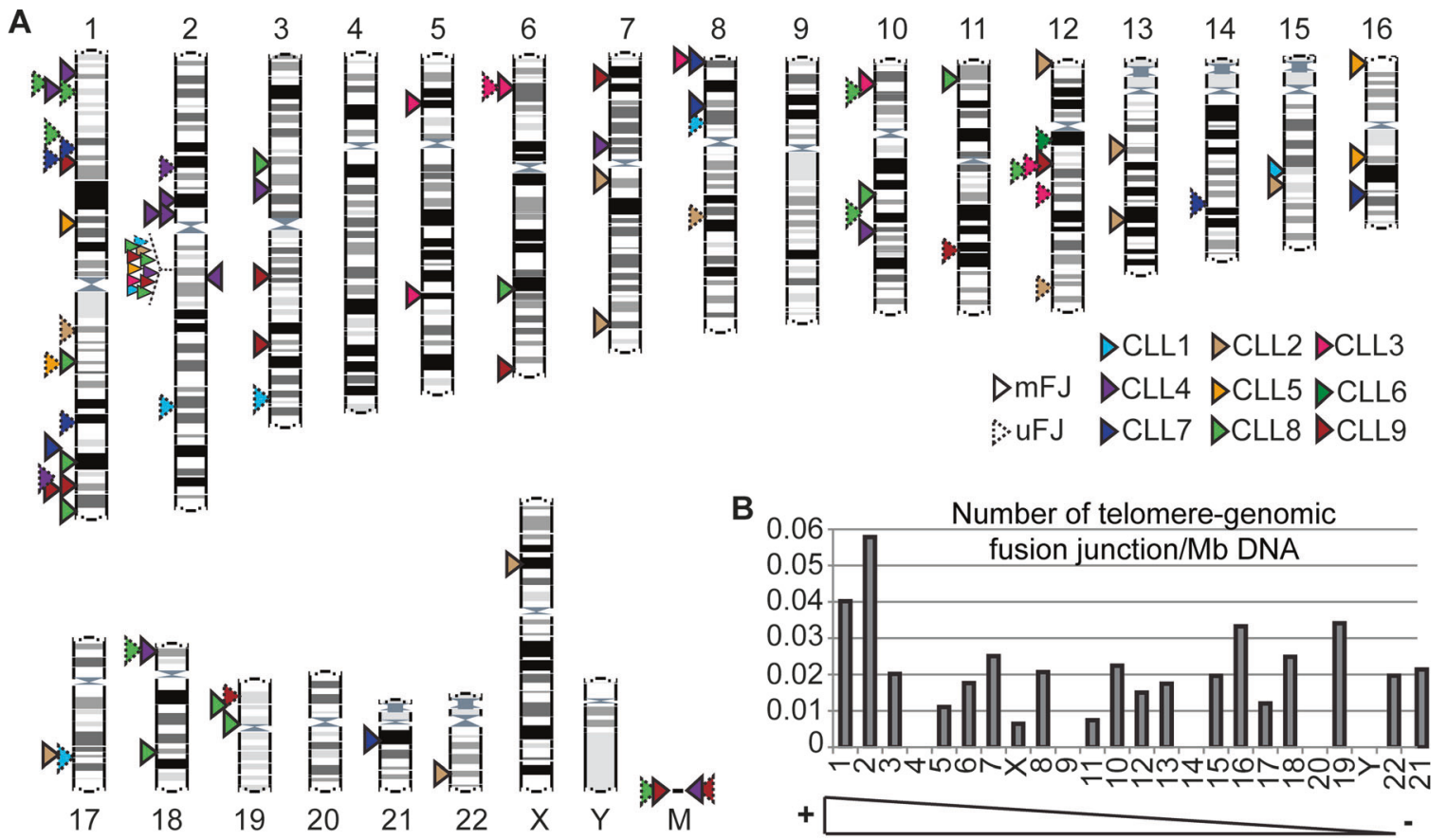
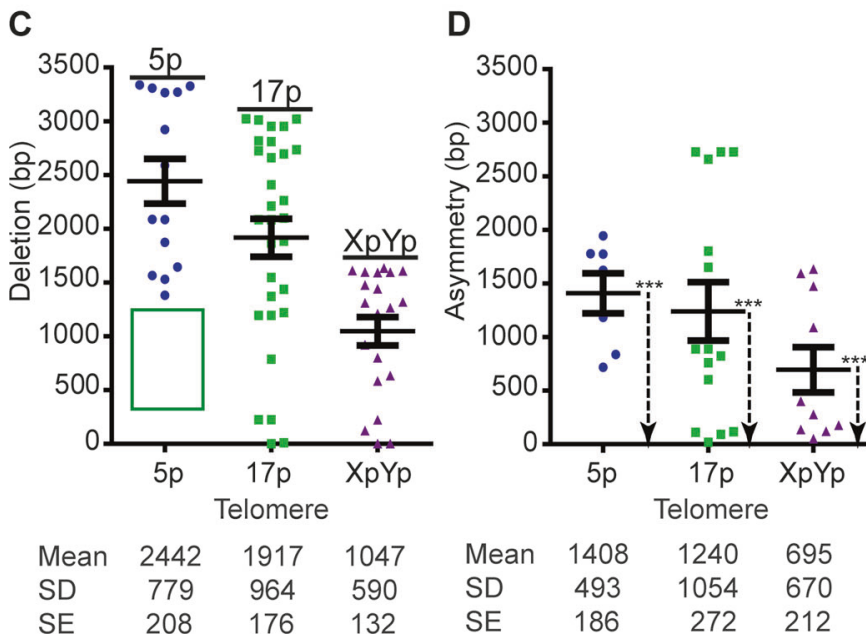

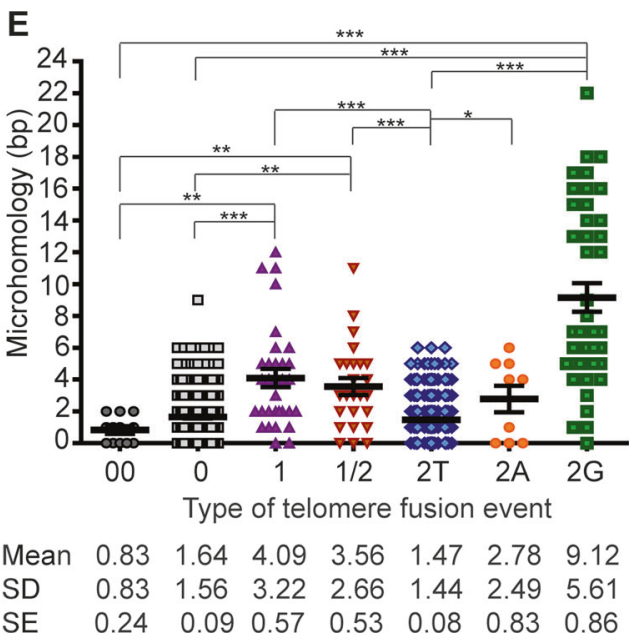

on the $5 \mathrm{p}$ sub-telomere. Location of the fusion primer indicated, determines the limit of the assay from the telomere. d Level of asymmetry was determined by calculating the deletion difference between each chromatid of the same fusion event. e Microhomology (bp) at the fusion junction was compared for the distinct type of events: TTAGGG-CCCTAA (00), Sub-telomere-TTAGGG (0), intrachromosomal (1), intra-chromosoma or inter-chromosomal of $16 \mathrm{p}-16 \mathrm{p}$ and $21 \mathrm{q}-21 \mathrm{q}$ families $(1 / 2)$, inter-chromosomal telomeric fusion events (2T), inter-chromosomal fusions with the ancestral telomere at $2 \mathrm{q} 13$ (2A) and inter-chromosomal fusions with genomic loci (2G). Mean, SD and SE are indicated below

1-21 nucleotides with a mean of 4.5 nucleotides. In contrast, no insertions were identified at fusions with non-telomeric loci. Statistically-significant differences in the extent of microhomology usage at fusion junctions were determined for the different types of telomere fusion events (KruskalWallis $p<0.001$ and Dunn's Multiple Comparison Test) 
(Fig. 2e; Supplementary Table 11). Inter-chromosomal fusions with non-telomeric loci (mean $=9.1 \mathrm{bp} ; n=43$ ), together with intra-chromosomal sister-chromatid events (mean $=4.1 \mathrm{bp} ; n=32$ ), displayed the greatest amounts of junction microhomology. In contrast, very low or an absence of microhomology at the fusion point was observed for inter-chromosomal telomeric fusions (mean $=1.5 \mathrm{bp}$; $n=315$ ), $\quad$ Telomere-Telomere (TTAGGG-CCCTAA; mean $=0.8 \mathrm{bp} ; \quad n=12) \quad$ and Telomere-Sub-telomere (mean $=1.6 \mathrm{bp} ; \quad n=303$ ) subgroups. Long tracts of microhomology of up to $23 \mathrm{bp}$, were observed at interchromosomal fusion junctions with non-telomeric loci (Fig. 2e). When the usage of microhomology was $>10 \mathrm{bp}$, the sequence was enriched for the repeat unit of $(A C)_{n}$ (Supplementary Figure 5); 40\% (6/15) of events that contained at least $(\mathrm{AC})_{5}$ (motif ACACACACAC), consistent with repair utilizing single-stranded annealing [11].

Taken together, our data reveal the impact of shortdysfunctional telomeres on the evolving CLL genome, generating tumour heterogeneity that may affect patient prognosis. We have revealed that dysfunctional telomeres predominantly fuse with protein-coding DNA including genes expressed in CLL B-cells and other tumours. We have also identified complex telomere fusions involving multiple non-telomeric loci across the CLL genome, including those with known copy number aberrations in CLL. Our data implicate diverse DNA repair mechanisms at play in CLL tumour initiation and progression, including C-NHEJ, A-NHEJ and SSA. These repair pathways provide potential therapeutic targets and combinations of therapeutic agents targeting these specific pathway components may effectively sensitise CLL B-cell clones with ongoing telomere dysfunction to improve patient outcomes.

Acknowledgements The authors would like to thank the CLL patients. The study was undertaken with the support of the UK CLL Clinical Trials Sub-Group. This work was supported by Cancer Research Wales, Cardiff University and Cancer Research UK (C17199/A18246). Patient material was obtained from the UK CLL Trials Biobank, University of Liverpool, which is funded by Bloodwise.

Author contributions LE performed the experimental work, analysed the experimental and bioinformatics data and wrote the manuscript; $\mathrm{KC}$ carried out the bioinformatics pipeline; $\mathrm{CF}$ provided clinical samples and edited the manuscript; $\mathrm{CP}$ provided clinical input and edited the manuscript; KL jointly supervised the study and edited the manuscript; DMB jointly supervised the study and edited the manuscript.

\section{Compliance with ethical standards}

Conflict of interest The authors declare that they have no conflict of interest.

Publisher's note: Springer Nature remains neutral with regard to jurisdictional claims in published maps and institutional affiliations.
Open Access This article is licensed under a Creative Commons Attribution 4.0 International License, which permits use, sharing, adaptation, distribution and reproduction in any medium or format, as long as you give appropriate credit to the original author(s) and the source, provide a link to the Creative Commons license, and indicate if changes were made. The images or other third party material in this article are included in the article's Creative Commons license, unless indicated otherwise in a credit line to the material. If material is not included in the article's Creative Commons license and your intended use is not permitted by statutory regulation or exceeds the permitted use, you will need to obtain permission directly from the copyright holder. To view a copy of this license, visit http://creativecommons. org/licenses/by/4.0/.

\section{References}

1. Lin TT, Norris K, Heppel NH, Pratt G, Allan JM, Allsup DJ, et al. Telomere dysfunction accurately predicts clinical outcome in chronic lymphocytic leukaemia, even in patients with early stage disease. Br J Haematol. 2014;167:214-23.

2. Letsolo BT, Rowson J, Baird DM. Fusion of short telomeres in human cells is characterized by extensive deletion and microhomology, and can result in complex rearrangements. Nucleic Acids Res. 2010;38:1841-52.

3. Liddiard K, Ruis B, Takasugi T, Harvey A, Ashelford KE, Hendrickson EA, et al. Sister chromatid telomere fusions, but not NHEJ-mediated inter-chromosomal telomere fusions, occur independently of DNA ligases 3 and 4 . Genome Res. 2016;26:588-600.

4. Lin TT, Letsolo BT, Jones RE, Rowson J, Pratt G, Hewamana S, et al. Telomere dysfunction and fusion during the progression of chronic lymphocytic leukemia: evidence for a telomere crisis. Blood. 2010;116:1899-907.

5. Salaverria I, Martin-Garcia D, Lopez C, Clot G, Garcia-Aragones M, Navarro A, et al. Detection of chromothripsis-like patterns with a custom array platform for chronic lymphocytic leukemia. Genes Chromosomes Cancer. 2015;54:668-80.

6. Fungtammasan A, Walsh E, Chiaromonte F, Eckert KA, Makova $\mathrm{KD}$. A genome-wide analysis of common fragile sites: what features determine chromosomal instability in the human genome? Genome Res. 2012;22:993-1005.

7. Subramanian A, Tamayo P, Mootha VK, Mukherjee S, Ebert BL, Gillette MA, et al. Gene set enrichment analysis: a knowledgebased approach for interpreting genome-wide expression profiles. Proc Natl Acad Sci USA. 2005;102:15545-50.

8. Pepper C, Ward R, Lin TT, Brennan P, Starczynski J, Musson M, et al. Highly purified CD38 + and CD38- sub-clones derived from the same chronic lymphocytic leukemia patient have distinct gene expression signatures despite their monoclonal origin. Leukemia. 2007;21:687-96.

9. von Wnuck Lipinski K, Sattler K, Peters S, Weske S, Keul P, Klump H, et al. Hepatocyte nuclear factor 1A Is a cell-intrinsic transcription factor required for B cell differentiation and development in mice. J Immunol. 2016;196:1655-65.

10. Capper R, Britt-Compton B, Tankimanova M, Rowson J, Letsolo B, Man S, et al. The nature of telomere fusion and a definition of the critical telomere length in human cells. Genes Dev. 2007;21:2495-508.

11. Bhargava R, Onyango DO, Stark JM. Regulation of single-strand annealing and its role in genome maintenance. Trends Genet. 2016;32:566-75.

12. Stong N, Deng Z, Gupta R, Hu S, Paul S, Weiner AK, et al. Subtelomeric CTCF and cohesin binding site organization using improved subtelomere assemblies and a novel annotation pipeline. Genome Res. 2014;24:1039-50. 
Leukemia (2019) 33:2098-2102

https://doi.org/10.1038/s41375-019-0421-0

Multiple myeloma gammopathies

\title{
BCL2 blockade overcomes MCL1 resistance in multiple myeloma
}

\author{
Ka Tat Siu ${ }^{1}$. Cherrie Huang ${ }^{2} \cdot$ Cristina Panaroni $^{1} \cdot$ Kenta Mukaihara $^{1} \cdot$ Keertik Fulzele $^{1} \cdot$ Rosemary Soucy $^{1}$. \\ Cassandra Thorburn ${ }^{1} \cdot$ Justin Cidado $^{3} \cdot$ Lisa Drew $^{3} \cdot$ Shrikanta Chattopadhyay $^{2} \cdot$ Noopur Raje $^{1}$
}

Received: 24 December 2018 / Revised: 3 February 2019 / Accepted: 7 February 2019 / Published online: 28 February 2019

(c) Springer Nature Limited 2019

\section{To the Editor:}

Disruption of the intrinsic apoptotic pathway by the aberrant expression of the BCL2 family members are frequent events in multiple myeloma (MM). In particular, the anti-apoptotic protein myeloid cell leukemia-1 (MCL1) is highly expressed in $\mathrm{MM}$ and plays a crucial role in disease progression [1, 2]. Using an unbiased approach to analyze cell death clustering, Gomez-Bougie and colleagues recently identified a group of MM patients insensitive to all the three classes of $\mathrm{BH} 3$ mimetics targeting MCL1, BCL2, and $\mathrm{BCLx}_{\mathrm{L}}$. These BH3 mimetic-resistant patients were mostly found at diagnosis, and they often do not possess any recurrent chromosomal translocations. BCL2 dependency is mainly found in patients with $\mathrm{t}$ $(11 ; 14)$ CCND1 translocation. BCLx $\mathrm{L}_{\mathrm{L}}$ dependency is rare in $\mathrm{MM}$ as they are often co-dependent on either BCL2 or MCL1. MCL1 dependency was strikingly predominant at relapse and in patients lacking common translocations and in the CCND1 subgroup. These findings suggested a shift of cellular plasticity towards MCL1 dependence during disease progression as a result of prior treatments or clonal selection [3].

A majority of well-established human MM cell lines and low-passage patient-derived myeloma cell lines have been shown to be MCL1 dependent using pharmacological inhibitors or gene editing approaches that specifically target MCL1 [4]. Clinically, overexpression of MCL1 is observed in $52 \%$ of MM patients at diagnosis and $81 \%$ at relapse. The

Supplementary information The online version of this article (https:// doi.org/10.1038/s41375-019-0421-0) contains supplementary material, which is available to authorized users.

Noopur Raje

NRAJE@mgh.harvard.edu

1 Massachusetts General Hospital Cancer Center, Harvard Medical School, Boston, MA 02114, USA

2 Broad Institute, Cambridge, MA 02142, USA

3 Bioscience, Oncology, IMED Biotech Unit, AstraZeneca, Boston, MA, USA level of MCL1 expression correlates with disease progression, and a higher MCL1 expression is associated with shorter survival [5]. Since MM is heavily reliant on MCL1, MM patients, particularly those at relapse, would benefit from an MCL1-targeted therapy. However, there is no FDA-approved drug with the ability to selectively target MCL1. To address this unmet medical need, a few selective MCL1 inhibitors are currently being developed in preclinical phase or clinical trials and have thus far shown promising results as single agents or used in combination with established therapies in various cancers, particularly in hematologic malignancies [6-8]. To further explore MCL1 biology in MM, we use a clinical-grade small-molecule MCL1 inhibitor, AZD5991, to investigate the mechanistic underpinning of MCL1 inhibition in MM.

AZD5991 is a potent and selective macrocyclic inhibitor of MCL1 [9] that is currently in phase I clinical trial in patients with relapsed or refractory $\mathrm{MM}$ and other hematologic malignancies (ClinicalTrials.gov Identifier: NCT03218683). Using AZD5991 as a test compound, we aimed to determine the survival dependency of human MM cells on the antiapoptotic protein MCL1. First, we evaluated the cytotoxicity of AZD5991 on a panel of MM cell lines. MM cell lines showed a heterogeneous response to MCL1 inhibition. AZD5991 treatment resulted in dose-dependent cytotoxicity with $\mathrm{EC}_{50}$ values (Table S1) ranging from $64 \mathrm{nM}$ to $417 \mathrm{nM}$ at $24 \mathrm{~h}$ for AZD5991-sensitive cell lines (Fig. 1a). We next assessed the effect of AZD5991 in MM patient-derived $\mathrm{CD}_{138^{+}}$cells. AZD5991 treatment led to 40-82\% decrease in viability of primary cells isolated from relapsed and refractory MM patients at a dose of $300 \mathrm{nM}$ at $24 \mathrm{~h}$ (Fig. 1b). AZD5991 also induces potent anti-MM activity in vivo [9]. Together, these results indicate that AZD5991 has promising singleagent activity, but it would be prudent to study it in combination with other anti-MM therapies.

To understand the mechanism of cytotoxicity, we treated the AZD5991-sensitive MM.1S and H929 cells with $50 \mathrm{nM}$ of AZD5991 for $24 \mathrm{~h}$. The decrease in cell viability upon MCL1 inhibition is due to an increase in apoptosis as shown by an increase in Annexin V signals after MCL1 inhibition. 


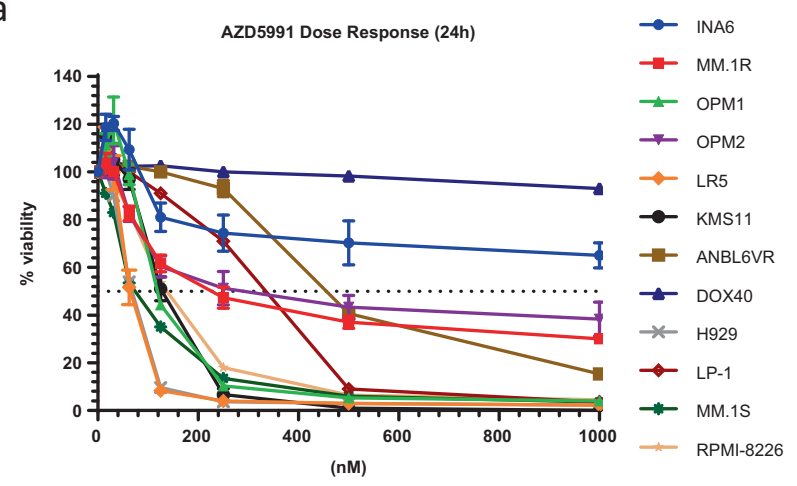

C

MCL1 inhibition in MM.1S (BMSC conditioned media)

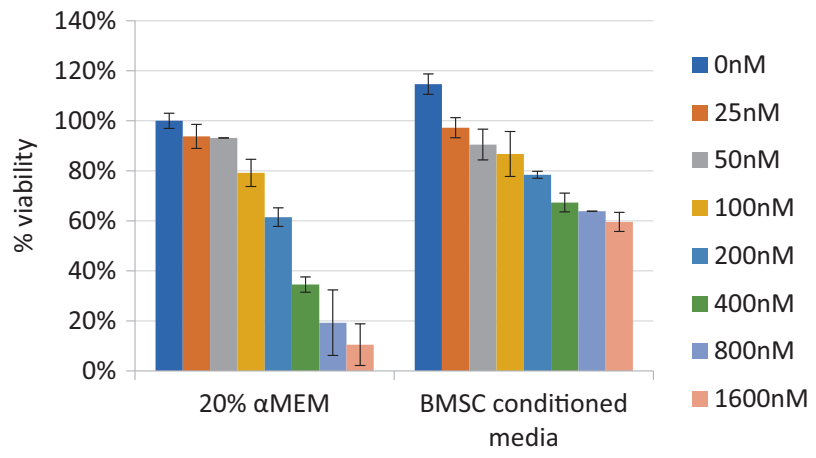

d

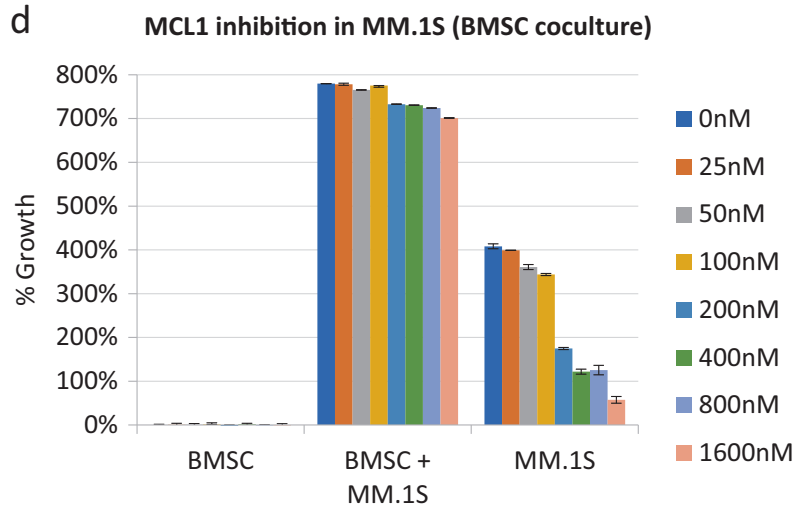

Fig. 1 The BM microenvironment confers a protective effect on MM cells against MCL1 inhibition. a A panel of human MM cell lines was treated with increasing doses of AZD5991 (0-1000 nM) for $24 \mathrm{~h}$, and cell viability was measured by CellTiter-Glo ${ }^{\circledR}$ One Solution Assay. b Patient-derived CD $138^{+}$MM cells were treated with increasing doses of AZD5991 for $24 \mathrm{~h}$, and cell viability was measured as in a. All the samples were derived from relapsed or refractory MM patients. c, d MM.1S cells were cultured with increasing doses of AZD5991 for $24 \mathrm{~h}$

On the other hand, the AZD5991-resistant DOX40 cells showed no increase in Annexin V signals at the low dose (Fig. S1). We next confirmed that the induction of apoptosis in the AZD5991-sensitive cells is caspase-dependent and it is induced primarily via the intrinsic apoptotic pathways as shown by an increase in caspase- 3 and caspase- 9 signals after AZD5991 treatment. The caspase signals were completely reversed with the addition of caspase inhibitors (Fig. S2).
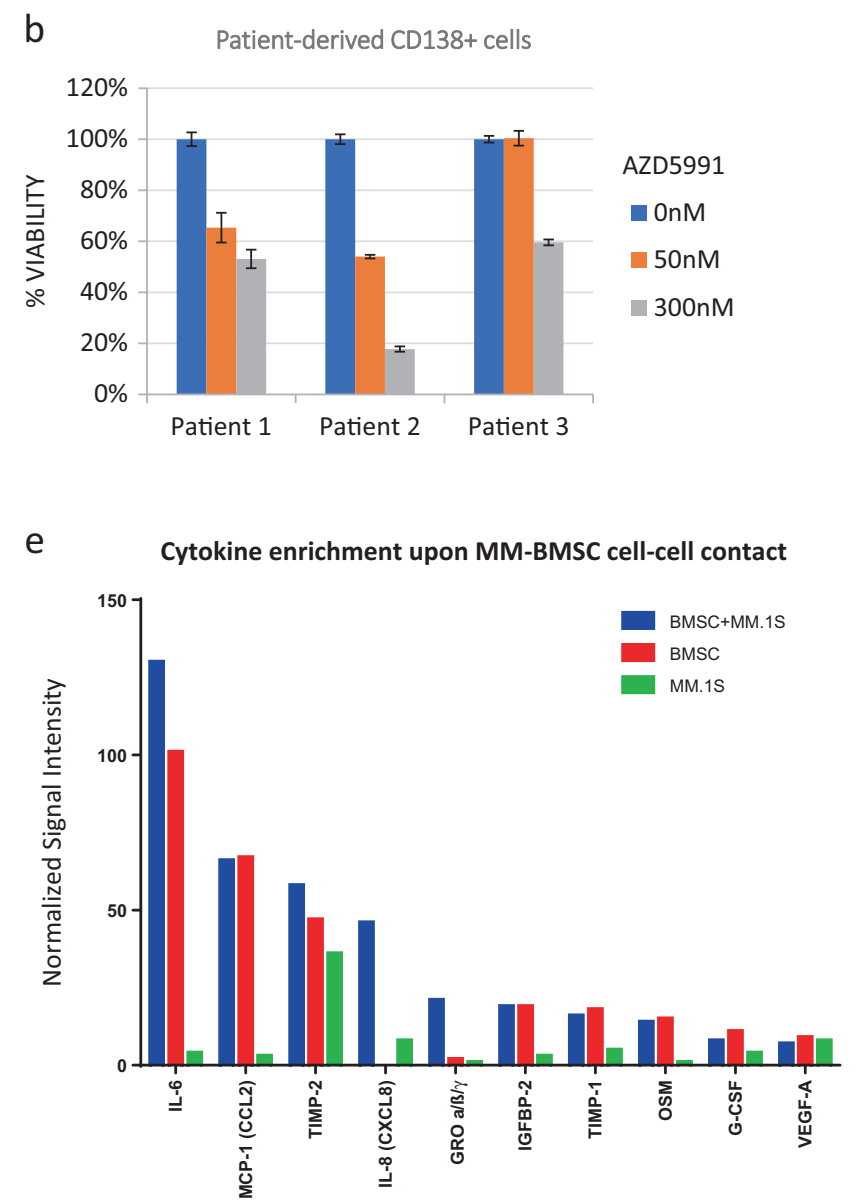

in the presence of (c) BMSC-conditioned media or (d) BMSCs. Cell viability in $\mathbf{c}$ was assessed by CellTiter-Glo ${ }^{\circledR}$ One Solution Assay. Cell proliferation in $\mathbf{d}$ was evaluated by $\mathrm{CyQUANT}^{\circledR} \mathrm{NF}^{\mathrm{N}}$ Cell Proliferation Assay. e Semi-quantitative detection of a panel of 80 human proteins in cell culture media of MM.1S cells, BMSCs, and BMSC+MM.1S co-culture. Shown here are the top ten most highly-expressed cytokines in the culture media. Signal intensity was normalized to uncultured media

Since the bone marrow (BM) microenvironment enhances tumor cell growth and survival in MM, we next assessed the effect of AZD5991 on the MCL1-sensitive MM.1S and H929 cells in the presence of BMSC-conditioned media and co-culture with bone marrow stromal cells (BMSCs). We found that soluble factors produced during the MM-BMSC interaction reduced the sensitivity of $\mathrm{MM}$ cells to AZD5991, and direct MM-BMSC contact blunted the cytotoxic effect of AZD5991 (Fig. 1c, d and Fig. S3). The 

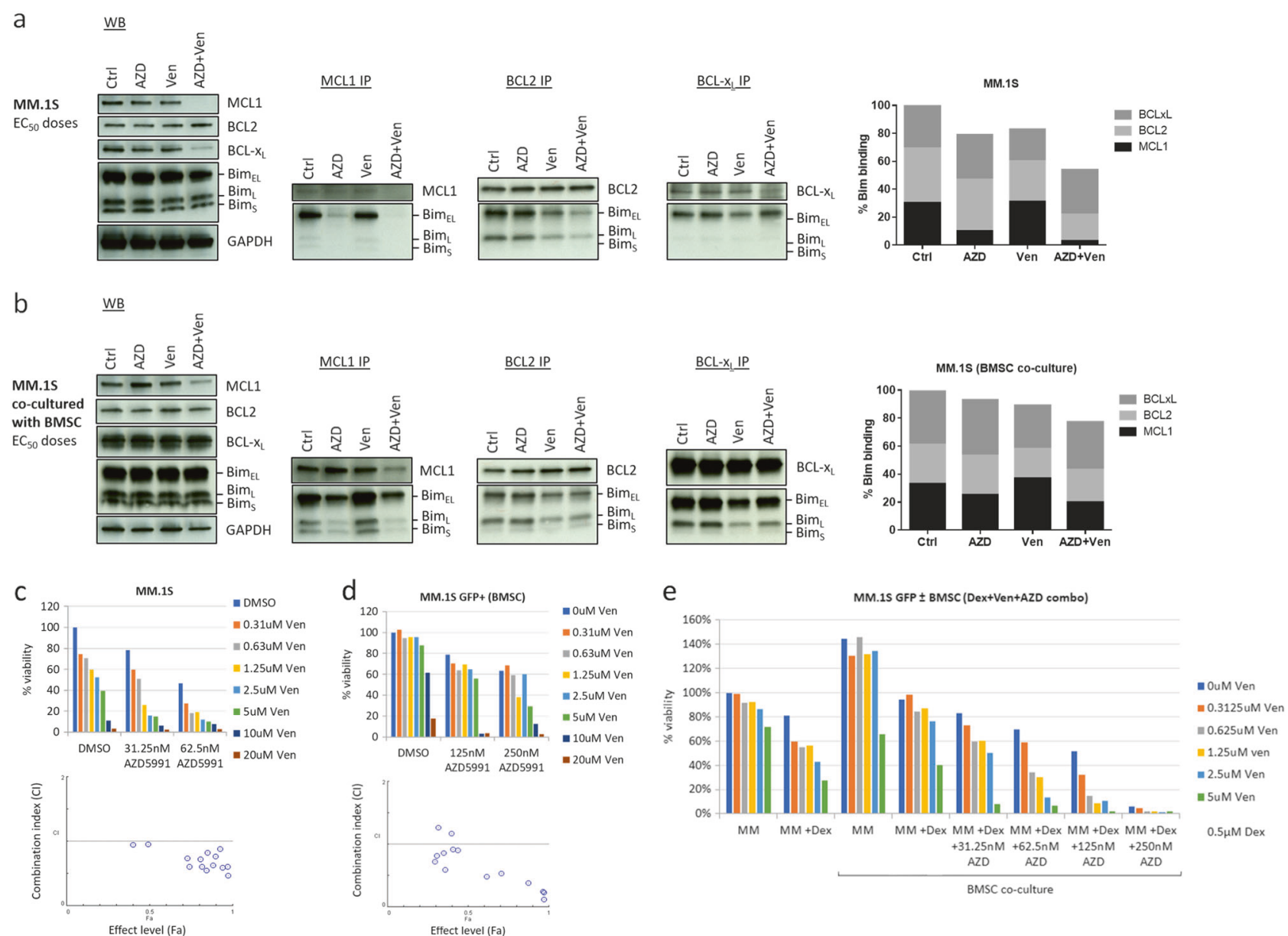

Fig. 2 AZD5991 in combination with Venetoclax induces synergistic anti-MM activity and overcomes MCL1 resistance in MM. MM.1S cells were either cultured alone (a) or co-cultured with BMSCs (b) and treated with $\mathrm{EC}_{50}$ doses of AZD5991, Venetoclax (Table S1-S2), or in combination for $6 \mathrm{~h}$. Protein lysates were prepared from MM.1S cells and subjected to co-immunoprecipitation with MCL1, BCL2, or $\mathrm{BCLx}_{\mathrm{L}}$ antibodies. The pull-down protein complexes were subjected to Western blot analysis to examine Bim binding to MCL1, BCL2, and $\mathrm{BCLx}_{\mathrm{L}}$, respectively. Total protein lysates were subjected to Western blot analysis to determine the amount of protein input for each treatment. Densitometric analysis of Bim binding was performed using the ImageJ software, and the percentage of Bim bound to MCL1, BCL2, and $\mathrm{BCLx}_{\mathrm{L}}$ under different treatment conditions were presented in the

protective effect of the BM microenvironment is mediated via cytokines, as well as through MM-BMSC contact [10]. Importantly, MCL1 is the only anti-apoptotic protein within the BCL2 family members whose expression is controlled by cytokine treatment of MM cells $[11,12]$. Therefore, we carried out a comprehensive analysis of 80 human proteins in cell culture media. Our cytokine array analysis revealed an enrichment of a panel of pro-survival cytokines and growth factors, with the cytokine IL- 6 being among the most highly up-regulated proteins, upon cell-cell contact between MM.1S cells and BMSCs (Fig. 1e and Fig. S4). IL6 is known to enhance MCL1 expression via STAT3 signaling in MM [11, 13], making the cells more MCL1

stacked bar graphs. c MM.1S cells were treated with increasing doses of AZD5991 and Venetoclax for $24 \mathrm{~h}$. Cell viability was assessed by CellTiter-Glo ${ }^{\circledR}$ One Solution Assay. The isobologram analysis confirms synergism. d The synergistic effect of the AZD5991/Venetoclax combination was examined on GFP-expressing MM.1S in the BMSC co-culture setting over $72 \mathrm{~h}$. Cell viability of MM.1S cells was assessed by quantitative fluorescence imaging. The isobologram analysis confirms greater than additive effect. e The combinatorial effect of the AZD5991/Venetoclax/Dexamethasone regimen was examined on GFP-expressing MM.1 S cells in the BMSC co-culture setting over $72 \mathrm{~h}$. Cell viability of MM.1S cells was assessed by quantitative fluorescence imaging

dependent. The fact that a higher concentration of AZD5991 could overcome the soluble resistant factors in the BM milieu implied cytokines and growth factors only contribute partially to MCL1 resistance. Direct cell-cell contact in the BM microenvironment protects $\mathrm{MM}$ cells from AZD5991-induced cell death. The co-culture with BMSCs increased MCL1, BCLx ${ }_{\mathrm{L}}$, and Bim expression in MM.1S cells (Fig. S5), further enhancing their codependence on MCL1 and BCLx $\mathrm{L}_{\mathrm{L}}$ for survival.

A shift in the balance of BCL2 family members is often the primary reason for drug resistance [14, 15]. Although MM cells mostly depend on MCL1 for survival, we hypothesized that MM cells could switch their survival dependency to other 
anti-apoptotic proteins upon stress. For example, when AZD5991 displaces Bim from MCL1, the excess Bim may be sequestered by BCL2 or BCLx $\mathrm{L}_{\mathrm{L}}$, thereby allowing MM cells to evade cell death. To test this hypothesis, we examined the impact of MCL1 and BCL2 inhibition on the binding pattern of Bim to anti-apoptotic proteins in MM. MM.1S cells and patient-derived $\mathrm{CD}_{138^{+}}$cells were either cultured alone or in co-culture with BMSCs and treated with AZD5991 or Venetoclax (a BH3 mimetic that selectively binds and inhibits BCL2 [16]) alone or in combination. The protein lysates prepared from the MM cells were then co-immunoprecipitated with antibodies against MCL1, BCL2, and $\mathrm{BCLx}_{\mathrm{L}}$ to determine the relative levels of Bim bound to each anti-apoptotic protein under each drug treatment condition. We found that MCL1 inhibition by AZD5991 leads to release of Bim from MCL1, but increased Bim binding to BCL2 and BCLxL. BCL2 inhibition by Venetoclax releases Bim from BCL2 but results in increased Bim binding to MCL1. Cotreatment with AZD5991 and Venetoclax decreases the overall Bim bound to the anti-apoptotic proteins (Fig. 2a, b and Fig. S6). These results suggest that MM cells switch their survival dependency to other anti-apoptotic proteins upon MCL1 inhibition and simultaneous inhibition of both MCL1 and BCL2 could be an effective way to overcome MCL1 resistance in MM.

Based on these observations, we combined AZD5991 with Venetoclax for the treatment of MM. A significant decrease in cell viability was observed with the combined therapy compared with both drugs used alone (Fig. 2c and Fig. S7). Isobologram analysis confirmed greater than additive or synergistic effect upon co-treatment. The same in vitro synergism was observed in AZD5991-resistant DOX40 cells and Venetoclax-resistant ANBL6VR cells (Fig. S8). The enhanced cytotoxic effect of the combined therapy was preserved even when the MM cells are in co-culture with BMSCs (Fig. 2d and Fig. S9). No cytotoxic effect was observed when patient-derived BMSCs were exposed to this combined therapy (Fig. S10). Cotreatment with AZD5991 and Venetoclax also enhanced primary MM cell death in patient-derived bone marrow (Fig. S11), suggesting that this combination regimen is effective in the BM milieu.

Although AZD5991 in combination with Venetoclax is effective in inducing synergistic anti-MM activity, the concentration of Venetoclax used in the initial testing was relatively high. A recent report showed that dexamethasone (Dex) enhances the expression of both BCL2 and Bim in MM, and consequently shifts Bim binding towards BCL2 and promotes BCL2 dependence in MM [17]. Thus, Dex sensitizes MM cells to Venetoclax. To achieve therapeutic concentrations, we added low-dose Dex to the AZD5991/ Venetoclax regimen and found that addition of Dex significantly augments the effect of MCL1 and BCL2 blockade in MM. We were able to achieve the same cytotoxic effect on MM cells in the BMSC coculture with a much lower dosage of both AZD5991 and Venetoclax (Fig. 2e and Fig. S12), which is critical for clinical translation.

We discovered a MCL1 resistance mechanism in MM that is driven by Bim binding to other anti-apoptotic proteins upon MCL1 inhibition. Our data demonstrated that the combined AZD5991/Venetoclax therapy overcomes MCL1 resistance in MM. Concomitant suppression of both MCL1 and BCL2 prevent MM cells from escaping apoptosis by releasing Bim from the anti-apoptotic proteins to activate the intrinsic apoptotic pathway. With the addition of Dex which enhances BCL2 and Bim expression and promotes BCL2 dependence, we can achieve therapeutic dosage for both AZD5991 and Venetoclax in MM treatment. As a proof of concept, our data indicate combining therapeutics that selectively target the anti-apoptotic proteins MCL1 and BCL2 could be an effective therapy for MM patients, particularly those who suffered from relapsed or refractory disease.

Acknowledgements This work is supported by the Multiple Myeloma Research Fund at the Massachusetts General Hospital. AstraZeneca provided the AZD5991 compound. The authors would like to thank the Flow, Image, and Mass Cytometry Core in the Department of Pathology at the Massachusetts General Hospital for their support in cell sorting and flow cytometry analysis.

Author contributions K.T.S., S.C., and N.R. designed the research; K. T.S. and C.H. performed the research; K.T.S., C.H., C.P., K.M., K.F., R.S., C.T., S.C., and N.R. analyzed the data; J.C. and L.D. provided the AZD5991 compound; K.T.S. and N.R. wrote the manuscript; and all the authors reviewed the manuscript.

\section{Compliance with ethical standards}

Conflict of interest J.C. and L.D. are employees of AstraZeneca. N.R. is on advisory boards of Amgen, Bristol-Myers Squibb, Celgene, Merck, Janssen and Takeda. N.R. has received research funding from AstraZeneca. The remaining authors declare that they have no conflict of interest.

Publisher's note: Springer Nature remains neutral with regard to jurisdictional claims in published maps and institutional affiliations.

\section{References}

1. Zhang B, Gojo I, Fenton RG. Myeloid cell factor-1 is a critical survival factor for multiple myeloma. Blood. 2002;99: 1885-93.

2. Derenne S, Monia B, Dean NM, Taylor JK, Rapp MJ, Harousseau $\mathrm{JL}$, et al. Antisense strategy shows that Mcl-1 rather than Bcl-2 or $\mathrm{Bcl}-\mathrm{x}(\mathrm{L})$ is an essential survival protein of human myeloma cells. Blood. 2002;100:194-9.

3. Gomez-Bougie P, Maiga S, Tessoulin B, Bourcier J, Bonnet A, Rodriguez MS, et al. BH3-mimetic toolkit guides the respective use of BCL2 and MCL1 BH3-mimetics in myeloma treatment. Blood. 2018;132:2656-69.

4. Gong JN, Khong T, Segal D, Yao Y, Riffkin CD, Garnier JM, et al. Hierarchy for targeting prosurvival BCL2 family proteins in multiple myeloma: pivotal role of MCL1. Blood. 2016;128:1834-44.

5. Wuilleme-Toumi S, Robillard N, Gomez P, Moreau P, Le Gouill $\mathrm{S}$, Avet-Loiseau $\mathrm{H}$, et al. Mcl-1 is overexpressed in multiple 
myeloma and associated with relapse and shorter survival. Leukemia. 2005;19:1248-52.

6. Caenepeel S, Brown SP, Belmontes B, Moody G, Keegan KS, Chui D, et al. AMG 176, a selective MCL1 inhibitor, is effective in hematologic cancer models alone and in combination with established therapies. Cancer Discov. 2018;8:1582-97.

7. Leverson JD, Zhang H, Chen J, Tahir SK, Phillips DC, Xue J, et al. Potent and selective small-molecule MCL-1 inhibitors demonstrate on-target cancer cell killing activity as single agents and in combination with ABT-263 (navitoclax). Cell Death Dis. 2015;6:e1590.

8. Kotschy A, Szlavik Z, Murray J, Davidson J, Maragno AL, Le Toumelin-Braizat G, et al. The MCL1 inhibitor S63845 is tolerable and effective in diverse cancer models. Nature. 2016;538: 477-82.

9. Tron AE, Belmonte MA, Adam A, Aquila BM, Boise LH, Chiarparin E, et al. Discovery of Mcl-1-specific inhibitor AZD5991 and preclinical activity in multiple myeloma and acute myeloid leukemia. Nat Commun. 2018;9:5341.

10. Hideshima T, Bergsagel PL, Kuehl WM, Anderson KC. Advances in biology of multiple myeloma: clinical applications. Blood. 2004;104:607-18.

11. Jourdan M, Veyrune JL, De Vos J, Redal N, Couderc G, Klein B. A major role for Mcl-1 antiapoptotic protein in the IL-6-induced survival of human myeloma cells. Oncogene. 2003;22:2950-9.
12. Jourdan M, De Vos J, Mechti N, Klein B. Regulation of Bcl-2family proteins in myeloma cells by three myeloma survival factors: interleukin-6, interferon-alpha and insulin-like growth factor 1. Cell Death Differ. 2000;7:1244-52.

13. Puthier D, Derenne S, Barille S, Moreau P, Harousseau JL, Bataille R, et al. Mcl-1 and Bcl-xL are co-regulated by IL- 6 in human myeloma cells. Br J Haematol. 1999;107:392-5.

14. Luedtke DA, Niu X, Pan Y, Zhao J, Liu S, Edwards H, et al. Inhibition of Mcl-1 enhances cell death induced by the Bcl-2selective inhibitor ABT-199 in acute myeloid leukemia cells. Signal Transduct Target Ther. 2017;2:17012.

15. Niu X, Zhao J, Ma J, Xie C, Edwards H, Wang G, et al. Binding of released Bim to Mcl-1 is a mechanism of intrinsic resistance to ABT-199 which can be overcome by combination with daunorubicin or cytarabine in AML cells. Clin Cancer Res. 2016;22:4440-51.

16. Souers AJ, Leverson JD, Boghaert ER, Ackler SL, Catron ND, Chen J, et al. ABT-199, a potent and selective BCL-2 inhibitor, achieves antitumor activity while sparing platelets. Nat Med. 2013;19:202-8.

17. Matulis SM, Gupta VA, Nooka AK, Hollen HV, Kaufman JL, Lonial S, et al. Dexamethasone treatment promotes Bcl-2 dependence in multiple myeloma resulting in sensitivity to venetoclax. Leukemia. 2016;30:1086-93.

Leukemia (2019) 33:2102-2104

https://doi.org/10.1038/s41375-019-0437-5

Acute lymphoblastic leukemia

\title{
Anti-CD19 CAR-T as a feasible and safe treatment against central nervous system leukemia after intrathecal chemotherapy in adults with relapsed or refractory B-ALL
}

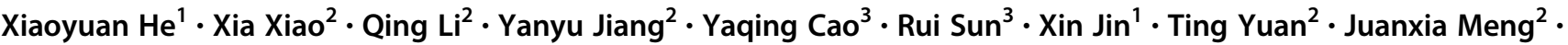 \\ $\mathrm{Li} \mathrm{Ma}{ }^{2} \cdot$ Wenyi $\mathrm{Lu}^{2} \cdot$ Cuicui $\mathrm{Lyu}^{2} \cdot$ Kaiqi Liu ${ }^{4} \cdot$ Mingfeng $\mathrm{Zhao}^{2,1}$
}

Received: 29 November 2018 / Revised: 14 February 2019 / Accepted: 15 February 2019 / Published online: 7 March 2019

(c) The Author(s) 2019. This article is published with open access

These authors contributed equally: Mingfeng Zhao, Kaiqi Liu

Supplementary information The online version of this article (https:// doi.org/10.1038/s41375-019-0437-5) contains supplementary material, which is available to authorized users.

Kaiqi Liu

yanghua94583@sina.com

$\triangle$ Mingfeng Zhao

mingfengzhao@sina.com

1 Nankai University School of Medicine, Tianjin, PR China

\section{To the Editor:}

Chimeric antigen receptor (CAR)- $\mathrm{T}$ cell treatment as an emerging tumor immunotherapy has produced exciting results in relapsed or refractory B cell acute lymphoblastic leukemia (B-ALL) [1-4]. However, few data are available on the therapeutic effect of CAR-T against central nervous system leukemia (CNSL). Here, we evaluated the feasibility and safety of

2 Department of hematology, Tianjin First Central Hospital, No. 24 Fu Kang Road, Tianjin, PR China

3 Tianjin medical university, Tianjin, PR China

4 Leukemia Center, Institute of Hematology and Blood Diseases Hospital, Chinese Academy of Medical Sciences and Peking Union Medical College, 288 Nanjing Road, Tianjin, PR China 
A

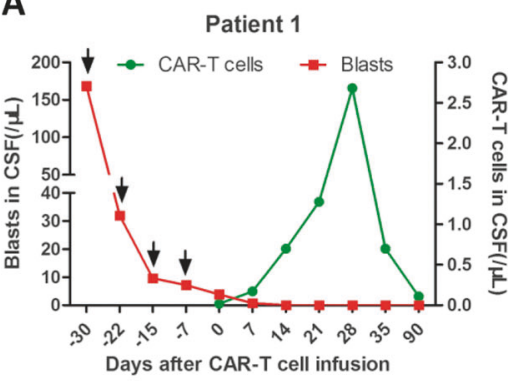

D
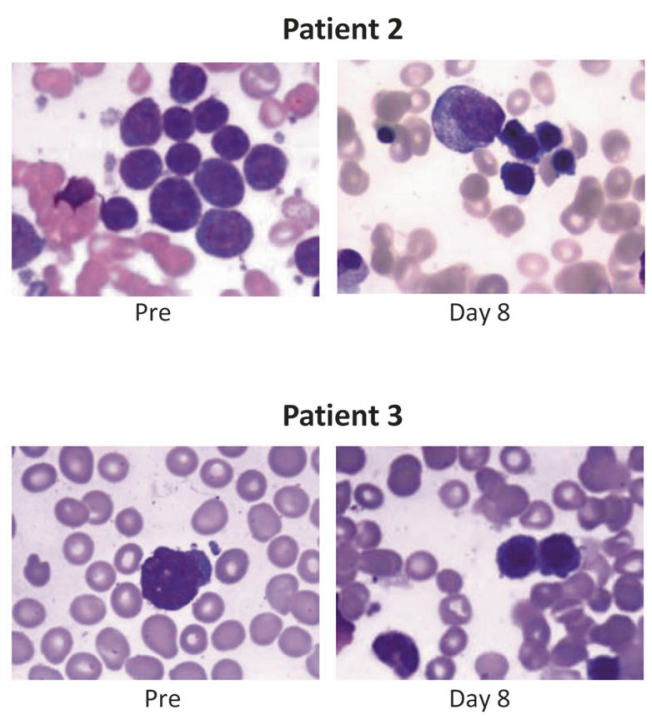

B

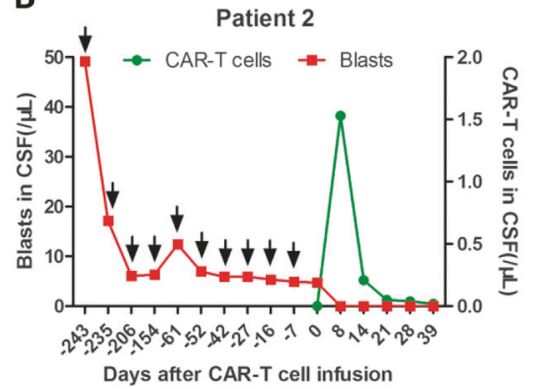

C

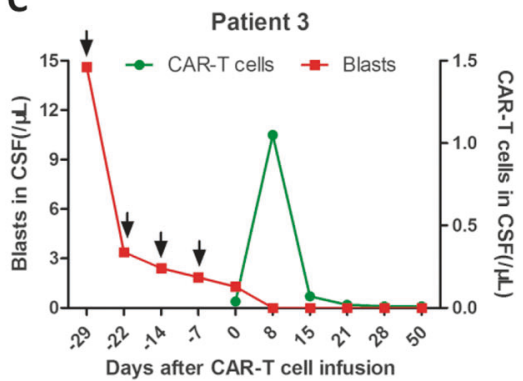

E

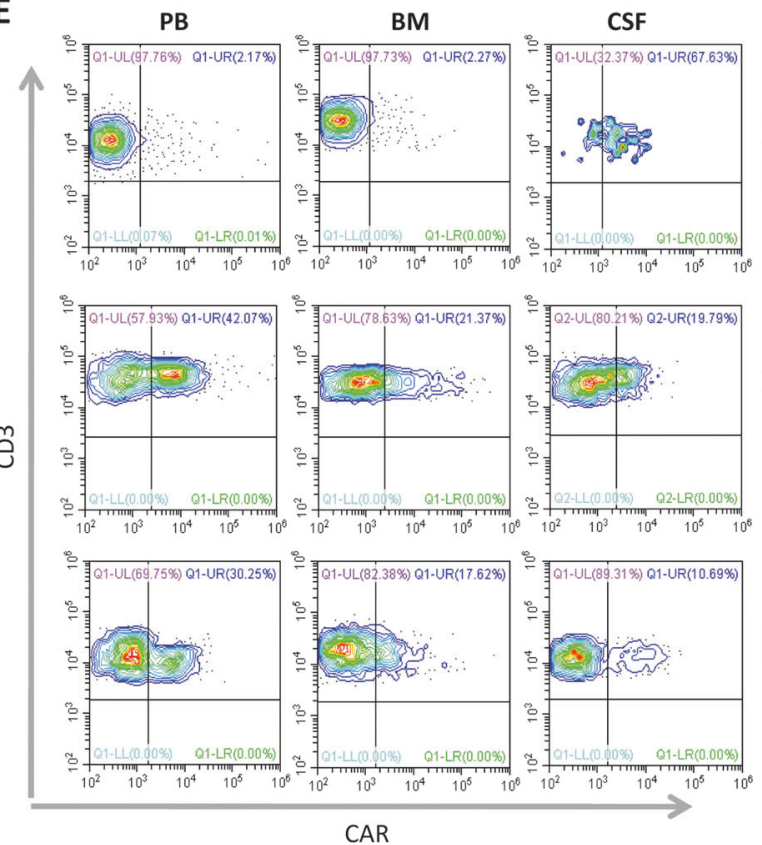

Patient 1

(Day 28)

Patient 2

(Day 8)

Patient 3

(Day 8)
Fig. 1 Clinical response, expansion and persistence of antiCD19chimeric antigen receptor (CAR)-T cells. a-c Cell counts of CAR-T cells and tumor cells in the cerebrospinal fluid (CSF) before and after CAR-T infusion. The black arrows indicate intrathecal

anti-CD19 CAR-T against CNSL after intrathecal chemotherapy in three adults with relapsed or refractory B-ALL.

Patient 1 with isolated CNSL, was refractory to high dose methotrexate plus vindesine and L-asparaginase, and intrathecal chemotherapy, accompanied by bone marrow (BM) sustained remission with minimal residual disease (MRD) negative. Patient 2 initially experienced a CNS relapse, and underwent intrathecal chemotherapy, systemic chemotherapy and radiotherapy. However, her CNSL was not controlled, accompanied by $\mathrm{BM}$ recurrence. Patient 3 received prophylactic intrathecal chemotherapy after his first complete remission (CR) but experienced a rapid recurrence in his BM and CNS. They were enrolled in our anti-CD19 CAR-T clinical trial (ChiCTR-ONN16009862). Prior to CAR-T cell infusion, all the patients received conditioning chemotherapy with fludarabine and cyclophosphamide, and intrathecal chemotherapy to reduce blasts in the cerebrospinal fluid (CSF). Detailed patient and chemotherapy. d Malignant cells in the bone marrow (BM) of patient 2 and patient 3 pre and post-infusion. e The peak expansion levels of CAR-T cells in the peripheral blood (PB), BM, and CSF

methodological information are described in Supplementary Methods, Table S1, and Figure S1.

First, we assessed the clinical response of CNSL to CAR-T therapy in these patients. All patients with CNSL achieved CR approximately one to two weeks post CAR-T infusion (Fig. 1a-c), accompanied by BM remission with MRD negative in patient 2 and patient 3 (Fig. 1d). One month after $\mathrm{CR}$, patient 2 received allogeneic hematopoietic stem cell transplantation. Until the most recent follow-up, her leukemia free survival has been over 2 months. Interestingly, patient 1 and patient 3 receiving no further therapy for CNSL after CAR-T infusion were in sustained remission for over 5 months (Table S1). A phase 1 dose-escalation trial reported that two B-ALL patients with CNSL achieved CR after CAR$\mathrm{T}$ therapy [3]. Another clinical trial showed that two CNSL patients at the time of CAR-T infusion subsequently had no blasts in the CSF [2]. Dai and colleagues also reported that two patients with active CNSL at the time of CAR-T infusion 
became CNS negative [5]. Altogether, CAR-T can be a feasible and effective treatment for CNSL.

We further evaluated the proliferation and persistence of CAR-T in vivo. Two patients reached the peak expansion of CAR-T cells in the CSF on day 8 (Fig. 1b, c), which coincided with the disappearance of CSF blasts in the responding patients. However, patient 1 exhibited peak expansion on day 28,2 weeks later than the disappearance of the tumor cells in the CSF (Fig. 1a). The persistence time of CAR-T cells in the CSF of patient 2 and patient 3 was about $2-3$ weeks (Fig. 1b, c), while in patient 1, 5.19\% of CAR-T cells persisted in the CSF on day 90 (Fig. 1a). Patient 1 who only had CNS relapse, showed significantly higher peak proportions of CAR-T cells in the CSF than those in the peripheral blood (PB) and BM. However, patient 2 and patient 3 both with BM and CNS recurrence exhibited markedly lower peak levels of CAR-T cells in the CSF compared to patient 1 (Fig. 1e), but relatively high peak levels in the PB and BM. These different distributions of CAR-T cells may be explained by chemotaxis and stimulated proliferation of effector cells at the tumor sites.

We next evaluated the adverse events associated with antiCD19 CAR-T treatment. Patient 1 only showed grade 1 anemia and grade 4 lymphopenia on day 3 after infusion (Table S2). She didn't complain of any discomfort post CAR$\mathrm{T}$ therapy. It was reported that the severity of the cytokine release syndrome (CRS) was correlated with tumor burdens and $\mathrm{T}$ cell proliferation $[2,3,6]$. However, the peak expansion time of patient 1 was two weeks later than the disappearance of the tumor cells in the CSF (Fig. 1a), which may explain the low risk of CRS. Patient 2 and patient 3 experienced grade 2 fever, grade 3 febrile neutropenia, grade 2 CRS, and grade 1 reduced consciousness. Patient 2 also had grade 1 cognitive impairment and grade 2 convulsion. Dexamethasone was administrated at $10 \mathrm{mg}$ q $8 \mathrm{~h}$ to control her seizure on day 8 , and was de-escalated on day 9 and discontinued on day 10 . These adverse events were well managed with supportive care and dexamethasone. Other adverse events related to CAR-T therapy are shown in Figure S2 and Table S2.

In summary, this study showed that anti-CD19 CAR-T could effectively eliminated leukemia cells in the CNS with fully reversible toxicity. We also found that patient with only CNS recurrence had higher levels of CAR-T in the CSF and relatively lower severity of toxic effects than those with BM and CNS recurrence. This study shows that anti-CD19 CAR-T might be a feasible and safe treatment for CNSL after intrathecal chemotherapy in adults with BALL, especially in isolated CNSL. More cases and further studies are needed to verify these findings.

Acknowledgements This work was supported by grants from the National Natural Sciences Foundation of China (81400092; to M. Zhao), the Tianjin Key Natural Science Foundation
(17JCZDJC35800, 15JCQNJC45500; to M. Zhao), and the Tianjin Key Science and Technology Program (2015K215, 15KG134, 16KG110; to M. Zhao), as well as Tianjin First Central Hospital. This work was also supported by the Ph.D. Candidate Research Innovation Fund of Nankai University (X. He).

Author contributions MFZ and KQL designed the research; XYH, XX, QL, YYJ, TY, JXM and LM performed the research; XYH, YQC, RS, XJ, WYL and CCL analyzed the data; XYH wrote the manuscript; $\mathrm{XYH}$ and MFZ revised the manuscript. All authors approved the final version of the manuscript.

\section{Compliance with ethical standards}

Ethical approval This study was conducted according to the principles of the Declaration of Helsinki and with the approval of the Ethics Committee of Tianjin First Central Hospital.

Informed consent All the enrolled patients or their families provided written informed consent.

Conflict of interest The authors declare that they have no conflict of interest.

Publisher's note: Springer Nature remains neutral with regard to jurisdictional claims in published maps and institutional affiliations.

Open Access This article is licensed under a Creative Commons Attribution 4.0 International License, which permits use, sharing, adaptation, distribution and reproduction in any medium or format, as long as you give appropriate credit to the original author(s) and the source, provide a link to the Creative Commons license, and indicate if changes were made. The images or other third party material in this article are included in the article's Creative Commons license, unless indicated otherwise in a credit line to the material. If material is not included in the article's Creative Commons license and your intended use is not permitted by statutory regulation or exceeds the permitted use, you will need to obtain permission directly from the copyright holder. To view a copy of this license, visit http://creativecommons. org/licenses/by/4.0/.

\section{References}

1. Maus MV, Grupp SA, Porter DL, June CH. Antibody-modified T cells: CARs take the front seat for hematologic malignancies. Blood. 2014;123:2625-35.

2. Maude SL, Frey N, Shaw PA, Aplenc R, Barrett DM, Bunin NJ, et al. Chimeric antigen receptor $\mathrm{T}$ cells for sustained remissions in leukemia. N Engl J Med. 2014;371:1507-17.

3. Lee DW, Kochenderfer JN, Stetler-Stevenson M, Cui YK, Delbrook C, Feldman SA. et al. T cells expressing CD19 chimeric antigen receptors for acute lymphoblastic leukaemia in children and young adults: a phase 1 dose-escalation trial. Lancet. 2015;385:517-28.

4. Xiao X, He X, Li Q, Zhang H, Meng J, Jiang Y, et al. Plasma exchange can be an alternative therapeutic modality for severe cytokine release syndrome after chimeric antigen receptor-t cell infusion: a case report. Clin Cancer Res. 2019;25:29-34.

5. Dai H, Zhang W, Li X, Han Q, Guo Y, Zhang Y, et al. Tolerance and efficacy of autologous or donor-derived $\mathrm{T}$ cells expressing CD19 chimeric antigen receptors in adult B-ALL with extramedullary leukemia. Oncoimmunology. 2015;4:e1027469.

6. Nellan A, Lee DW. Paving the road ahead for CD19 CAR T-cell therapy. Curr Opin Hematol. 2015;22:516-20. 
Lymphoma

\title{
Degradation of Bruton's tyrosine kinase mutants by PROTACs for potential treatment of ibrutinib-resistant non-Hodgkin lymphomas
}

\author{
Yonghui Sun ${ }^{1} \cdot$ Ning Ding $^{2} \cdot$ Yuqin Song ${ }^{2} \cdot$ Zimo Yang $^{1} \cdot$ Wanli Liu $^{3} \cdot$ Jun Zhu $^{2} \cdot$ Yu Rao $^{1}$
}

Received: 24 December 2018 / Revised: 31 January 2019 / Accepted: 15 February 2019 / Published online: 11 March 2019

(c) Springer Nature Limited 2019

\section{To the Editor:}

Diffuse large B-cell lymphoma (DLBCL) is the most common type of non-Hodgkin lymphoma (NHL). In the United States and United Kingdom, the annual prevalence of DLBCL is as high as $0.08 \%$ [1]. The first-line clinical treatment for DLBCL is combined chemo-immunotherapy with a 5-year survival rate of around $58 \%$ for senior adults [2]. Mantle cell lymphoma (MCL) contributes to more than $6-8 \%$ of NHL worldwide [3]. Because of the $t(11 ; 14)(q 13$; q32) chromosomal translocation and upregulated expression of cyclin D1, malignant proliferation is commonly observed

These authors contributed equally: Yonghui Sun, Ning Ding, Yuqin Song

These authors jointly supervised this work: Wanli Liu, Jun Zhu, Yu Rao

Supplementary information The online version of this article (https:// doi.org/10.1038/s41375-019-0440-x) contains supplementary material, which is available to authorized users.

Wanli Liu

liuwanli@biomed.tsinghua.edu.cn

$\triangle$ Jun Zhu

zhu-jun2017@outlook.com

$\triangle$ Yu Rao

yrao@tsinghua.edu.cn

1 MOE Key Laboratory of Protein Sciences, School of Pharmaceutical Sciences, MOE Key Laboratory of Bioorganic Phosphorus Chemistry \& Chemical Biology, Tsinghua University, Beijing 100084, P.R. China

2 Key laboratory of Carcinogenesis and Translational Research (Ministry of Education), Department of Lymphoma, Peking University Cancer Hospital \& Institute, No.52 Fucheng Road, Haidian District, Beijing 100142, China

3 MOE Key Laboratory of Protein Sciences, Center for Life Sciences, Institute for Immunology, School of Life Sciences, Beijing Key Lab for Immunological Research on Chronic Diseases, Tsinghua University, Beijing 100084, China in MCL [4]. Unfortunately, there is no optimal therapy for MCL [5] and the 5-year survival rate for MCL patients in the United States is $<50 \%$ [6]. These statistics highlight an urgent need for the development of more effective treatments for patients with DLBCL or MCL.

$\mathrm{B}$-cell receptor (BCR) signaling is indispensable for the adhesion, survival, and growth of B cells. As an essential membrane proximal signal molecule in the BCR pathway, Bruton's tyrosine kinase (BTK) plays a critical role in Bcell activation and proliferation [7]. In 2013, the BTK covalent inhibitor ibrutinib was approved by the Food and Drug Administration for the treatment of MCL. Additionally, activated B-cell-like (ABC)-DLBCL patients achieved remission after treatment with ibrutinib [8]. Unfortunately, drug-resistant tumor cells have been isolated from MCL patients during treatment with ibrutinib and the relapsespecific C481S missense BTK mutation contributes to this resistance [9]. In the growth inhibition of DLBCL, the BTK C481S mutant also resulted in resistance to ibrutinib [10].

Proteolysis-targeting chimera (PROTAC) is a novel strategy for selective knockdown of target proteins by small molecules [11]. PROTAC molecules are heterobifunctional compounds with three components: a target protein-binding moiety, an E3 ligase ligand, and a linker connecting the two (Fig. 1a). The degradation machinery brings the target cellular protein to the corresponding E3 ligase, resulting in degradation by the ubiquitinproteasome system. In recent years, this newly developed method has been widely used in antitumor studies $[12,13]$. Recently, we developed the first PROTACderived degrader for selective BTK degradation [10, 14, 15]. Although preliminary data showed that our degrader effectively controlled BTK C481S mutant-induced ibrutinib-resistant B-cell malignancies in vitro, the following critical questions remain unaddressed. (1) Is the BTK degrader also effective for DLBCL in vivo? Due to the poor aqueous solubility of the first generation of our degrader, a new generation of BTK degraders with improved solubility must be developed for in vivo 
a
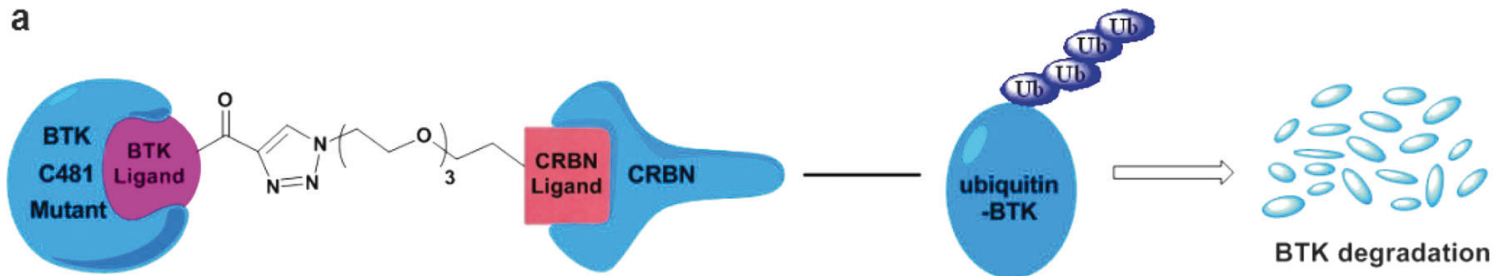

b

L18I (nM)
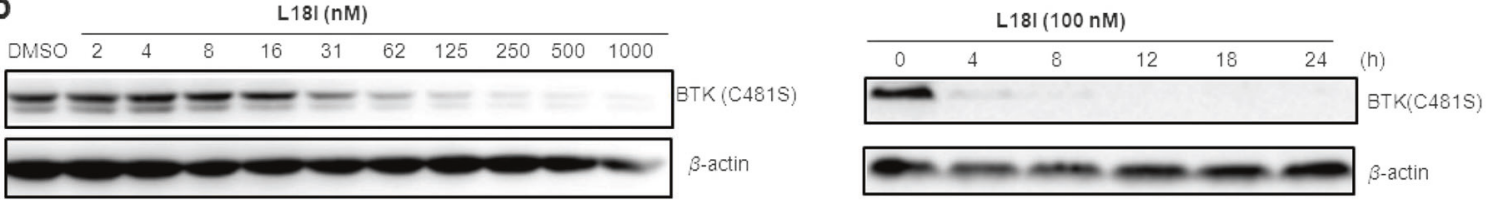

\section{C}

\begin{tabular}{|cccccc|}
\hline Name & Abbreviation & Letter & Codon & Catalytic Function & Degradation \\
\hline Cysteine & Cys & C & UGC & $\sqrt{ }$ & $\sqrt{ }$ \\
Serine & Ser & S & AGC & $\sqrt{ }$ & $\sqrt{ }$ \\
Threonine & Thr & T & ACC & $\sqrt{ }$ & $\sqrt{ }$ \\
Glycine & Gly & G & GGC & weak & $\sqrt{ }$ \\
Alanine & Ala & A & GCG & unknown & $\sqrt{ }$ \\
Tryptophan & Trp & W & UGG & $\times$ & \\
\hline
\end{tabular}
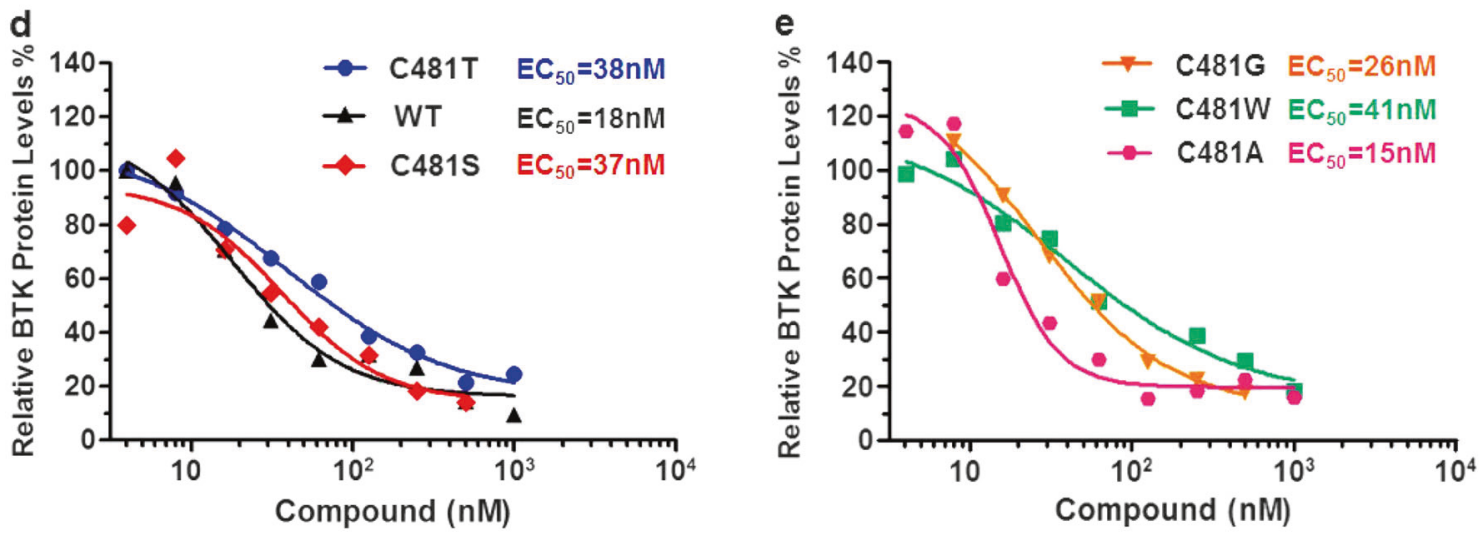

f
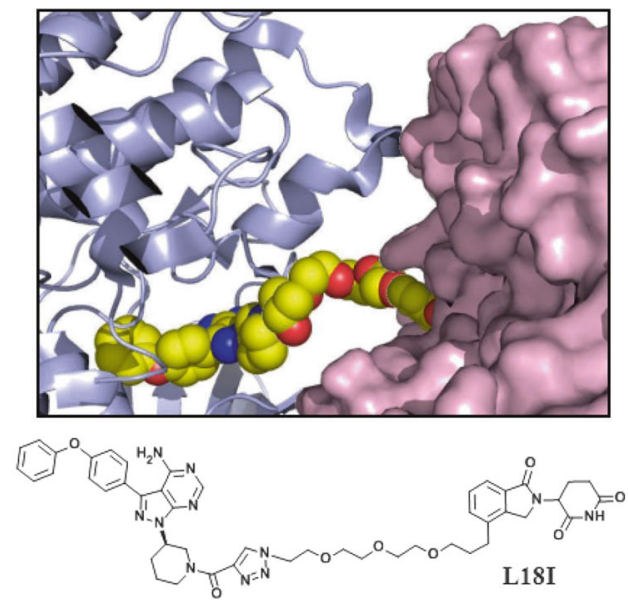

g
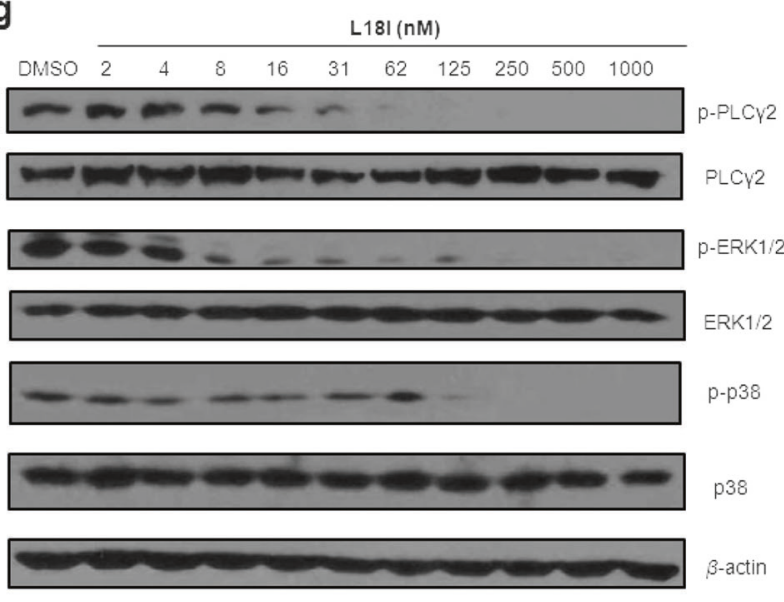
Fig. 1 Schematic diagram and characterization of L18I, which degrades the ibrutinib-resistant BTK C481 mutant. a Mechanism of the newly developed BTK C481 mutant degrader. b Western blotting analysis for C481S BTK and $\beta$-actin proteins after $36 \mathrm{~h}$ of treatment of C481S BTK HBL-1 cells with indicated concentrations of L18I (left panel). Western blotting analysis for C481S BTK and $\beta$-actin proteins after treatment of C481S BTK HBL-1 cells with $100 \mathrm{nM} \mathrm{L18I}$ for the indicated exposures (right panel). c Codons for amino acids in six different C481 mutated BTK proteins. Catalytic function and degradation of C481 mutated BTK proteins were indicated. d Plasmids expressing full-length constructs of C481T (C/S) BTK were transfected into HeLa cells using Lipo2000. These C481 mutated BTK proteins have stronger catalytic function. Western blotting analysis for C481T (C/S) BTK and $\beta$-actin proteins after 4 days of treatment of HeLa cells with the indicated concentrations of L18I. e Plasmids expressing full-length constructs of C481G (W/A) BTK were transfected into HeLa cells using Lipo2000. Western blotting analysis for C481G (W/A) BTK and $\beta$-actin proteins after 4 days of treatment of HeLa cells with the indicated concentrations of L18I. f Schematic diagram of BTK degrader design. $\mathbf{g}$ Western blotting analysis for pPLC $\gamma$-2, PLC $\gamma$-2, p-ERK1/2, ERK1/2, p-p38, p38, and $\beta$-actin proteins after $36 \mathrm{~h}$ of treatment of C481S BTK HBL-1 cells with indicated concentrations of L18I

evaluation. (2) Can our PROTAC molecules degrade clinically relevant BTK mutants other than the C481S mutant? (3) Does our degrader work well for treatment of MCL? (4) Can our degrader achieve synergistic effects with other inhibitors for ibrutinib-resistant B-cell malignancies?

Here we reported the development of a next-generation BTK degrader, L18I, based on the lenalidomide ligand for cereblon. L18I exhibited good solubility in phosphate-buffered saline. Remarkably, L18I induced degradation of ibrutinib-resistant C481S BTK at a working concentration as low as $30 \mathrm{nM}$ in a human $\mathrm{ABC}$ DLBCL cell line, HBL-1, with exogenous overexpression of the BTK C481S mutant. Moreover, L18I achieved much lower half maximal growth-inhibitory concentration $\left(\mathrm{GI}_{50}\right)$ values than ibrutinib in inhibiting the growth of both DLBCL and MCL cells in vitro. As a further test, L18I effectively degraded different C481 mutated BTK proteins that were observed in clinically relevant B-cell tumors. More importantly, in vivo experiments showed that L18I induced rapid tumor regression of C481S BTK HBL-1 xenograft tumors with no signs of toxicity in mice. Lastly, combined with SYK, PI3K, or lyn inhibitor, L18I achieved even higher inhibitory activity against C481S BTK HBL-1 cells.

To develop an ideal degrader with improved aqueous solubility for both in vitro and in vivo evaluations, we optimized both ligand and linker (Fig. 1). After many attempts, a suitable degrader, L18I, with ibrutinib and lenalidomide ligands connected by a polyethylene glycol (PEG) linker was identified. The schematic diagram of BTK degrader design was shown in Fig. 1f. This breakthrough provided an opportunity to carry out pharmacological experiments in vitro and in vivo (Supplementary Table 1).

L18I efficiently degraded C481S BTK in HBL-1 cells, and the half maximal degradative concentration $\left(\mathrm{DC}_{50}\right)$ was $29 \mathrm{nM}$ (Fig. 1b and Supplementary Fig. S1). PROTACmediated degradation of C481S BTK occurred rapidly and specifically. The half-life of C481S BTK in DLBCL cells was $<2 \mathrm{~h}$ in the presence of L18I (Fig. 1b and Supplementary Figs. S2 and S3). As competitive inhibitors, ibrutinib and pomalidomide effectively blocked L18I-mediated degradation of C481S BTK. NEDD8-activating enzyme inhibitor MLN4924 or proteasome inhibitor bortezomib also effectively prevented the degradation (Fig. 1a and Supplementary Fig. S4).

Besides the C481S mutation, we investigated other mutations at the 481 position of the BTK protein. C481T is catalytically active ibrutinib-resistant BTK mutant, and the C481G mutant has very weak catalytic activity [16], while the C481A point mutation results in no covalent binding to ibrutinib probe [17]. Therefore, new treatments to tackle these potential drug-resistant mutants are urgently needed. To confirm the degradation activity of L18I for different BTK single-point mutants at the 481 position, six plasmids expressing BTK C481 mutants were constructed. Except for alanine and tryptophan mutations, all BTK single-point mutants retained catalytic function (Fig. 1c). L18I efficiently degraded all BTK single-point mutants, and the half maximal effective concentrations were around $30 \mathrm{nM}$ (Fig. 1d, e).

Next, to evaluate the antitumor effect of L18I in vitro, the C481S BTK HBL-1 cell line was tested. L18I effectively inhibited the growth of mutant HBL-1 cells with a $\mathrm{GI}_{50}$ of $64 \mathrm{nM}$. By contrast, the $\mathrm{GI}_{50}$ of ibrutinib was $2526 \mathrm{nM}$ due to drug resistance (Fig. 2a). To study the detailed effects of L18I in C481S BTK HBL-1 cells, we examined the activities of downstream BCR signaling molecules upon BTK degradation. In remarkable contrast to ibrutinib, L18I potently inhibited the phosphorylation of PLC $\gamma-2$, ERK1/2, and p38 (Fig. 1g and Supplementary Fig. S8). We also assessed the in vitro antitumor efficacy of L18I in MCL cells (Mino cells and Z138 cells) with exogenous expression of the BTK C481S mutant. As expected, L18I efficiently halted cell proliferation at much lower concentrations than ibrutinib in C481S BTK MCL cells. $\mathrm{GI}_{50} \mathrm{~s}$ of $\mathrm{L} 18 \mathrm{I}$ were all bellow $10 \mathrm{nM}$, almost 300-fold lower than those of ibrutinib (Fig. 2b). These results illustrated that ibrutinib was unable to inhibit the C481S BTK mutant in vitro, while the newly developed degrader L18I showed excellent inhibitory effects in both DLBCL and MCL BTK C481 mutant-expressing tumor cells.

Based on these potent in vitro efficacies, L18I was further examined in a mouse xenograft model inoculated with 


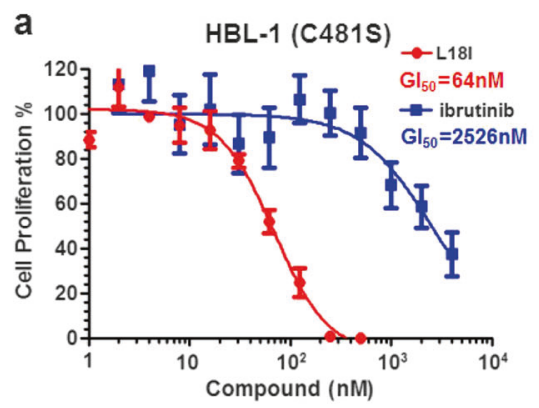

C

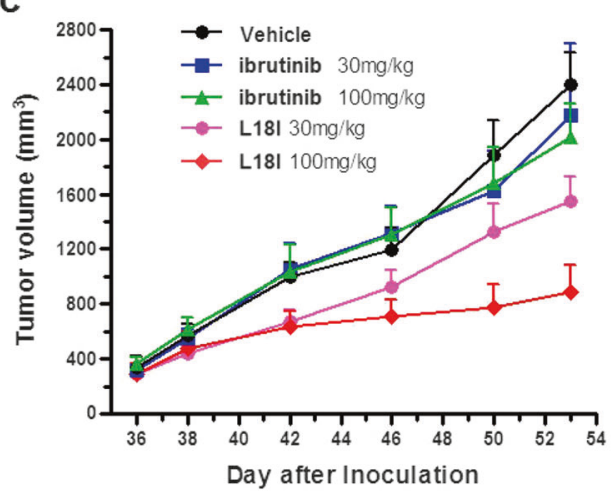

e
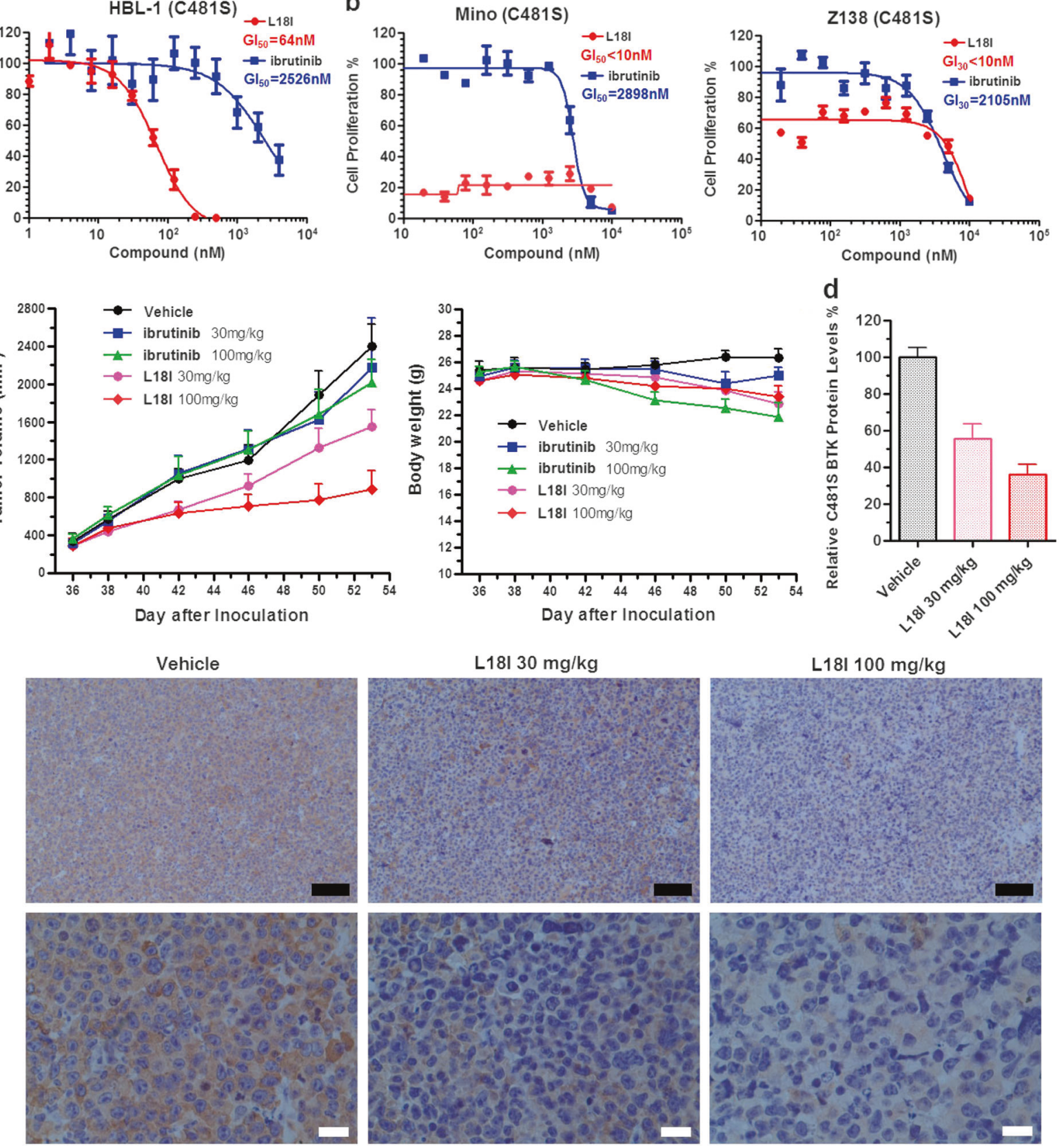

L18I $100 \mathrm{mg} / \mathrm{kg}$

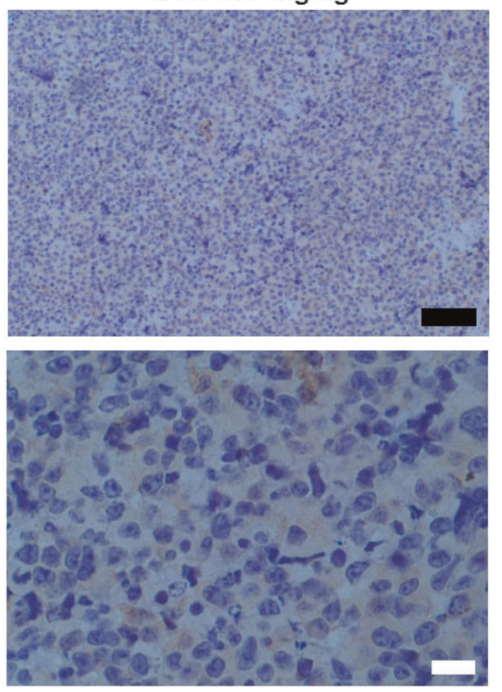

f

In vivo Acute Toxicity
\begin{tabular}{|c|c|c|}
\hline $\begin{array}{c}\text { Dose } \\
(\mathrm{mg} / \mathrm{kg})\end{array}$ & $\begin{array}{c}\text { Mouse } \\
\text { strain }\end{array}$ & $\begin{array}{c}\text { Mice } \\
\text { survival } \\
(21 \mathrm{~d})\end{array}$ \\
\hline 250 & B6 & $7 / 7$ \\
\hline 300 & B6 & $7 / 7$ \\
\hline
\end{tabular}

g
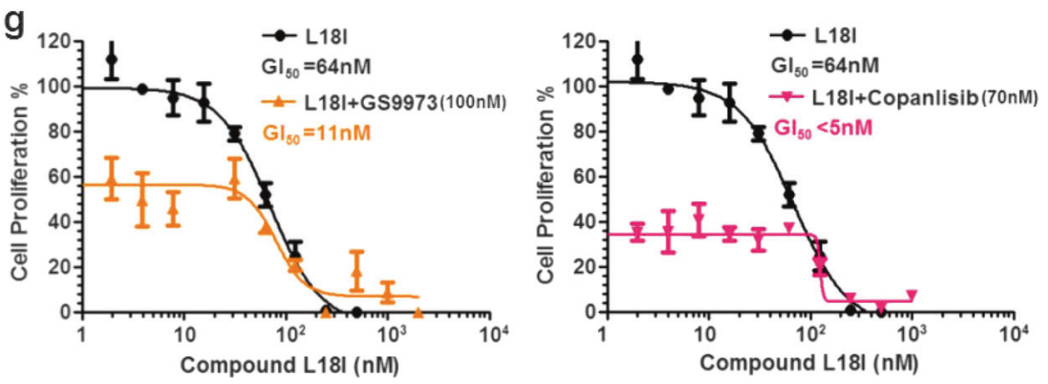
Fig. 2 Pharmacodynamic and safety evaluation of L18I. a In vitro study of growth inhibition effect on C481S BTK HBL-1 cells by L18I and ibrutinib. In 96-well plates, 3000 cells were incubated in each well at $37^{\circ} \mathrm{C}$ for $72-96 \mathrm{~h}$. The final $\mathrm{GI}_{50}$ was calculated using CCK-8. b In vitro study of growth inhibition effect on MCL (Mino or Z138) BTK C481S mutant overexpression cells by L18I and ibrutinib. In 96-well plates, 3000 cells were incubated in each well at $37^{\circ} \mathrm{C}$ for $72-96 \mathrm{~h}$. The final results were calculated using MTT. c L18I induced tumor regression in the xenograft model of human C481S BTK HBL-1 tumor cells with minimal body weight change compared with ibrutinibtreated control. Tumor volume (means \pm SEM) of vehicle-treated mice $(n=7)$, mice treated with ibrutinib $(30 \mathrm{mg} / \mathrm{kg}, n=7 ; 100 \mathrm{mg} / \mathrm{kg}, n=$ 7), or mice treated with L18I (30 mg/kg, $n=7 ; 100 \mathrm{mg} / \mathrm{kg}, n=7)$. d Relative C481S BTK protein levels based on immunoblotting of tumor lysates from mice treated with L18I $(30 \mathrm{mg} / \mathrm{kg}, n=7$; $100 \mathrm{mg} / \mathrm{kg}, n=7)$ and vehicle-treated mice $(n=7)$. e Immunohistochemistry results of tumor biopsies from mice treated with L18I (30 and $100 \mathrm{mg} / \mathrm{kg}$ ) and vehicle-treated mice. Black bars represent $100 \mu \mathrm{M}$. White bars represent $20 \mu \mathrm{M}$. f In vivo acute toxicity experiment results from mice treated with L18I $(250$ and $300 \mathrm{mg} / \mathrm{kg}$ ). g DLBCL drug combination therapies. In vitro study of growth inhibition effect on C481S BTK HBL-1 cells by L18I combined with GS9973 or copanlisib. In 96-well plates, 3000 cells were incubated in each well at $37^{\circ} \mathrm{C}$ for $72-96 \mathrm{~h}$. The final $\mathrm{GI}_{50}$ was calculated using CCK-8

C481S BTK HBL-1 cells. Rapid tumor regression was achieved with 30 or $100 \mathrm{mg} / \mathrm{kg}$ of L18I administered intraperitoneally every day for 2 weeks. Ibrutinib (30 and $100 \mathrm{mg} / \mathrm{kg}$ ) was used as a negative control. Compared with the vehicle group, tumor size of the $30 \mathrm{mg} / \mathrm{kg} \mathrm{L18I-treated}$ group was reduced by $36 \%(p=0.0126)$. In the $100 \mathrm{mg} / \mathrm{kg}$ L18I-treated group, tumor size was reduced by $63 \%$ ( $p=$ 0.0004). By contrast, in the ibrutinib treatment groups, almost no reduction in tumor size was observed at low or high doses (Fig. 2c). Relative C481S BTK protein levels in fresh ex vivo tumor cells were also tested by immunoblotting and immunohistochemistry. C481S BTK levels in isolated tumors from L18I-treated mice were significantly lower than those in the vehicle group (Fig. 2d, e). From the safety evaluation, it was clear that mice treated with ibrutinib suffered from more severe body weight loss than mice treated with L18I. To further confirm the safety of L18I, acute toxicity experiments were conducted in the B6 mouse model. All mice in the L18I-treated groups (250 and 300 $\mathrm{mg} / \mathrm{kg}$ ) were in good health during the 3 weeks after treatment (Fig. 2f). Therefore, the newly developed BTK C481 mutant degrader L18I was well-tolerated and had a highly efficacious antitumor effect in this mouse xenograft model.

Drug combination strategies with small-molecule inhibitors are commonly used to treat refractory cancers. In the current study, we for the first time tested the possibility of a drug combination therapy strategy with both BTK degrader and BCR signaling molecule inhibitors. The inhibitory effect against ibrutinib-resistant cell lines was tested using several different targets. For instance,
GS-9973, a SYK inhibitor, has been used in potential overcoming ibrutinib-resistant clones [18]. PI3K upregulation has been documented in MCL with ibrutinib resistance [9]. In addition, ibrutinib-resistant cells retain sensitivity to lyn inhibitors, such as dasatinib [19]. Thus, it is of interest to examine the synergistic effect of L18I with SYK, PI3K, or lyn inhibitors. We performed these experiments with C481S BTK HBL-1 cells. Remarkably, in combination with GS-9973, L18I was more effective in inhibiting C481S BTK HBL-1 cells, and the $\mathrm{GI}_{50}$ was as low as $11 \mathrm{nM}$. Compared with the treatment using L18I alone, a combination of L18I and a PI3K inhibitor, copanlisib, dramatically improved the inhibitory effect on C481S BTK HBL-1 cells, and the $\mathrm{GI}_{50}$ was lower than 5 nM. Additionally, a combination of L18I and dasatinib effectively inhibited the growth of ibrutinib-resistant HBL-1 cells with a $\mathrm{GI}_{50}$ under $5 \mathrm{nM}$ (Fig. $2 \mathrm{~g}$ and Supplementary Fig. S9).

In summary, we present a newly designed C481 BTK mutant-specific degrader L18I. With lenalidomide as the cereblon E3 ubiquitin ligase ligand, the BTK degrader was considerably more soluble. A series of clinically relevant BTK mutants (C481S/T/G/W/A) were efficiently degraded by L18I. Proliferation of BTK C481S mutant-expressing DLBCL and MCL cells was potently inhibited in vitro by compound L18I, whereas BTK covalent inhibitor ibrutinib exhibited very weak efficacy. Meanwhile, downstream signaling activities were strongly blocked by L18I, with effective concentration below $10 \mathrm{nM}$. More importantly, pharmacologic action of L18I in vivo also resulted in an obvious antitumor effect in mouse xenograft models inoculated with C481S BTK HBL-1 cells. By contrast, ibrutinib had nearly no inhibitory activity in vivo, which was consistent with the results from the in vitro experiments. What's more, compound L18I was found to be safe and well-tolerated. Lastly, combined with GS-9973, copanlisib, or dasatinib, L18I showed dramatically improved efficacy in inhibiting ibrutinib-resistant cells, indicating potential for combinations of inhibitor and degrader in the treatment of drug-resistant cancers.

Acknowledgements This work was supported by National Natural Science Foundation of China (\#81573277, 81622042, and 81773567), National Major Scientific and Technological Special Project for "Significant New Drugs Development" (\#SQ2017ZX095003), and Tsinghua University Initiative Scientific Research Program. This work was also financially supported by NSFC (No. 81670187) and Beijing Natural Science Foundation (No. 7172047).

\section{Compliance with ethical standards}

Conflict of interest The authors declare that they have no conflict of interest.

Publisher's note: Springer Nature remains neutral with regard to jurisdictional claims in published maps and institutional affiliations. 


\section{References}

1. Morton LM, Wang SS, Devesa SS, Hartge P, Weisenburger DD, Linet MS. Lymphoma incidence patterns by WHO subtype in the United States, 1992-2001. Blood. 2006;107:265-76.

2. Feugier P, van Hoof A, Sebban C, Solal-Celigny P, Bouabdallah $\mathrm{R}$, Fermé $\mathrm{C}$, et al. Long-term results of the R-CHOP study in the treatment of elderly patients with diffuse large B-cell lymphoma: a study by the groupe d'Etude des lymphomes de l'adulte. J Clin Oncol. 2005;23:4117-26.

3. Pérez-Galán P, Dreyling M, Wiestner A. Mantle cell lymphoma: biology, pathogenesis, and the molecular basis of treatment in the genomic era. Blood. 2011;117:26-38.

4. Li JY, Gaillard F, Moreau A, Harousseau JL, Laboisse C, Milpied $\mathrm{N}$, et al. Detection of translocation $\mathrm{t}(11 ; 14)(\mathrm{q} 13$; q32) in mantle cell lymphoma by fluorescence in situ hybridization. Am J Pathol. 1999;154:1449-52.

5. Rajabi B, Sweetenham JW. Mantle cell lymphoma: observation to transplantation. Ther Adv Hematol. 2015;6:37-48.

6. Herrmann A, Hoster E, Zwingers T, Brittinger G, Engelhard M, Meusers $\mathrm{P}$, et al. Improvement of overall survival in advanced stage mantle cell lymphoma. J Clin Oncol. 2009;27:511-8.

7. Wang ML, Rule S, Martin P, Goy A, Auer R, Kahl BS, et al. Targeting BTK with ibrutinib in relapsed or refractory mantle-cell lymphoma. N Engl J Med. 2013;369:507-16.

8. Wilson WH, Young RM, Schmitz R, Yang Y, Pittaluga S, Wright $\mathrm{G}$, et al. Targeting $\mathrm{B}$ cell receptor signaling with ibrutinib in diffuse large B cell lymphoma. Nat Med. 2015;21:922-6.

9. Chiron D, Di Liberto M, Martin P, Huang X, Sharman J, Blecua $\mathrm{P}$, et al. Cell-cycle reprogramming for PI3K inhibition overrides a relapse-specific C481S BTK mutation revealed by longitudinal functional genomics in mantle cell lymphoma. Cancer Discov. 2014;4:1022-35.

10. Sun YH, Zhao XW, Ding N, Gao HY, Wu Y, Yang YQ, et al. PROTAC-induced BTK degradation as a novel therapy for mutated BTK C481S induced ibrutinib-resistant B-cell malignancies. Cell Res. 2018;28:779-81.

11. Sakamoto KM, Kim KB, Kumagai A, Mercurio F, Crews CM, Deshaies RJ. Protacs: chimeric molecules that target proteins to the Skp1-Cullin-F box complex for ubiquitination and degradation. Proc Natl Acad Sci USA. 2001;98:8554-9.

12. Toure M, Crews CM. Small-molecule PROTACS: new approaches to protein degradation. Angew Chem Int Ed. 2016;55: 1966-73.

13. Dobrovolsky D, Wang ES, Morrow S, Leahy C, Faust T, Nowak $\mathrm{RP}$, et al. Bruton's tyrosine kinase degradation as a therapeutic strategy for cancer. Blood. 2019;133:952-61.

14. Buhimschi AD, Armstrong HA, Toure M, Jaime-Figueroa S, Chen TL, Lehman AM, et al. Targeting the C481S ibrutinibresistance mutation in Bruton's tyrosine kinase using PROTACmediated degradation. Biochemistry. 2018;57:3564-75.

15. Zorba A, Nguyen C, Xu Y, Starr J, Borzilleri K, Smith J, et al. Delineating the role of cooperativity in the design of potent PROTACs for BTK. Proc Natl Acad Sci USA. 2018;115:E7285-92.

16. Hamasy A, Wang Q, Blomberg KEM, Mohammad DK, Yu L, Vihinen M, et al. Substitution scanning identifies a novel, catalytically active ibrutinib-resistant BTK cysteine 481 to threonine (C481T) variant. Leukemia. 2017;31:177-85.

17. Furman RR, Cheng S, Lu P, Setty M, Perez AR, Guo A, et al. Ibrutinib resistance in chronic lymphocytic leukemia. N Engl J Med. 2014;370:2352-4.

18. Liu TM, Woyach JA, Zhong Y, Lozanski A, Lozanski G, Dong S, et al. Hypermorphic mutation of phospholipase $C, \gamma 2$ acquired in ibrutinib-resistant CLL confers BTK independency upon B-cell receptor activation. Blood. 2015;126:61-8.

19. Cheng S, Guo A, Lu P, Ma J, Coleman M, Wang YL. Functional characterization of $B T K^{C 481 S}$ mutation that confers ibrutinib resistance: exploration of alternative kinase inhibitors. Leukemia. 2015;29:895-900. 
Leukemia (2019) 33:2111-2115

https://doi.org/10.1038/s41375-019-0444-6

Chronic lymphocytic leukemia

\title{
$K R A S, N R A S$, and BRAF mutations are highly enriched in trisomy 12 chronic lymphocytic leukemia and are associated with shorter treatment-free survival
}

\author{
Elena Vendramini ${ }^{1} \cdot$ Riccardo Bomben $^{1} \cdot$ Federico Pozzo $^{1}$ - Dania Benedetti ${ }^{1}$. Tamara Bittolo ${ }^{1}$. \\ Francesca Maria Rossi ${ }^{1} \cdot$ Michele Dal Bo ${ }^{1}$ Kari G. Rabe ${ }^{2}$. Gabriele Pozzato ${ }^{3}$. Francesco Zaja ${ }^{3}$. Annalisa Chiarenza ${ }^{4}$. \\ Francesco Di Raimondo ${ }^{4}$ Esteban Braggio ${ }^{5} \cdot$ Sameer A. Parikh ${ }^{5} \cdot$ Neil E. Kay ${ }^{5} \cdot$ Tait D. Shanafelt $^{6}$. \\ Giovanni Del Poeta ${ }^{7} \cdot$ Valter Gattei $^{1} \cdot$ Antonella Zucchetto $^{1}$
}

Received: 4 March 2019 / Accepted: 6 March 2019 / Published online: 14 March 2019

(c) The Author(s) 2019. This article is published with open access

\section{To the Editor:}

$K R A S$ mutations are among the most common oncogenic events in human carcinomas of endodermal origin, whose presence predicts for resistance to several target therapies [1]. Conversely, little is known regarding the role and/or clinical impact of KRAS mutations in the setting of the hematological malignancies, including chronic lymphocytic leukemia (CLL), and only in recent years extensive sequencing data have highlighted the recurrent mutations of genes affecting the Ras-MAPK pathway in CLL [2, 3]. These mutations, by leading to a constitutive activation of MAPK signaling pathway, have emerged as relevant in driving impaired clinical responses to lenalidomide and chlorambucil, and acquired resistance to fludarabine as well as to PI3K and BCL2 inhibitors [4-6]. In this context, some studies pinpointed a higher frequency of mutations in

These authors contributed equally: Valter Gattei, Antonella Zucchetto

Supplementary information The online version of this article (https:// doi.org/10.1038/s41375-019-0444-6) contains supplementary material, which is available to authorized users.

Valter Gattei

vgattei@cro.it

$\triangle$ Antonella Zucchetto

zucchetto.soecs@cro.it

1 Clinical and Experimental Onco-Hematology Unit, Centro di Riferimento Oncologico di Aviano (CRO) IRCCS, Aviano (PN), Italy

2 Division of Biomedical Statistics and Informatics, Department of Health Sciences Research, Mayo Clinic, Rochester, MN, USA members of the Ras-MAPK pathway in CLL cases with specific clinico-biological features [6, 7], including the presence of trisomy 12 , a cytogenetic aberration associated with a unique pathophysiology among CLL [8, 9], and/or an unmutated (UM) configuration of IGHV genes, although a dedicated and comprehensive analysis of these aspects is still missing.

This study, approved by the IRB of the Aviano Centro di Riferimento Oncologico (Approvals n. IRB-05-2010 and n. IRB-05-2015), included 534 primary CLL from treatmentnaive patients. The cohort was purposely enriched in trisomy 12 CLL by including 110 cases from the Mayo Clinic, Rochester, MN [8] to better evaluate the incidence of mutations of the Ras-MAPK pathway in these subsets. Overall, out of 534 cases, trisomy 12 CLL accounted for 300 cases (190 with trisomy 12 as the sole abnormality [trisomy 12-only], and 110 with trisomy 12 plus another abnormality on FISH [trisomy 12-plus]), 332 cases had UM IGHV genes, and 214 cases had NOTCH1 aberrations (details in Table S1). CLL patients were diagnosed and treated according to the current iwCLL 2018 guidelines [10], and all samples were collected at diagnosis from treatment-naive patients. In 442/534 cases (clinical cohort),

3 Department of Internal Medicine and Haematology, Maggiore General Hospital, University of Trieste, Trieste, Italy

4 Division of Hematology, Ferrarotto Hospital, Catania, Italy

5 Division of Hematology, Department of Medicine, Mayo Clinic, Rochester, MN, USA

6 Department of Hematology/Oncology, Stanford University, Stanford, CA, USA

7 Division of Hematology, S. Eugenio Hospital and University of Tor Vergata, Rome, Italy 
treatment-free survival (TFS) data were available along with a comprehensive clinical and biological characterization (Table S1 and Supplemental Methods). This cohort showed the expected clinical behavior according to both the stratification of the established cytogenetic categories and to the canonical prognosticators by univariable and multivariable analyses (Supplemental Figure S1 and Table S2). Mutation testing for KRAS, NRAS, BRAF, TP53, NOTCH1, BIRC3, and $S F 3 B 1$ was performed on DNA from $\mathrm{CD} 19^{+}$enriched CLL samples by Next Generation Sequencing (NGS) assays with at least $1000 \times$ coverage and $1 \%$ sensitivity (details in Supplemental Methods). Groups were compared by chisquare test; TFS was computed from diagnosis to treatment and analyzed by log-rank test and Cox regression analysis with a stepwise procedure using MedCalc Statistical Software version 16.8.4 (MedCalc Software bvba, Ostend, Belgium; https://www.medcalc.org; 2016).

The mutation analysis of the Ras-MAPK pathway was focused on the $K R A S, N R A S$, and $B R A F$ genes, previously reported as the most frequently mutated genes among the members of the pathway [2]. We found 91 missense point mutations in 64 CLL cases, with a prevalence of $K R A S$ (44 mutations in 38 [7.1\%] patients), followed by BRAF (32 mutations in 24 [4.5\%] patients) and NRAS (15 mutations in 13 [2.4\%] patients). Nearly all mutations were previously associated with the gain-of-function phenotype and increased RAS/ERK downstream signaling (Fig. 1a and Table S3) [1]. In particular, among the most frequent KRAS/ NRAS mutations, almost half of the mutations $(27 / 59,45 \%)$, overall affecting $23 / 49$ (47\%) patients, involved the G12/ G13 codons, in keeping with what was observed in colon and lung cancers (Table S3) [1]. The co-occurrence of 2 mutated genes was observed in 11 cases (KRAS and BRAF in 8/11 cases, KRAS and NRAS in 2/11 cases, NRAS and $B R A F$ in $1 / 11$ cases), whereas mutations affecting all three genes were not found in our cohort. The mutations were mainly subclonal (mean Variant Allele Fraction, VAF, $12.3 \%$, range $1.3-61.6 \%$ ) with one-third of mutations (33/ 91) above $10 \% \mathrm{VAF}$. The presence of multiple mutations affecting the same gene occurred in 14 cases, including 5 cases that presented mutations in the same or adjacent codons (i.e., one case with both K601N and K601E BRAF mutations, one case with V600E and K601E BRAF mutations, and three cases with two simultaneous KRAS mutations at the G12 and G13 codons) suggesting that multiple genetic hits are positively selected in different subclones within the same leukemia specimen.

A strong association between KRAS/NRAS/BRAF mutations and the presence of an UM IGHV gene status and trisomy 12 was observed (Fig. 1b and Table S4). Overall, $87.3 \%$ of KRAS/NRAS/BRAF mutated cases had UM IGHV $(p<0.0001)$ and $79.7 \%$ were trisomy 12 CLL $(p<0.0001)$. Concordantly, the highest KRAS/NRAS/BRAF mutation frequency was found in CLL patients with concomitant UM $I G H V$ and trisomy 12 -only $(38 / 133,28.6 \%)$. This group was characterized by 25 KRAS (18.8\%), 8 NRAS (6\%) and 11 BRAF (8.3\%) mutated cases. Of note, the UM IGHVI trisomy 12-only group was characterized by a higher frequency of KRAS/NRAS/BRAF mutations also when compared to the UM $I G H V /$ trisomy 12-plus group $(8 / 49$, $16.3 \%$ ). Finally, the lowest frequency of KRAS/NRAS/ $B R A F$ mutations was observed in the context of CLL patients with $\mathrm{M} I G H V(8 / 186,4.3 \%)$ and del13q as the sole chromosomal aberration $(2 / 94,2.1 \%$ in the whole cohort, and $2 / 53,3.8 \%$ in the context of UM IGHV cases).

We then correlated the presence of KRAS/NRAS/BRAF mutations to other biological features (Table S4). When considering the whole CLL cohort, the only variables associated with a higher frequency of KRAS/NRAS/BRAF mutations were the absence of BIRC3 mutations $(p=0.02)$ and the positive expression $(\geq 30 \%)$ of CD49d $(p=0.04)$. On the other hand, if circumscribing the analysis to UM IGHV/trisomy $12 \mathrm{CLL}, \mathrm{CD} 49 \mathrm{~d}$ positive expression lost its association with $K R A S / N R A S / B R A F$ mutations, as expected due to the almost universal CD49d expression in trisomy 12 CLL patients [9]. Conversely, we observed a higher frequency of KRAS/NRAS/BRAF mutations in NOTCH1 wild type cases $(29 / 92,31.5 \%)$ and $B I R C 3$ wild type cases $(41 / 132,31.1 \%)$ compared to their mutated counterparts (NOTCH1 mutated: 17/90, 18.9\%; BIRC3 mutated: 4/30, $13.3 \% ; p=0.05$ in both cases), pointing to a mutual exclusivity of these mutations in the pathogenesis of the disease. No other significant associations with other known prognostic variables such as presence of TP53 mutations/ disruption, SF3B1 mutations, ZAP-70 and CD38 expression, Rai staging, age at diagnosis, and gender were observed either in the whole cohort or in the UM IGHVI trisomy 12 cohort (Table S4).

We finally evaluated the prognostic relevance of $K R A S, N R A S$, and $B R A F$ mutations as predictors of TFS. In the context of the clinical cohort, the presence of either $K R A S$ or NRAS mutations or the concomitant presence of KRAS/NRAS mutations were associated with shorter TFS ( $p=0.07, p=0.05$, and $p=0.02$, respectively) (Table 1 , Fig. 1c). Conversely, BRAF mutations were not associated with TFS, pointing to a secondary role of BRAF in the Ras-MAPK pathway in CLL, in line with studies indicating the lack of therapeutic effects of BRAF inhibition in CLL [11]. In a multivariable model that included the main known CLL prognosticators, the presence of KRAS/NRAS mutations retained its independent prognostic power as predictor for shorter TFS $(p=0.03$, Table 1). Moreover, circumscribing the analysis to the CLL subgroup with the highest incidence of these mutations (i.e., UM IGHV/trisomy 12-only/NOTCH1wt), both KRAS mutations alone $(p=0.005)$ and KRAS/ 

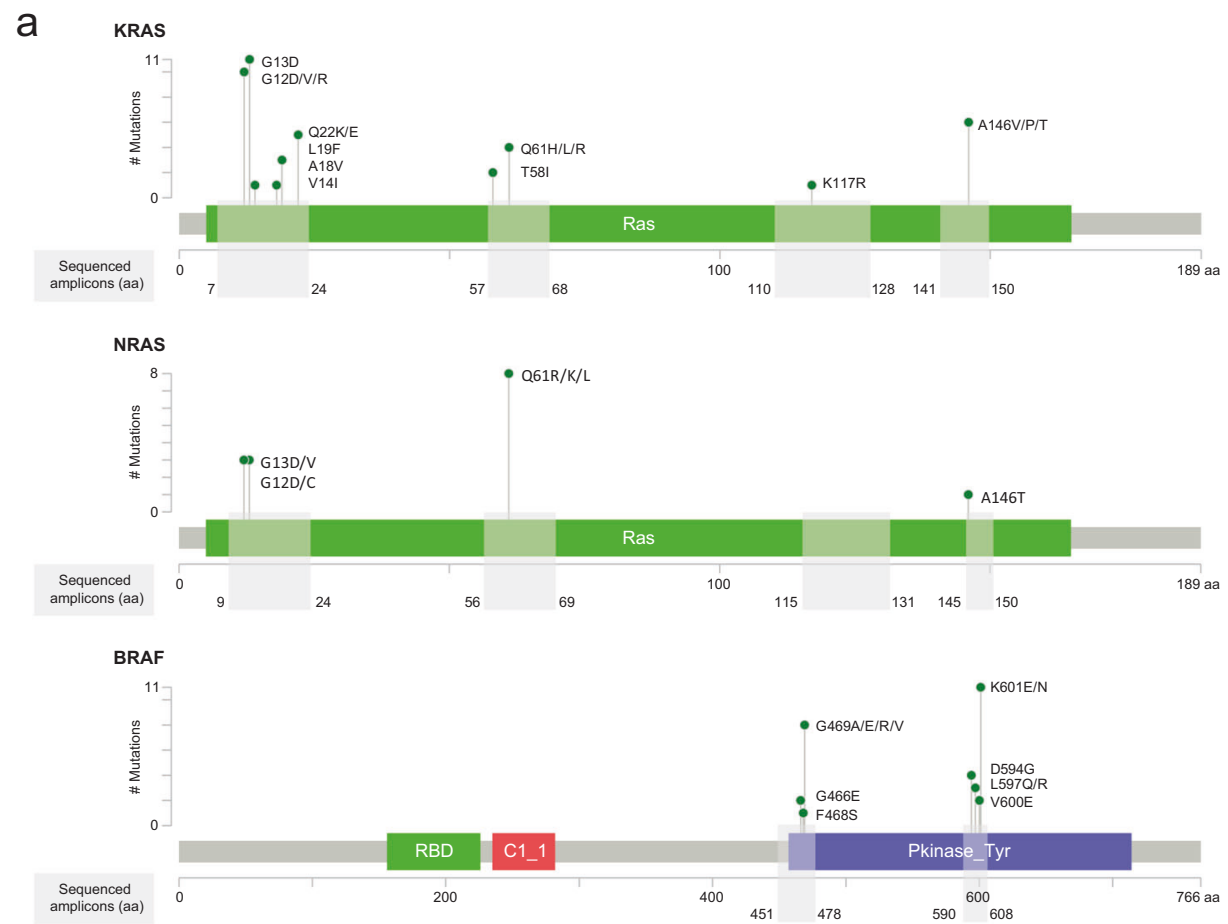

b

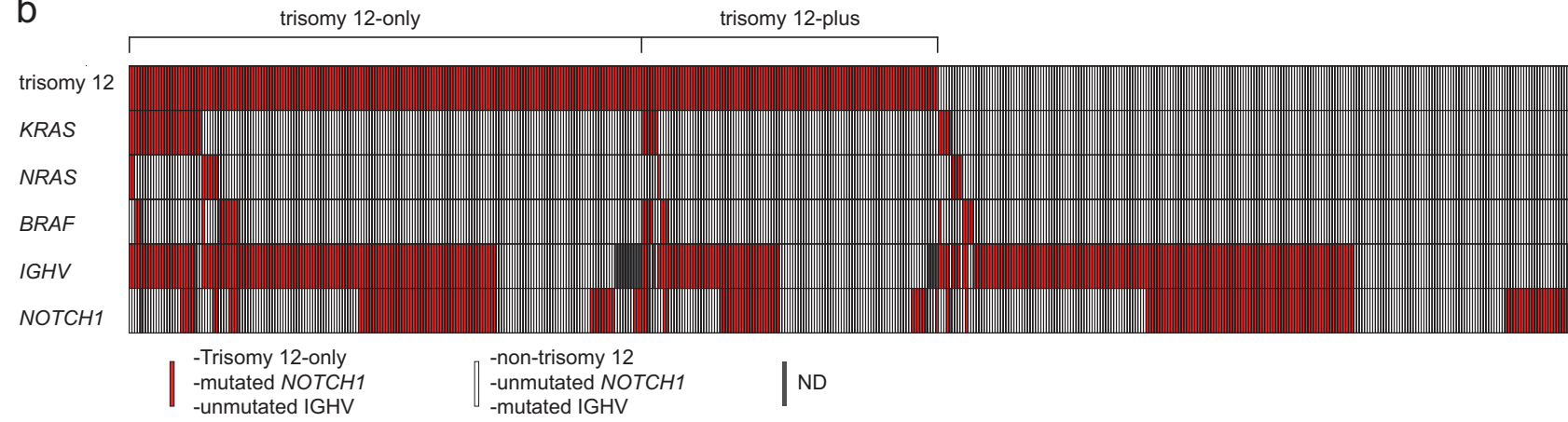

C

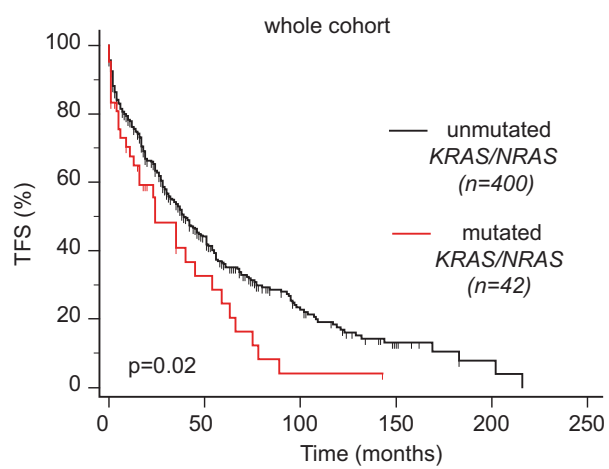

Fig. 1 Type, incidence and prognostic impact of KRAS, NRAS and $B R A F$ mutations. a Lollipop plots of mutations found in $K R A S, N R A S$, and $B R A F$ genes. Sites and frequency of missense point mutations, and schematic presentation of the protein structure and functional domains are shown (MutationMapper, cBioPortal Version 1.14.0, Gao et al. Sci. Signal. 2013 and Cerami et al. Cancer Discov. 2012). Gray boxes indicate amino acids (aa) regions corresponding to the sequenced amplicons. $R B D$, Ras-binding domain; $C 1 \_1$, phorbol esters/diacylglycerol binding domain ( $\mathrm{C} 1$ domain); Pkinase_Tyr, protein

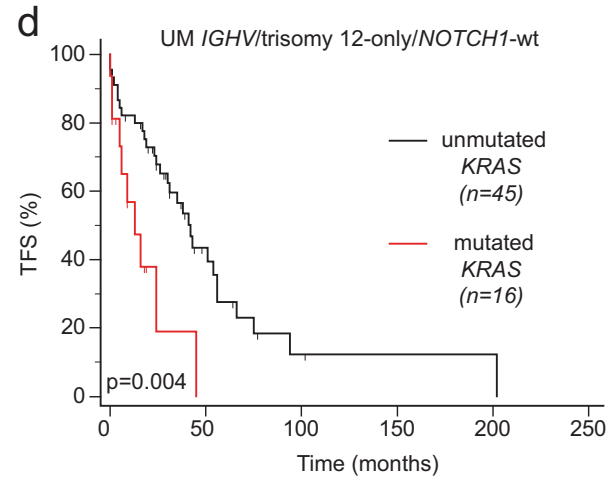

tyrosine kinase domain. b Co-mutation plot of 534 CLL analyzed for $K R A S, N R A S, B R A F$ mutations. Incidence of trisomy 12, KRAS, NRAS, and BRAF missense mutations, NOTCHI aberrations and IGHV status are shown. c Kaplan-Meier curves of treatment-free survival (TFS) of 442 CLL patients stratified by the presence of KRAS and/or NRAS mutations. d Kaplan-Meier curves of TFS of 61 CLL patients in the $I G H V$ unmutated/trisomy 12-only/NOTCHI-wt group stratified by the presence of KRAS mutations 
Table 1 Cox regression analysis of treatment-free survival in the whole cohort

\begin{tabular}{|c|c|c|c|c|c|}
\hline & \multirow[b]{2}{*}{$\begin{array}{l}\mathrm{N} \text { pts } \\
\text { analyzed }\end{array}$} & \multirow{2}{*}{$\begin{array}{l}\text { Univariable } \\
\text { HR }(95 \% \mathrm{CI})\end{array}$} & \multirow[b]{2}{*}{$p$-value } & \multicolumn{2}{|c|}{ Multivariable $(n=365)$} \\
\hline & & & & $\mathrm{HR}(95 \% \mathrm{CI})$ & $p$-value \\
\hline male gender & 442 & $0.97(0.76-1.22)$ & 0.8 & - & - \\
\hline age $\geq 65$ & 441 & $0.97(0.77-1.23)$ & 0.8 & - & - \\
\hline Rai stage II-III-IV & 434 & $2.60(2.03-3.32)$ & $<0.0001$ & $2.59(1.98-3.41)$ & $<0.0001$ \\
\hline CD49d positive $(\geq 30 \%)$ & 440 & $1.48(1.13-1.92)$ & 0.004 & $1.65(1.22-2.23)$ & 0.001 \\
\hline CD38 positive $(\geq 30 \%)$ & 439 & $1.13(0.89-1.43)$ & 0.3 & - & - \\
\hline ZAP-70 positive $(\geq 20 \%)$ & 389 & $1.44(1.11-1.87)$ & 0.005 & n.i. & n.i. \\
\hline I $G H V$ unmutated & 428 & $2.16(1.66-2.8)$ & $<0.0001$ & $1.83(1.37-2.45)$ & $<0.0001$ \\
\hline $\begin{array}{l}\text { TP53 disrupted (del17p and/or } \\
\text { TP53 mutated) }\end{array}$ & 442 & $1.70(1.24-2.32)$ & 0.0008 & $1.46(1.05-2.03)$ & 0.024 \\
\hline NOTCH1 mutated & 442 & $1.37(1.08-1.73)$ & 0.009 & n.i. & n.i. \\
\hline SF3B1 mutated & 327 & $1.46(0.90-2.38)$ & 0.1 & - & - \\
\hline BIRC3 mutated & 343 & $0.93(0.65-1.34)$ & 0.7 & - & - \\
\hline$K R A S$ mutated & 442 & $1.49(0.96-2.30)$ & 0.073 & - & - \\
\hline NRAS mutated & 442 & $1.86(0.99-3.50)$ & 0.055 & - & - \\
\hline$B R A F$ mutated & 442 & $1.34(0.75-2.40)$ & 0.3 & - & - \\
\hline$K R A S / N R A S$ mutated & 442 & $1.54(1.05-2.25)$ & 0.025 & $1.56(1.04-2.36)$ & 0.033 \\
\hline
\end{tabular}

Factors with $p$-value $<0.05$ in univariable analysis were entered in the multivariable analysis

$H R$ hazard ratio, $C I$ confidence interval, $n . i$. variables not included in the model after stepwise selection
NRAS mutations $(p=0.05)$ were associated with shorter TFS (Fig. 1d and Table S5), and the presence of KRAS mutations retained its prognostic value in a multivariable analysis that included all the variables with an impact in univariable analysis $(p=0.01$, Table S5). The subclonal or clonal pattern of KRAS/NRAS mutations had similar negative impact in our series (not shown), as previously observed for other gene mutations in CLL [12], and in keeping with the known capability of KRAS mutated tumor cells to enhance the overall tumor cell fitness by influencing the non-mutated neoplastic component [13].

In the present study, we demonstrated that KRAS, $N R A S$, and BRAF mutations were almost exclusively found in UM IGHV/trisomy $12 \mathrm{CLL}$ and were almost mutually exclusive with NOTCH1 and BIRC 3 mutations. The type of genomic structural variants, especially trisomy 12 and del13q, strongly influenced KRAS/NRAS/ $B R A F$ mutation incidence, that turned out to be at the highest level in cases bearing trisomy 12 as the sole genomic aberration, intermediate in cases in which trisomy 12 was associated with other genetic aberrations, mainly del13q, and at the lowest level in cases bearing del13q as the sole FISH detectable genetic aberration. This peculiar distribution of KRAS/NRAS/BRAF mutation incidence is in keeping with a CLL pathogenetic model in which the two main founder genetic lesions (i.e., trisomy 12 and del13q) identify CLL subgroups following different patho-biological pathways. In particular, the presence of del13q, given its link to the miR15/miR16-
BCL2 axis, characterizes a CLL subset especially oriented toward the amplification of anti-apoptotic signals [14]. On the other hand, in trisomy 12 CLL, the copresence of KRAS/NRAS/BRAF mutations and/or NOTCH1 mutations and/or BIRC3 mutations along with a UM $I G H V$ gene status and over-expression of surface receptors mediating microenvironment interactions (e.g., CD49d) more likely characterizes CLL with amplified pro-survival and proliferative signals $[8,9,15]$. This may explain the clinical association between KRAS/NRAS mutations and shorter TFS, as shown in the present analysis.

Given the reported high risk of poor response and development of chemo-resistance characterizing CLL cases with KRAS/NRAS mutations [4-6], additional therapeutic strategies should be considered for the treatment of these cases, including MEK/ERK inhibitors, employed alone or in combination with conventional therapies.

Acknowledgements The study was supported by the Fondazione Umberto Veronesi, Post-doctoral Fellowships-year 2018 (to EV); Associazione Italiana Ricerca Cancro (AIRC), Investigator Grant IG21687; Progetto Giovani Ricercatori no. GR-2011-02346826, no. GR2011-02347441, and no.GR-2011-02351370, Ministero della Salute, Rome, Italy; Progetto Ricerca Finalizzata PE 2016-02362756, Ministero della Salute, Rome, Italy; Associazione Italiana contro le Leucemie, linfomi e mielomi (AIL), Venezia Section, Pramaggiore Group, Italy; Linfo-check - Bando ricerca - contributo art. 15, comma 2, lett b) LR 17/2014; "5x1000 Intramural Program", Centro di Riferimento Oncologico, Aviano, Italy; National Cancer Institute, CA197120 (to TDS and NEK). Authors wish to thank Gustavo Baldassarre (Division 
of Molecular Oncology, Department of Translational Research, CRO Aviano, Italy) for helpful discussion.

\section{Compliance with ethical standards}

Conflict of interest The authors declare that they have no conflict of interest.

Publisher's note: Springer Nature remains neutral with regard to jurisdictional claims in published maps and institutional affiliations.

Open Access This article is licensed under a Creative Commons Attribution 4.0 International License, which permits use, sharing, adaptation, distribution and reproduction in any medium or format, as long as you give appropriate credit to the original author(s) and the source, provide a link to the Creative Commons license, and indicate if changes were made. The images or other third party material in this article are included in the article's Creative Commons license, unless indicated otherwise in a credit line to the material. If material is not included in the article's Creative Commons license and your intended use is not permitted by statutory regulation or exceeds the permitted use, you will need to obtain permission directly from the copyright holder. To view a copy of this license, visit http://creativecommons. org/licenses/by/4.0/.

\section{References}

1. Simanshu DK, Nissley DV, McCormick F. RAS proteins and their regulators in human disease. Cell. 2017;170:17-33.

2. Landau DA, Tausch E, Taylor-Weiner AN, Stewart C, Reiter JG, Bahlo J, et al. Mutations driving CLL and their evolution in progression and relapse. Nature. 2015;526:525-30.

3. Puente XS, Bea S, Valdes-Mas R, Villamor N, Gutierrez-Abril J, Martin-Subero JI, et al. Non-coding recurrent mutations in chronic lymphocytic leukaemia. Nature. 2015;526:519-24.

4. Herling CD, Abedpour N, Weiss J, Schmitt A, Jachimowicz RD, Merkel $\mathrm{O}$, et al. Clonal dynamics towards the development of venetoclax resistance in chronic lymphocytic leukemia. Nat Commun. 2018;9:727.

5. Pandzic T, Larsson J, He L, Kundu S, Ban K, Akhtar-Ali M, et al. Transposon mutagenesis reveals fludarabine resistance mechanisms in chronic lymphocytic leukemia. Clin Cancer Res. 2016;22:6217-27.

6. Takahashi K, Hu B, Wang F, Yan Y, Kim E, Vitale C, et al. Clinical implications of cancer gene mutations in patients with chronic lymphocytic leukemia treated with lenalidomide. Blood. 2018;131:1820-32.

7. Gimenez N, Martinez-Trillos A, Montraveta A, Lopez-Guerra M, Rosich L, Nadeu F, et al. Mutations in RAS-BRAF-MAPKERK pathway define a specific subgroup of patients with adverse clinical features and provide new therapeutic options in chronic lymphocytic leukemia. Haematologica. 2018;104: 576-86.

8. Bulian P, Bomben R, Bo MD, Zucchetto A, Rossi FM, Degan M, et al. Mutational status of IGHV is the most reliable prognostic marker in trisomy 12 chronic lymphocytic leukemia. Haematologica. 2017;102:e443-e446.

9. Zucchetto A, Caldana C, Benedetti D, Tissino E, Rossi FM, Hutterer E, et al. CD49d is overexpressed by trisomy 12 chronic lymphocytic leukemia cells: evidence for a methylation-dependent regulation mechanism. Blood. 2013;122:3317-21.

10. Hallek M, Cheson BD, Catovsky D, Caligaris-Cappio F, Dighiero $\mathrm{G}$, Dohner $\mathrm{H}$, et al. iwCLL guidelines for diagnosis, indications for treatment, response assessment, and supportive management of CLL. Blood. 2018;131:2745-60.

11. Yaktapour N, Meiss F, Mastroianni J, Zenz T, Andrlova H, Mathew NR, et al. BRAF inhibitor-associated ERK activation drives development of chronic lymphocytic leukemia. J Clin Invest. 2014;124:5074-84.

12. Nadeu F, Clot G, Delgado J, Martin-Garcia D, Baumann T, Salaverria I, et al. Clinical impact of the subclonal architecture and mutational complexity in chronic lymphocytic leukemia. Leukemia. 2018;32:645-53.

13. Grabocka E, Bar-Sagi D. Mutant KRAS enhances tumor cell fitness by upregulating stress granules. Cell. 2016;167:1803-13.

14. Cimmino A, Calin GA, Fabbri M, Iorio MV, Ferracin M, Shimizu M, et al. miR-15 and miR-16 induce apoptosis by targeting BCL2. Proc Natl Acad Sci USA. 2005;102:13944-9.

15. Benedetti D, Tissino E, Pozzo F, Bittolo T, Caldana C, Perini C, et al. NOTCH1 mutations are associated with high CD49d expression in chronic lymphocytic leukemia: link between the NOTCH1 and the NF-kappaB pathways. Leukemia. 2018;32: 654-62. 
Leukemia (2019) 33:2116-2120

https://doi.org/10.1038/s41375-019-0443-7

Chronic myelogenous leukemia

\title{
Skeletal muscle toxicity associated with tyrosine kinase inhibitor therapy in patients with chronic myeloid leukemia
}

\author{
L. Janssen ${ }^{1,2}$ - S. J. C. M. Frambach ${ }^{3,4}$ - N. A. E. Allard ${ }^{1}$ - M. T. E. Hopman ${ }^{1}$ - T. J. J. Schirris ${ }^{3,4}$ - N. C. Voermans ${ }^{5}$. \\ R. J. Rodenburg ${ }^{4,6}$ - N. M. A. Blijlevens ${ }^{2}$ - S. Timmers ${ }^{1,7}$
}

Received: 3 December 2018 / Revised: 21 February 2019 / Accepted: 22 February 2019 / Published online: 14 March 2019

(c) The Author(s) 2019. This article is published with open access

\section{To the Editor:}

Up to $80 \%$ of CML patients using tyrosine kinase inhibitors (TKIs) reports muscle complaints [1]. These muscle complaints are strongly related to the presence of fatigue and contributes to both diminished disease control [2] and impaired quality of life [3]. Although the mechanism by which TKIs cause muscle complaints is poorly understood, mitochondrial dysfunction has been suggested to play a pivotal role in TKI-induced cardiac muscle toxicity [4, 5]. We assessed whether TKIs disturb skeletal muscle mitochondrial density and function (cellular level), and if this translates into alterations in muscle contractile function (muscle tissue level) and maximal exercise performance (whole-body level). To gain a better insight into TKI-induced muscle complaints, these outcomes were compared between CML patients with and without muscle complaints. Written informed consent was obtained from the participants prior to study enrollment. This study was approved by the Local Committee on Research Involving Human Subjects of the region Arnhem and Nijmegen,

These authors contributed equally: S. J. C. M. Frambach, N. A. E. Allard and N. M. A. Blijlevens, S. Timmers

$\triangle$ N. M. A. Blijlevens

Nicole.Blijlevens@radboudumc.nl

$\triangle$ S. Timmers

Silvie.Timmers@radboudumc.nl

1 Radboud Institute for Health Sciences, Department of Physiology, Radboud University Medical Center, Nijmegen, The Netherlands

2 Radboud Institute for Health Sciences, Department of Hematology, Radboud University Medical Center, Nijmegen, The Netherlands

3 Department of Pharmacology and Toxicology, Radboud Institute for Molecular Life Sciences, Nijmegen, The Netherlands the Netherlands and registered at The Netherlands Trial Registry (NTR6373).

A total of twenty $\mathrm{Ph}^{+}$CP-CML patients on TKI therapy aged $\geq 18$ were recruited from the Department of Hematology at the Radboud University Medical Center (Nijmegen, The Netherlands). CML patients were assigned to a group with $(\mathrm{CML}+\mathrm{MC}, N=10)$ or without (CML - MC, $N=10)$ muscle complaints (MC) on the basis of presence, onset and course of muscle cramps, pain, and/or weakness. This was quantified on a Likert scale from 1 (not at all) to 4 (very much) resulting in significant different scores between $\mathrm{CML}+\mathrm{MC}$ and $\mathrm{CML}-\mathrm{MC}$ (median 4.0 (interquartile range (IQR) 3.0-4.0) and 2.5 (IQR 2.0-3.0), respectively; $P=0.002$ ). The Brief Fatigue Inventory (BFI) [6] was used to compare the degree of fatigue in CML patients, showing higher fatigue levels in $\mathrm{CML}+\mathrm{MC}$ when compared to CML - MC $(3.58 \pm 2.19$ and $0.95 \pm 1.11$, respectively; $P=$ 0.005). Ten control participants were matched on group level for age, gender, BMI and physical activity level, assessed by The Short Questionnaire to Assess HealthEnhancing Physical Activity (SQUASH) [7]. Subjects were ineligible if they had hereditary muscle defects, diabetes mellitus, hypo- or hyperthyroidism, severe electrolyte disturbances, or used co-medication known to cause muscle symptoms or have an effect on mitochondrial function (e.g. statins, steroids, and metformin). Furthermore, subjects

4 Center for Systems Biology and Bioenergetics, Radboud Center for Mitochondrial Medicine, Radboud University Medical Center, Nijmegen, The Netherlands

5 Department of Neurology, Donders Institute for Brain, Cognition, and Behaviour, Radboud University Medical Center, Nijmegen, the Netherlands

6 Radboud Center for Mitochondrial Medicine, Translational Metabolic Laboratory, Department of Pediatrics, Radboud University Medical Center, Nijmegen, The Netherlands

7 Human and Animal Physiology, Wageningen University, Wageningen, The Netherlands 
with contra-indications for maximal exercise testing according to the ACC/AHA guidelines [8] and muscle biopsy (e.g. anticoagulant therapy, bleeding disorders) were excluded. The demographic and hematological characteristics shown in Table 1 are not statistically significant different between CML patients and controls and between CML + MC and CML - MC, except for a higher Charlson Comorbidity Index [9] score in CML patients when compared to controls (median 2.0 (IQR 2.0-2.0) and 0.0 (IQR $0.0-0.0$ ), respectively; $P<0.001)$ caused by the presence of CML. All participants completed the study protocol, i.e. a vastus lateralis muscle biopsy, electrical quadriceps femoris stimulations, and an incremental cycling test.

Vastus lateralis muscle needle biopsies were performed under local anesthesia in overnight fasted state and processed for mitochondrial measurements according to standard lab techniques as previously published [10]. Citrate synthase activity, a marker for mitochondrial density, was not different between CML patients and controls $(195 \pm 80 \mathrm{mU} / \mathrm{mg}$ protein and $171 \pm 30 \mathrm{mU} / \mathrm{mg}$ protein, respectively, $P=0.24$ ) and between $\mathrm{CML}+\mathrm{MC}$ and $\mathrm{CML}-\mathrm{MC} \quad(P=0.33)$.
Furthermore, mitochondrial function, assessed by ATP production capacity (Fig. 1a, c) and $\left[1-{ }^{14} \mathrm{C}\right]$-pyruvate oxidation rates in the presence of malate or carnitine (Fig. 1b, d) was not different between groups.

Maximal voluntary muscle strength of the dominant quadriceps femoris muscle [11], did neither differ between CML patients and controls $(8.3 \pm 2.0 \mathrm{~N} / \mathrm{kg}$ and $7.9 \pm 1.8 \mathrm{~N} / \mathrm{kg}$, respectively; $P=0.59)$, nor between $\mathrm{CML}+\mathrm{MC}$ and CML-MC ( $P=0.97)$. Resistance to fatigue was assessed by electrically stimulating the quadriceps femoris muscle repetitively at $40 \%$ of the MVC using $30 \mathrm{~Hz}$ bursts of onesecond duration every other second for two minutes [11]. This fatigue protocol resulted in a significantly larger force decline in CML patients as compared to controls $(31.8 \pm$ $8.7 \%$ and $23.6 \pm 7.7 \%$, respectively; $P=0.010$; Fig. 1e). Although a similar fatigability pattern was observed between CML + MC and CML - MC (force decline $29 \pm$ $9 \%$ and $34 \pm 9 \%$, respectively; $P=0.24$ ), the contractile properties of the quadriceps femoris muscle during repeated stimulation were explored in more detail. After two minutes of stimulation $\mathrm{CML}+\mathrm{MC}$ showed a

Table 1 Subject and hematological characteristics

\begin{tabular}{|c|c|c|c|c|c|c|}
\hline Characteristics & CML patients & Controls & $P$ value & $\mathrm{CML}+\mathrm{MC}$ & CML - MC & $P$ value \\
\hline Subject number, $N$ & 20 & 10 & - & 10 & 10 & - \\
\hline Gender, male/female & $14 / 6$ & $7 / 3$ & 1.00 & $7 / 3$ & $7 / 3$ & 1.00 \\
\hline Age, years & $54 \pm 8$ & $58 \pm 7$ & 0.25 & $55 \pm 9$ & $54 \pm 8$ & 0.86 \\
\hline BMI, $\mathrm{kg} / \mathrm{m}^{2}$ & $25.8 \pm 4.1$ & $27.5 \pm 5.4$ & 0.34 & $25.8 \pm 3.6$ & $25.8 \pm 4.8$ & 0.97 \\
\hline Physical activity, METmin/week; median (IQR) & $2288(1545-4982)$ & $2850(1965-4868)$ & 0.53 & $2541(1689-5488)$ & $2070(1403-4570)$ & 0.63 \\
\hline Smoker, \% & 0 & 0 & - & 0 & 0 & - \\
\hline Age at Dx, years & $46 \pm 8$ & N/A & - & $47 \pm 7$ & $46 \pm 9$ & 0.78 \\
\hline BCR-ABL level, $N(\%)$ & & N/A & - & & & 1.00 \\
\hline No MMR & $1(5)$ & & & $1(10)$ & $0(0)$ & \\
\hline MMR or deeper & $19(95 \%)$ & & & $9(90)$ & $10(100)$ & \\
\hline TKI, $N(\%)$ & & & - & & & 0.89 \\
\hline Imatinib & $10(50)$ & N/A & & $6(60)$ & $4(40)$ & \\
\hline Dasatinib & $5(25)$ & N/A & & $2(20)$ & $3(30)$ & \\
\hline Nilotinib & $2(10)$ & N/A & & $1(10)$ & $1(10)$ & \\
\hline Bosutinib & $2(10)$ & N/A & & $1(10)$ & $1(10)$ & \\
\hline Ponatinib & $1(5)$ & N/A & & $0(0)$ & $1(10)$ & \\
\hline Duration of current TKI therapy, months; median (IQR) & $42.5(21.0-114.8)$ & N/A & - & $66.5(19.0-121.5)$ & $38.0(16.5-73.3)$ & 0.63 \\
\hline Prior TKIs, $N$; median (IQR) & $0.5(0.0-1.0)$ & N/A & - & $0.0(0.0-1.0)$ & $1.0(0.0-1.0)$ & 0.53 \\
\hline Charslon Comorbidity Index; median (IQR) & $2.0(2.0-2.0)$ & $0.0(0.0-0.0)$ & $<0.001$ & $2.0(2.0-2.0)$ & $2.0(2.0-2.0)$ & 0.74 \\
\hline Potassium, mmol/l & $3.9 \pm 0.28$ & $4.0 \pm 0.20$ & 0.50 & $3.9 \pm 0.21$ & $4.0 \pm 0.34$ & 0.76 \\
\hline Magnesium, mmol/l & $0.82 \pm 0.06$ & $0.84 \pm 0.06$ & 0.49 & $0.82 \pm 0.05$ & $0.83 \pm 0.06$ & 0.63 \\
\hline Phosphate, mmol/1 & $0.82 \pm 0.12$ & $0.91 \pm 0.17$ & 0.11 & $0.83 \pm 0.10$ & $0.81 \pm 0.15$ & 0.75 \\
\hline Calcium, mmol/1 & $2.29 \pm 0.09$ & $2.30 \pm 0.06$ & 0.68 & $2.29 \pm 0.09$ & $2.29 \pm 0.10$ & 0.91 \\
\hline Albumin, g/l & $38.7 \pm 2.5$ & $37.3 \pm 2.0$ & 0.13 & $39.1 \pm 2.8$ & $38.3 \pm 2.2$ & 0.48 \\
\hline TSH, mE/l; median (IQR) & $2.1(1.4-2.6)$ & $2.0(1.3-2.8)$ & 0.90 & $2.0(0.8-2.9)$ & $2.1(1.5-2.7)$ & 0.61 \\
\hline CK, U/l; median (IQR) & $137(89-236)$ & $120(109-166)$ & 0.61 & $169(103-312)$ & $127(84-216)$ & 0.90 \\
\hline
\end{tabular}

Values are presented as mean \pm SD unless indicated otherwise. There were no significant differences in subject and hematological characteristics between CML patients, except for a higher Charslon Comorbidity Index score in CML patients Also, there were no significant differences between CML patients with and without TKI induced muscle complaints

$M C$ muscle complaints, $B M I$ body mass index, $M E T$ metabolic equivalent of task, $I Q R$ interquartile range, $D x$ diagnosis, $M M R$ major molecular response, $T K I$ tyrosine kinase inhibitor, $T S H$ thyroid-stimulating hormone, $C K$ creatine kinase 

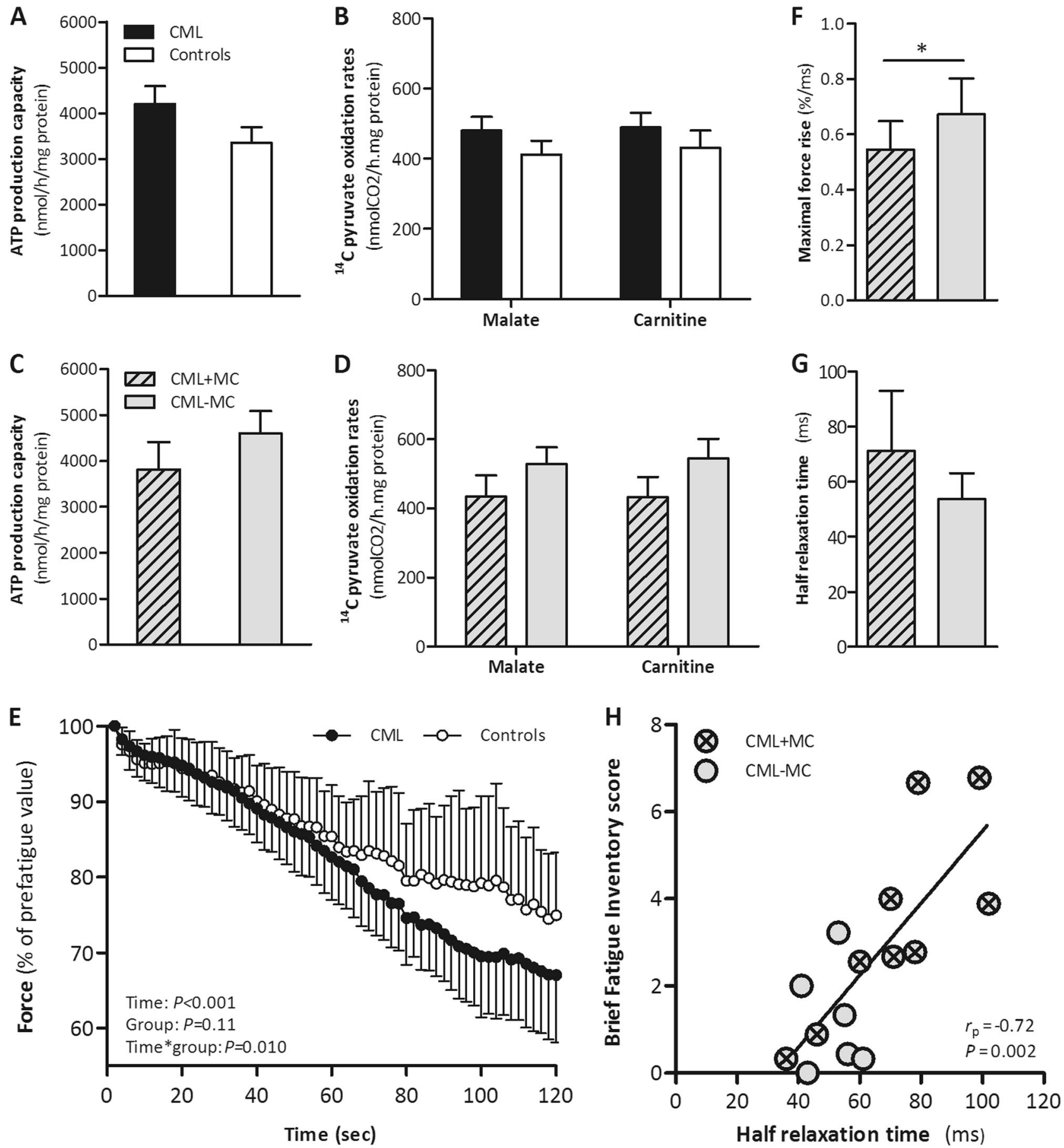

Fig. 1 Skeletal muscle mitochondrial function and muscle function parameters measured in CML patients and controls. a ATP production rate normalized to muscle protein content and (b) $\left[1-{ }^{14} \mathrm{C}\right]$-pyruvate oxidation rates in the presence of malate and carnitine normalized to muscle protein content measured in mitochondrial fractions from fresh vastus lateralis muscle biopsies were not affected by TKI use. There were also no differences in (c) ATP production rate and $(\mathbf{d})\left[1-{ }^{14} \mathrm{C}\right]$ pyruvate oxidation rates in the presence of malate and carnitine between CML + MC and CML-MC. e Force decline expressed as percentage of the prefatigue value during two minutes repetitive electrical stimulation of the quadriceps femoris muscle shows a higher level of muscle fatigue in CML patients compared to controls. Force

responses are plotted every second during the complete $(120 \mathrm{sec})$ fatigue protocol. f Maximal force rise after two minutes of electrical quadriceps femoris stimulation was significantly lower in CML + MC when compared to CML-MC. g Quadriceps femoris muscle in CML + MC showed a tendency toward longer relaxation time after two minute repetitive stimulation when compared to CML - MC. h Reported fatigue by CML patients (assessed by the Brief Fatigue Inventory) correlates with half relaxation time in quadriceps femoris muscle after two minutes repetitive electrical stimulation $(N=15)$. Data are presented as means \pm SEM for $\mathbf{a}-\mathbf{d}$; and means \pm SD for $\mathbf{e}-\mathbf{g}$. $* P$ value $<0.05$ is considered statistically significant 
significantly lower maximal force rise (maximal slope of force increment normalized for peak force) compared to CML-MC $(0.54 \pm 0.10 \% / \mathrm{ms}$ and $0.67 \pm 0.13 \% / \mathrm{ms}$, respectively; $P=0.038$; Fig. 1f) and a tendency toward longer half relaxation time (time taken for force to decline from 50 to $25 \%$ of the peak force; $P=0.07$; Fig. $1 \mathrm{~g}$ ). The half relaxation time at the end of the fatigue protocol strongly correlated with reported fatigue $\left(r_{p}=0.72 ; P=\right.$ 0.002; Fig. 1h). Since muscle relaxation is dependent upon the activity of sarco/endoplasmic reticulum $\mathrm{Ca}^{2+}$-ATPase (SERCA), an enzyme that mediates the re-uptake of calcium into the sarcoplasmic reticulum (SR) of skeletal muscle, SERCA activity was measured in whole-muscle homogenates [11]. However, no significant differences in SERCA activity were observed between CML + MC and CML - MC (98.9 (IQR 79.3-110.7 mU/mg) and 101.5 (IQR $77.0-109.8 \mathrm{mU} / \mathrm{mg}$ ), respectively; $P=0.97$ ).

To measure whole-body fitness levels, all subjects performed an incremental cycle ergometer test (Lode Excalibur; Groningen, the Netherlands) with continuous ECG monitoring [10] to assess peak oxygen uptake $\left(\mathrm{VO}_{2 \text { peak }}\right)$. $\mathrm{VO}_{2 \text { peak }}$ was $34.6 \pm 8.4 \mathrm{ml} / \mathrm{kg} / \mathrm{min}(100 \pm 9 \%$ predicted) in the CML patients, which was not different from the controls $\left(\mathrm{VO}_{2 \text { peak }} 35.6 \pm 7.5 \mathrm{ml} / \mathrm{kg} / \mathrm{min}, 100 \pm 9 \%\right.$ predicted; $P=$ $0.75)$. In addition, no differences in $\mathrm{VO}_{2 \text { peak }}$ were observed between CML + MC and CML - MC $(P=0.38)$.

Collectively, CML patients on TKI therapy show no signs of skeletal muscle mitochondrial dysfunction. However, quadriceps femoris muscle of TKI users fatigues to a larger extent upon repetitive stimulation when compared to controls. Changes in muscle contractile properties are associated with TKI-induced muscle complaints, as CML $+\mathrm{MC}$ show a significant lower maximal force rise and a tendency toward a delayed muscle relaxation after two minutes of electrical quadriceps femoris stimulations. CML patients did not have impaired maximal exercise performance.

On a cellular level, no effects of TKI therapy on skeletal muscle mitochondrial density and function were found. These results are in line with the only previous clinical case report in which two CML patients, who had to interrupt or reduce therapy with nilotinib because of muscle pain, failed to show disturbances in mitochondrial oxidative enzyme reactions [12]. Intriguingly, in vitro studies in $\mathrm{C} 2 \mathrm{C} 12$ myotubes showed no decline in ATP levels upon short-term imatinib incubation of $30 \mathrm{~min}$ [13], whereas long-term TKI-incubation of $24 \mathrm{~h}$ showed decreased ATP levels overtime [5, 13].

Disturbances in heart mitochondrial function are suggested to occur secondary to activation of a stress response in the endoplasmic reticulum [4]. Perhaps, in skeletal muscle, changes in the function of other cellular organelles also precede mitochondrial disturbances. In support of this hypothesis, CML patients on TKI therapy showed significantly more muscle fatigue than controls, and CML +
MC showed delayed quadriceps femoris muscle force generation and a trend toward delayed relaxation in fatigued muscle compared to CML - MC. Since muscle fatigability, force generation, and relaxation are largely dependent on $\mathrm{Ca}^{2+}$ regelulation by the SR, changes in SR functioning may underlie these findings [14]. In that respect, disturbances in $\mathrm{Ca}^{2+}$ homeostasis [15], and SR abnormalities (i.e., dilated SR with membrane whorls) [4] have been found upon imatinib treatment in myocytes, but have never been linked to muscle complaints. Although we found no difference in SERCA activity between CML + MC and CML - MC, muscle half relaxation time after 2-min stimulation correlated positively with the perception of fatigue in CML patients, and may therefore be an important key for understanding the mechanism underlying fatigue in CML.

To the best of our knowledge, maximal exercise capacity has not been assessed before in CML patients or other TKIusers. Compared to controls, CML patients do not have diminished maximal exercise capacity as measured by $\mathrm{VO}_{2 \text { peak }}$ and have similar physical activity levels as controls. $\mathrm{VO}_{2 \text { peak }}$ was also not different between $\mathrm{CML}+\mathrm{MC}$ and CML - MC, despite higher subjective fatigue levels in CML + MC. These findings fit with the unaltered mitochondrial ATP production capacity, which is an important determinant of $\mathrm{VO}_{2 \text { peak }}$.

There are several limitations to this study. Due to the exploratory character of the study a relatively large number of measurements were performed in a small sample size. Therefore, results should be cautiously interpreted. Nonetheless, this design made it possible to examine the influence of TKIs on multiple levels (i.e. cellular, muscle tissue and whole body level) which offers broad insight into the effects of TKIs in CML patients. Secondly, participants were only included when they were able to perform all study measurements. Thus patients who were unable to perform exercise testing were excluded. Consequently, extreme cases of TKIinduced skeletal muscle complaints were not included in this study, which may have underestimated the results.

This study provides important information concerning the effects of TKIs on skeletal muscle function and whole body fitness and lays foundation for further studies to elucidate the precise mechanism by which TKI therapy causes muscle complaints and affects muscle function.

Acknowledgements We would like to thank Berendien StoltenborgHogenkamp, Karina Horsting-Wethly and Theo van Lith of the Translational Metabolic Laboratory at the Radboudumc for their assistance with the mitochondrial measurements.

\section{Compliance with ethical standards}

Conflict of interest The authors declare that they have no conflict of interest. 
Publisher's note: Springer Nature remains neutral with regard to jurisdictional claims in published maps and institutional affiliations.

Open Access This article is licensed under a Creative Commons Attribution 4.0 International License, which permits use, sharing, adaptation, distribution and reproduction in any medium or format, as long as you give appropriate credit to the original author(s) and the source, provide a link to the Creative Commons license, and indicate if changes were made. The images or other third party material in this article are included in the article's Creative Commons license, unless indicated otherwise in a credit line to the material. If material is not included in the article's Creative Commons license and your intended use is not permitted by statutory regulation or exceeds the permitted use, you will need to obtain permission directly from the copyright holder. To view a copy of this license, visit http://creativecommons. org/licenses/by/4.0/.

\section{References}

1. Kekäle M, Peltoniemi M, Airaksinen M. Patient-reported adverse drug reactions and their influence on adherence and quality of life of chronic myeloid leukemia patients on per oral tyrosine kinase inhibitor treatment. Patient Prefer Adherence. 2015;9:1733-40.

2. Marin D, Bazeos A, Mahon F-X, Eliasson L, Milojkovic D, Bua $\mathrm{M}$, et al. Adherence is the critical factor for achieving molecular responses in patients with chronic myeloid leukemia who achieve complete cytogenetic responses on imatinib. J Clin Oncol. 2010;28:2381-8

3. Efficace F, Baccarani M, Breccia M, Cottone F, Alimena G, Deliliers GL, et al. Chronic fatigue is the most important factor limiting health-related quality of life of chronic myeloid leukemia patients treated with imatinib. Leukemia. 2013;27: 1511-9.

4. Kerkela R, Grazette L, Yacobi R, Iliescu C, Patten R, Beahm C, et al. Cardiotoxicity of the cancer therapeutic agent imatinib mesylate. Nat Med. 2006;12:908-16.

5. Will Y, Dykens JA, Nadanaciva S, Hirakawa B, Jamieson J, Marroquin LD, et al. Effect of the multitargeted tyrosine kinase inhibitors imatinib, dasatinib, sunitinib, and sorafenib on mitochondrial function in isolated rat heart mitochondria and H9c2 cells. Toxicol Sci. 2008;106:153-61.

6. Mendoza TR, Wang XS, Cleeland CS, Morrissey M, Johnson BA, Wendt JK, et al. The rapid assessment of fatigue severity in cancer patients: use of the Brief Fatigue Inventory. Cancer. 1999;85: 1186-96.

7. Wendel-Vos GC, Schuit AJ, Saris WH, Kromhout D. Reproducibility and relative validity of the short questionnaire to assess health-enhancing physical activity. J Clin Epidemiol. 2003;56: 1163-9.

8. Gibbons RJ, Balady GJ, Bricker JT, Chaitman BR, Fletcher GF, Froelicher VF, et al. ACC/AHA 2002 guideline update for exercise testing: summary article. A report of the American College of Cardiology/American Heart Association Task Force on Practice Guidelines (Committee to Update the 1997 Exercise Testing Guidelines). J Am Coll Cardiol. 2002;40:1531-40.

9. Charlson ME, Pompei P, Ales KL, MacKenzie CR. A new method of classifying prognostic comorbidity in longitudinal studies: development and validation. J Chronic Dis. 1987;40:373-83.

10. Allard NAE, Schirris TJJ, Verheggen RJ, Russel FGM, Rodenburg RJ, Smeitink JAM, et al. Statins affect skeletal muscle performance: evidence for disturbances in energy metabolism. J Clin Endocrinol Metab. 2018;103:75-84.

11. Gerrits HL, De Haan A, Hopman MT, van Der Woude LH, Jones DA, Sargeant AJ. Contractile properties of the quadriceps muscle in individuals with spinal cord injury. Muscle Nerve. 1999; 22:1249-56.

12. Caocci G, Maioli MA, Atzeni S, Piras R, Carboni N, La Nasa G. Absence of histological myopathy in chronic myeloid leukemia patients complaining of muscle spasms and myalgia during treatment with nilotinib. Leuk Res. 2012;36:e206-8.

13. Damaraju VL, Kuzma M, Cass CE, Putman CT, Sawyer MB. Multitargeted kinase inhibitors imatinib, sorafenib and sunitinib perturb energy metabolism and cause cytotoxicity to cultured C2C12 skeletal muscle derived myotubes. Biochem Pharmacol. 2018;155:162-71.

14. Westerblad H, Allen DG. Changes of myoplasmic calcium concentration during fatigue in single mouse muscle fibers. J Gen Physiol. 1991;98:615-35.

15. Barr LA, Makarewich CA, Berretta RM, Gao H, Troupes CD, Woitek $\mathrm{F}$, et al. Imatinib activates pathological hypertrophy by altering myocyte calcium regulation. Clin Transl Sci. 2014;7:360-7. 
Leukemia (2019) 33:2121-2125

https://doi.org/10.1038/s41375-019-0445-5

Acute myeloid leukemia

\title{
Insertional mutagenesis identifies cooperation between Setbp1 and MIlt3 in inducing myeloid leukemia development
}

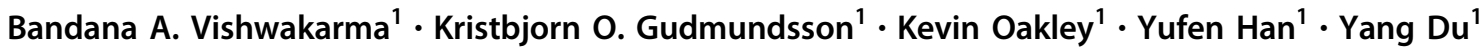

Received: 4 January 2019 / Revised: 20 February 2019 / Accepted: 8 March 2019 / Published online: 20 March 2019

(c) Springer Nature Limited 2019

\section{To the Editor:}

Multiple cooperating mutations are required to induce transformation during the development of acute myeloid leukemias (AMLs), and identification of these cooperating mutations is essential for developing better combinatorial AML therapies. SETBP1, which encodes an AT-hook transcription factor $[1,2]$, likely plays a significant role in driving human primary AML development as it was overexpressed in up to $30 \%$ of primary AML patients [3, 4], and its overexpression was capable of inducing AML development in mice [5]. Consistent with its association with poor patient prognosis [3, 4], SETBP1 overexpression also likely plays an important role in the maintenance of leukemiainitiating cells (LICs) as it was identified as a top component of a LIC gene expression signature for human AMLs [6]. SETBP1 may control the self-renewal of LICs through direct transcription activation of oncogenes Hoxa9, Hoxa10, and $M y b$, and repression of tumor suppressor gene Runx1 [1, 5]. SETBP1 may also promote AML development through its interaction and stabilization of oncoprotein SET [3]. Despite the potentially significant contribution by SETBP1 overexpression to the initiation and maintenance of primary human AMLs, its cooperating oncogenic partners in AML development remain unknown.

Using a mouse bone marrow transduction and transplantation system, we showed previously that overexpression of Setbpl induced AML development in over

Supplementary information The online version of this article (https:// doi.org/10.1038/s41375-019-0445-5) contains supplementary material, which is available to authorized users.

Yang Du

yang.du@usuhs.edu

1 Department of Pediatrics, Uniformed Services University of the Health Sciences, Bethesda, MD, USA
$50 \%$ of the recipient mice in 10 months [5]. Such systems, as shown by us and others, also could be used as a powerful tool for identifying cooperating oncogenic mutations due to insertional mutagenesis induced by retroviral vectors [7, 8]. Therefore, to identify potential cooperating mutations for SETBP1 overexpression in AML development, we cloned and sequenced a total of 26 retroviral integration sites from 16 Setbpl-induced mouse AMLs by splinkerette polymerase chain reaction (Supplementary Table 1). Integration site sequences were subsequently matched against the mouse genome sequence to identify their genomic locations. Interestingly, two leukemias carry independent insertions at Mllt3 (Fig. 1a). Given that retroviruses integrate in a largely random fashion into the genome, recurrent integrations at Mllt3 strongly suggest that such integrations may cooperate with Setbpl in AML induction in these mice. These two leukemias also expressed significantly higher levels of Mllt3 mRNA than leukemias without such integrations (Fig. 1b), further indicating that Mllt3 overexpression potentially induced by the viral integrations was likely responsible for cooperating with Setbpl in leukemia induction. The lack of Mllt3 overexpression in the rest of the mouse leukemias examined suggests a non-essential role for Mllt3 in Setbp1-induced leukemia development; however, significantly higher levels of MLLT3 expression were detected in human AMLs with high-SETBP1 expression than in samples with low-SETBPI expression in an expression profiling study of human AMLs (Fig. 1c) [9], suggesting that this potential Setbpl/Mllt3 cooperation is likely conserved and prevalent in human AMLs with SETBP1 overexpression.

MLLT3, also known as $A F 9$, first was identified as a fusion partner for $M L L 1$ in human myeloid leukemias [10]. Gene targeting in mice has revealed a critical role of Mllt3 in embryogenesis [11]. MLLT3 later was found to regulate transcriptional elongation as a component of the super elongation complex (SEC) [12]. This function of MLLT3 is likely dependent on its ability to recognize H3K9 
A

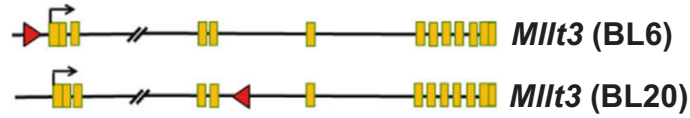

B
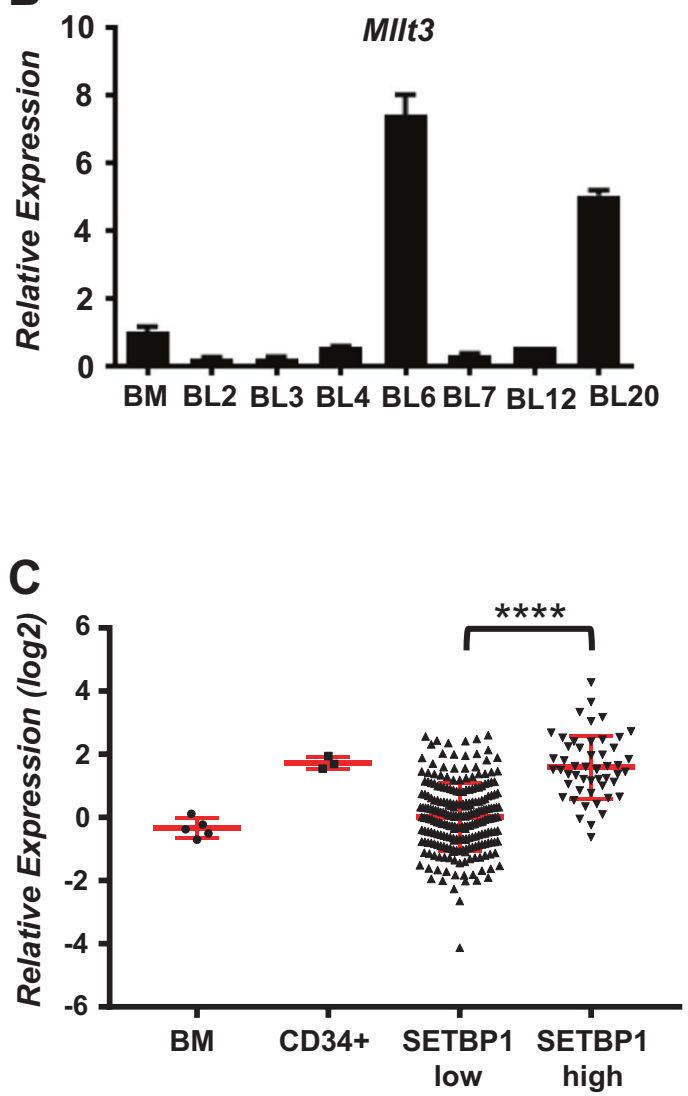

Fig. 1 Mllt3 cooperates with Setbpl to induce AML development. a Schematic diagrams of genomic locations of retroviral insertions (red triangles) at Mllt3 in two Setbp1-induced mouse leukemias BL6 and BL20. b Real-time RT-PCR analysis of Mllt3 expression in indicated Setbpl-induced leukemias relative to Rpl4 mRNA levels and control healthy bone marrow cells (BM). c Relative expression levels $(\log 2)$ of MLLT3 in human normal bone marrow (BM), CD34 ${ }^{+}$cells, and AML cells with and without SETBP1 overexpression (SETBP1 high and low). Normalized expression data from microarray dataset published by Valk et al. [9] was downloaded from Oncomine website (http://www.oncomine.org/) and analyzed. d Schematic diagram depicting mouse bone marrow transduction and subsequent serial replating and transplantation assays for testing Setbp 1/Mllt3 cooperation in inducing leukemia transformation. e Mean and SD of relative colony-forming potential of 5-fluorouracil (5-FU) treated bone marrow

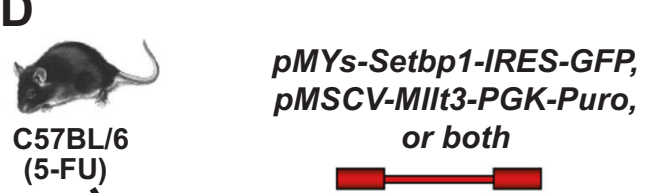

E

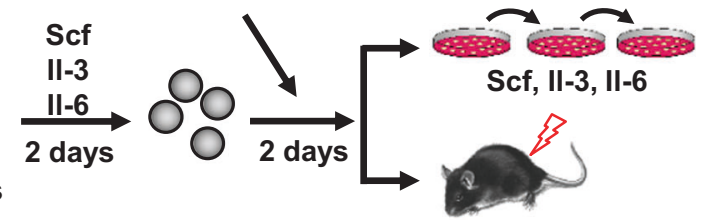

B6-Ly5.2

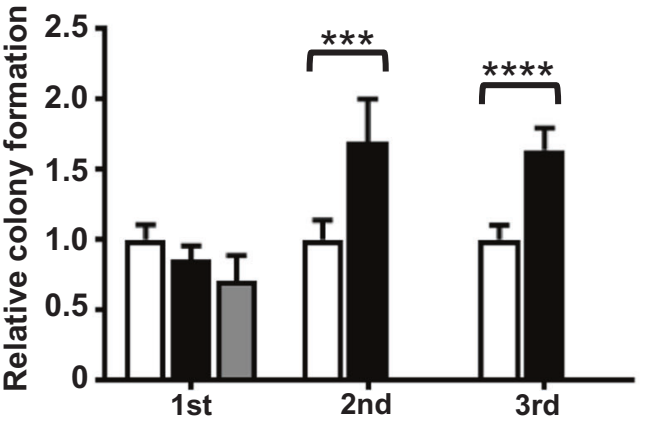

$\square \mathrm{S}$

M+S

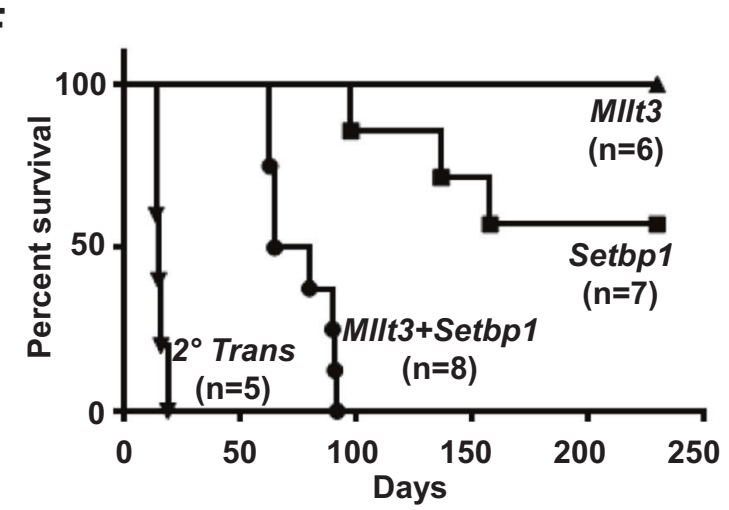

(BM) progenitors transduced with pMYs-Setbp1-IRES-GFP (S), pMSCV-Mllt3-PGK-Puro $(M)$, or the combination $(M+S)$ in primary (1st), secondary (2nd), and tertiary (3rd) platings on methylcellulose in the presence of murine Scf $(100 \mathrm{ng} / \mathrm{ml})$, Il-6 $(10 \mathrm{ng} / \mathrm{ml})$, and Il-3 $(6 \mathrm{ng} / \mathrm{ml})(n=3$ for each transduction). The titer of Mllt3 and Setbpl virus used for co-transduction was reduced by half compared to the single-transduction groups to ensure same total viral titer being used for each transduction group. Depending on the virus used, transduced cells were purified by selection with puromycin at $48 \mathrm{~h}$ post-transduction, by FACS based on GFP positivity at $72 \mathrm{~h}$ post-transduction, or both before primary platings. Cells were re-plated every five days. f Survival curves of irradiated B6-Ly5.2 mice receiving similarly transduced cells as in $\mathrm{E}$ and also secondary recipient mice receiving $1 \times 10^{6}$ spleen cells from primary Mllt3 + Setbp 1 leukemic mice ( $2^{\circ}$ Trans). ${ }^{* * *} P<0.001 ;{ }^{* * * *} P<0.0001$ (two-tailed Student's $t$ test)

effects of co-transduction with pMSCV-Mllt3-PGK-Puro plus $p M Y s$-Setbpl-IRES-GFP viruses on 5-fluorouracil (5-FU)-treated bone marrow progenitors from C57BL/6 mice (Fig. 1d). We first compared the self-renewal potential of co-transduced cells to cells singly transduced with Setbpl 
or Mllt3 virus by serial replating assay on methylcellulose. Cells singly transduced with Mllt3 virus failed to form colonies after first plating, suggesting that Mllt3 overexpression is not capable of inducing their self-renewal in vitro (Fig. 1e). Both co-transduced cells and cells infected with Setbpl virus alone continued to form colonies of myeloid progenitors on secondary and tertiary platings (Fig. 1e), suggesting that the combined expression of Setbpl and Mllt3 like Setbpl expression alone is capable of immortalizing myeloid progenitors. Interestingly, considerably increased colony formation by co-transduced cells compared to cells singly transduced by Setbpl virus was observed at both secondary and tertiary plating (Fig. 1e), further indicating that overexpression of Mllt3 may significantly enhance Setbpl-induced self-renewal of myeloid progenitors.

To test whether co-expression of Setbpl and Mllt3 could lead to accelerated leukemia development in vivo, we also transplanted unpurified transduced cells into lethally irradiated B6-Ly5.2 mice. As expected from our previous studies, three of seven mice receiving cells singly transduced by Setbpl virus developed AML in 8 months (Fig. 1f). In contrast, none of the recipient mice in Mllt3 transduction group developed leukemia in the same period (Fig. 1f), suggesting the overexpression of Mllt3 alone is not sufficient to induce leukemia development. Importantly, 100\% of the recipient mice for the co-transduced cells developed AML at a much reduced latency [76 \pm 13 days (mean \pm SD); $p<0.0001, \log$-rank test] than mice of the Setbpl group (Fig. 1f). Resembling leukemic mice induced by Setbpl alone, these mice developed similarly enlarged spleens and displayed significant infiltrations of leukemic cells into nonhematopoietic tissues including liver and lung (Supplementary Table 2 and Supplementary Figure 1A). Fluorescence-activated cell sorting analyses of the two leukemia types showed similar percentages of green fluorescent protein-positive leukemia cells (83-95\%) in the bone marrow and spleen with a majority (75-85\%) of the leukemia cells in the bone marrow being positive for Gr-1 and only a minority of the cells being weakly positive for CD19, CD4, or Ter119 (Supplementary Figure 1B). However, Mllt3 + Setbp1 AMLs have greatly increased number of ckit-positive cells $(59 \pm 2 \%$ vs. $3 \pm 1 \%$, mean \pm SD) and less Sca-1-positive cells $(2 \pm 1 \%$ vs. $10 \pm 3 \%$, mean \pm SD) in bone marrow than Setbpl AMLs (Supplementary Figure 1B). Consistent with the c-kit expression pattern, cytospin preparations of leukemic bone marrow and spleens (Supplementary Figure 1C) revealed significantly higher frequencies of myeloid blasts in Mllt3 + Setbpl leukemic mice than Setbpl leukemic mice $[70 \pm 6 \%$ vs. $30 \pm 8 \%$ (mean $\pm \mathrm{SD}$ ) of all nucleated cells in the bone marrow]. Mllt3 + Setbpl leukemias are also transplantable as secondary recipients receiving $1 \times 10^{6}$ spleen cells from primary leukemic mice developed AML with a comparable latency to recipients of Setbpl leukemia cells (16 \pm 2 days vs. $17 \pm 4$ days, mean \pm SD) (Supplementary Figure 2). Moreover, to confirm that co-expression of Setbpl and Mllt3 in same cell is required for their cooperativity, both proviruses were detected in genomic DNA from all randomly selected colonies generated by these leukemic cells (Supplementary Figure 3).

Hoxa9 activation is essential for Setbpl-induced transformation [1]. It has been shown previously that Meis 1 overexpression can cooperate with Hoxa9 activation to induce AML development [14]. Therefore, we tested the possibility that co-expression of Mllt3 with Setbpl may increase Meisl expression in hematopoietic stem and progenitor cells by transducing mouse $\operatorname{lin}^{-} \mathrm{Sca}-1^{+} \mathrm{c}-\mathrm{kit}^{+}$(LSK) cells and analyzing their Meis 1 expression at $72 \mathrm{~h}$ after transduction and also in their primary, secondary, and tertiary colonies. Mllt3 overexpression alone is not sufficient to activate Meisl as it failed to increase Meis 1 mRNA levels at $72 \mathrm{~h}$ post-transduction (Supplementary Figure 4). Although both overexpression of Setbpl alone and together with Mllt3 upregulated Meis 1 mRNA to similar levels at 72 h (Supplementary Figure 4), significantly higher levels of Meis 1 mRNA and protein were detected in all serial colonies overexpressing both Setbpl and Mllt3 than in colonies overexpressing Setbpl only (Fig. 2a, b). Significantly higher levels of Meisl expression also were detected in Mllt3 + Setbpl AMLs than in Setbpl AMLs (Fig. 2c, d). Moreover, in supporting a critical role of increased Meisl expression in transformation induced by Setbpl/Mllt3 cooperation, Meis1 deletion by Cre/ERT2 in secondary colony cells produced from Meis 1 conditional LSK cells after Mllt3 + Setbp 1 transduction significantly decreased their colony-forming capability (Fig. 2e). These results strongly suggest that a major cooperating mechanism for Setbpl and Mllt3 in leukemia induction may be their cooperation in inducing high levels of Meisl expression. Interestingly, by performing chromatin immunoprecipitation analysis on tertiary colony cells generated by LSK cells co-expressing Setbp1 and Mllt3, we also detected significant Mllt3 binding at the Meis1 locus (Fig. 2f), further suggesting that Meis 1 is a direct transcriptional target of Mllt3. This direct regulation of Meis 1 transcription by Mllt3 is also conserved in human AML cells as a significant positive correlation between MLLT3 and MEIS1 expression was observed in human AMLs expressing high levels of SETBP1 (Supplementary Figure 5).

Overexpression of SETBP1 in primary AMLs has been associated with poor disease prognosis, suggesting better therapies are critically needed to improve treatment outcome. Our study identifies MLLT3 as a common cooperating partner for SETBPI in inducing human AML development, indicating that inhibition of signaling 
A

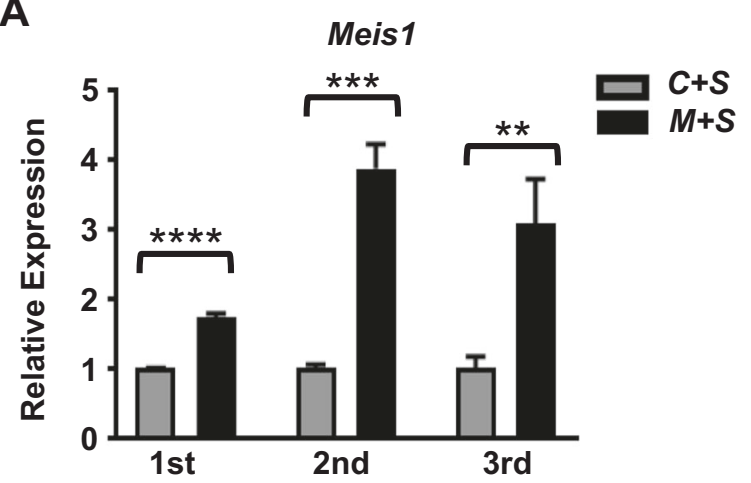

C

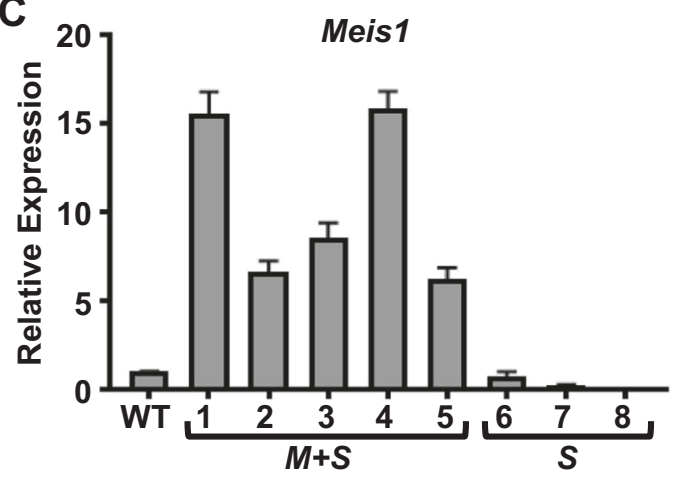

E

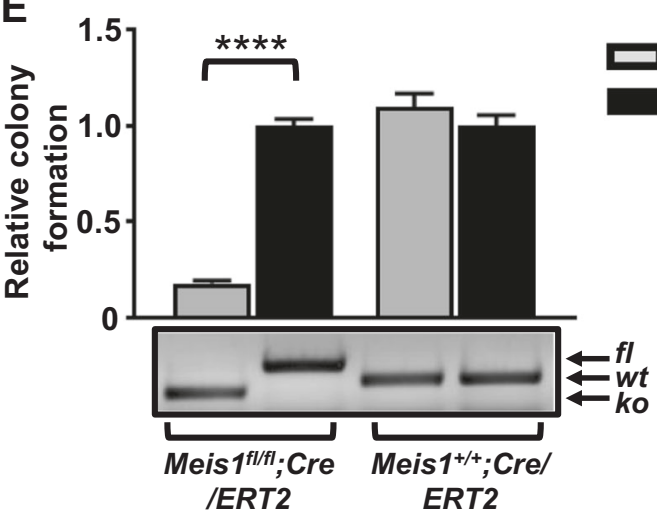

Fig. 2 Meis 1 is a direct transcriptional target of Mllt3. a Real-time RTPCR analysis of Meis 1 expression in cells of primary (1st), secondary (2nd), and tertiary (3rd) colonies formed by LSK cells transduced by pMSCV-PGK-Puro + pMYs-Setbp1-IRES-GFP $(C+S)$, or pMSCVMllt3-PGK-Puro + pMYs-Setbp1-IRES-GFP $(M+S)$ viruses. Relative expression levels (mean $\pm \mathrm{SD}$ ) were calculated by normalizing to Rpl4 mRNA levels in the same sample and also to $C+S$ cells $(n=3$ for each transduction). GFP positive and puromycin resistant cells were collected at $72 \mathrm{~h}$ post-transduction for the serial replating assay. b Western blotting analyses of whole cell extracts prepared from the same colony cells as in (a) using indicated antibodies. $\mathbf{c}$ Real-time RTPCR analysis of Meisl expression in spleen cells of leukemic mice induced by Mllt3 + Setbp1 co-transduction $(M+S)$ or Setbp1 transduction alone $(S)$ and control mouse bone marrow cells (WT).
B
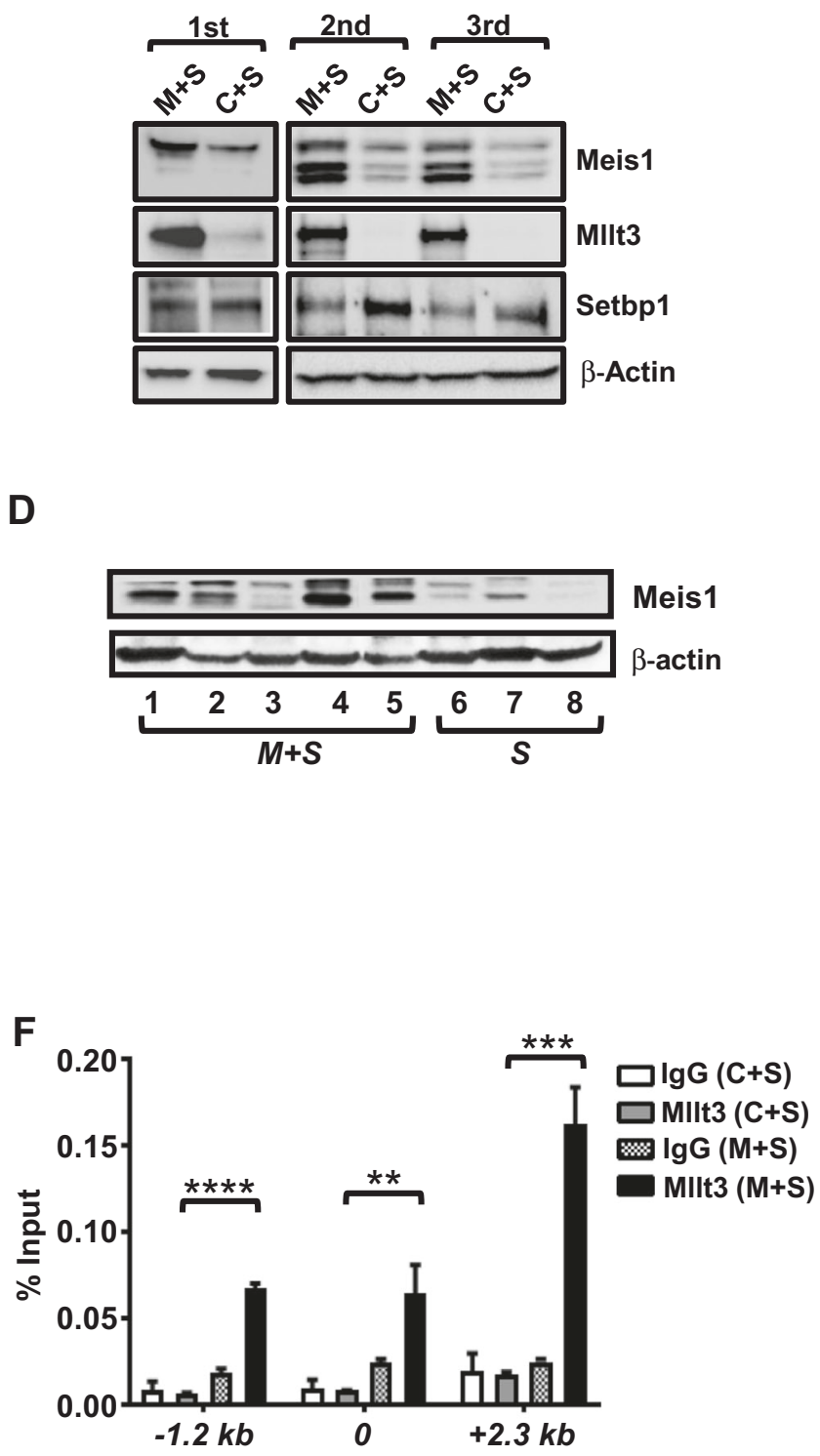

d Western blotting analyses of whole cell extracts prepared from the same leukemia cells as in C using indicated antibodies. e Upper panel, secondary colony cells generated by Mllt3 + Setbp1 co-transduced LSK cells of indicated genotypes were examined by colony-forming assay after treatment with 4-hydroxytamoxifen (4-OHT) or control ethanol $(\mathrm{EtOH})$ and their relative colony-forming potentials are shown (mean $\pm \mathrm{SD}, n=3$ for each transduction). Lower panel, different Meis 1 alleles including floxed $(f)$, knockout $(k o)$, and wild-type $(w t)$ detected by PCR in the secondary colony cells after 4-OHT or EtOH treatment. f Quantitative ChIP analysis of indicated genomic regions relative to Meis1 transcriptional start site using a Mllt3-specific antibody or control IgG in tertiary colony cells generated by mouse LSK cells similarly transduced as in $(\mathbf{a}) .{ }^{* *} P<0.01 ;{ }^{* * * *} P<0.001$; ${ }^{* * * * *} P<0.0001$ (two-tailed Student's $t$ test) 
pathways downstream of MLLT3 may prove valuable for treating such AMLs. MLLT3 activation in these AMLs is likely independent of SETBPI as no significant correlation was detected between their expression levels and Setbpl overexpression also failed to increase Mllt3 expression in mouse LSK cells (Supplementary Figures 6 and 7). Cooperativity also may exist between MLLT3 and SETBP1 missense mutations in the development of other myeloid neoplasms since SETBP1 missense mutants are known to activate similar targets as wild-type SETBP1 [15]. As a component of SEC, MLLT3 was shown to regulate transcriptional elongation, but whether its overexpression could play any role in cancer development was unclear. Our study demonstrates for the first time that MLLT3 overexpression can promote AML development by activating MEIS1 transcription. Further studies using genomic and proteomic approaches will be required to identify additional MLLT3 transcriptional targets promoting AML development and also other transcriptional cofactors critical for such activation.

Acknowledgements This work was supported by National Institutes of Health (NIH) grant RO1CA143193 (Y.D.) and USUHS Pediatrics Grant QP86GI (Y.D.). The views presented in this paper are those of the authors; no endorsement by the Uniformed Services University of the Health Sciences or the Department of Defense has been given or should be inferred.

\section{Compliance with ethical standards}

Conflict of interest The authors declare that they have no conflict of interest.

Publisher's note: Springer Nature remains neutral with regard to jurisdictional claims in published maps and institutional affiliations.

\section{References}

1. Oakley K, Han Y, Vishwakarma BA, Chu S, Bhatia R, Gudmundsson $\mathrm{KO}$, et al. Setbp1 promotes the self-renewal of murine myeloid progenitors via activation of Hoxa9 and Hoxa10. Blood. 2012;119:6099-108.

2. Piazza R, Magistroni V, Redaelli S, Mauri M, Massimino L, Sessa A, et al. SETBP1 induces transcription of a network of development genes by acting as an epigenetic hub. Nat Commun. 2018;9:2192.

3. Cristobal I, Blanco FJ, Garcia-Orti L, Marcotegui N, Vicente C, Rifon J, et al. SETBP1 overexpression is a novel leukemogenic mechanism that predicts adverse outcome in elderly patients with acute myeloid leukemia. Blood. 2010;115:615-25.

4. Lucas CM, Scott LJ, Carmell N, Holcroft AK, Hills RK, Burnett AK, et al. CIP2A- and SETBP1-mediated PP2A inhibition reveals AKT S473 phosphorylation to be a new biomarker in AML. Blood Adv. 2018;2:964-8.

5. Vishwakarma BA, Nguyen N, Makishima H, Hosono N, Gudmundsson KO, Negi V, et al. Runx1 repression by histone deacetylation is critical for Setbp1-induced mouse myeloid leukemia development. Leukemia. 2016;30:200-8.

6. Gentles AJ, Plevritis SK, Majeti R, Alizadeh AA. Association of a leukemic stem cell gene expression signature with clinical outcomes in acute myeloid leukemia. J Am Med Assoc. 2010;304:2706-15.

7. Du Y, Spence SE, Jenkins NA, Copeland NG. Cooperating cancer-gene identification through oncogenic-retrovirus-induced insertional mutagenesis. Blood. 2005;106:2498-505.

8. Jin G, Yamazaki Y, Takuwa M, Takahara T, Kaneko K, Kuwata $\mathrm{T}$, et al. Trib1 and Evil cooperate with Hoxa and Meis1 in myeloid leukemogenesis. Blood. 2007;109:3998-4005.

9. Valk PJ, Verhaak RG, Beijen MA, Erpelinck CA, Barjesteh van Waalwijk van Doorn-Khosrovani S, Boer JM, et al. Prognostically useful gene-expression profiles in acute myeloid leukemia. New Engl J Med. 2004;350:1617-28.

10. Nakamura T, Alder H, Gu Y, Prasad R, Canaani O, Kamada N, et al. Genes on chromosomes 4, 9, and 19 involved in 11q23 abnormalities in acute leukemia share sequence homology and/or common motifs. Proc Natl Acad Sci USA. 1993;90:4631-5.

11. Collins EC, Appert A, Ariza-McNaughton L, Pannell R, Yamada Y, Rabbitts TH. Mouse Af9 is a controller of embryo patterning, like Mll, whose human homologue fuses with Af9 after chromosomal translocation in leukemia. Mol Cell Biol. 2002;22:7313-24.

12. Lin C, Smith ER, Takahashi H, Lai KC, Martin-Brown S, Florens $\mathrm{L}$, et al. AFF4, a component of the ELL/P-TEFb elongation complex and a shared subunit of MLL chimeras, can link transcription elongation to leukemia. Mol Cell. 2010;37:429-37.

13. Li Y, Wen H, Xi Y, Tanaka K, Wang H, Peng D, et al. AF9 YEATS domain links histone acetylation to DOT1L-mediated H3K79 methylation. Cell. 2014;159:558-71.

14. Thorsteinsdottir U, Kroon E, Jerome L, Blasi F, Sauvageau G. Defining roles for HOX and MEIS1 genes in induction of acute myeloid leukemia. Mol Cell Biol. 2001;21:224-34.

15. Nguyen N, Vishwakarma BA, Oakley K, Han Y, Przychodzen B, Maciejewski JP, et al. Myb expression is critical for myeloid leukemia development induced by Setbp1 activation. Oncotarget. 2016;7:86300-12. 